\title{
Evolution and maintenance of Batesian mimicry, with particular reference to hover
} flies (Diptera: Syrphidae)

\author{
By
}

Arash Rashed

\author{
A thesis submitted to \\ the Faculty of Graduate Studies and Research \\ in partial fulfilment of \\ the requirements for the degree of \\ Doctor of Philosophy
}

Department of Biology
Carleton University
Ottawa, Ontario

August 2006

(C) 2006, Arash Rashed 


$\begin{array}{ll}\begin{array}{l}\text { Library and } \\ \text { Archives Canada }\end{array} & \begin{array}{l}\text { Bibliothèque et } \\ \text { Archives Canada }\end{array} \\ \begin{array}{l}\text { Published Heritage } \\ \text { Branch }\end{array} & \begin{array}{l}\text { Direction du } \\ \text { Patrimoine de l'édition }\end{array} \\ \begin{array}{l}\text { 395 Wellington Street } \\ \text { Ottawa ON K1A ON4 }\end{array} & \begin{array}{l}\text { 395, rue Wellington } \\ \text { Ottawa ON K1A ON4 } \\ \text { Canada }\end{array}\end{array}$

Your file Votre référence ISBN: 978-0-494-18233-8 Our file Notre référence ISBN: 978-0-494-18233-8

NOTICE:

The author has granted a nonexclusive license allowing Library and Archives Canada to reproduce, publish, archive, preserve, conserve, communicate to the public by telecommunication or on the Internet, loan, distribute and sell theses worldwide, for commercial or noncommercial purposes, in microform, paper, electronic and/or any other formats.

The author retains copyright ownership and moral rights in this thesis. Neither the thesis nor substantial extracts from it may be printed or otherwise reproduced without the author's permission.
AVIS:

L'auteur a accordé une licence non exclusive permettant à la Bibliothèque et Archives Canada de reproduire, publier, archiver, sauvegarder, conserver, transmettre au public par télécommunication ou par l'Internet, prêter, distribuer et vendre des thèses partout dans le monde, à des fins commerciales ou autres, sur support microforme, papier, électronique et/ou autres formats.

L'auteur conserve la propriété du droit d'auteur et des droits moraux qui protège cette thèse. $\mathrm{Ni}$ la thèse ni des extraits substantiels de celle-ci ne doivent être imprimés ou autrement reproduits sans son autorisation.
In compliance with the Canadian

Privacy Act some supporting forms may have been removed from this thesis.

While these forms may be included in the document page count, their removal does not represent any loss of content from the thesis.
Conformément à la loi canadienne sur la protection de la vie privée, quelques formulaires secondaires ont été enlevés de cette thèse.

Bien que ces formulaires aient inclus dans la pagination, il n'y aura aucun contenu manquant.

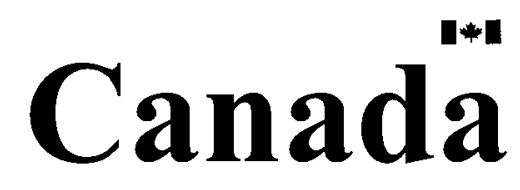




\begin{abstract}
In this project I tackled some of the unanswered questions regarding morphological and behavioural mimicry in hoverflies (Diptera: Syrphidae), using novel approaches.

First, I tested the possible role of invertebrate predators, specifically dragonflies, in the evolution of mimicry in hover flies. While dragonflies showed a significant tendency to attack small-sized prey compared to large-sized prey types, they did not seem to avoid the wasp-like colours and patterns of mimetic hover flies and attacked both mimics and non-mimetic prey types, of the same size, at a similar rate.

Second, a test of the 'competitive mimicry' hypothesis is performed. The basic tenet of this hypothesis is that mimetic hover flies benefit from their similarity to predatory yellow-jackets by an improved access to resources since other pollinators avoid visiting flowers that they occupy. Pollinators were more likely to visit unoccupied flowers compared to flowers occupied with either natural or artificial specimens. However, pollinators did not show reduced visits to flowers pinned with specimens bearing wasplike colours compared to flowers occupied by same-sized specimens that were nonmimetic.
\end{abstract}

Third, we used neural network to objectively assess the degree of similarity between hover fly images and their wasp models. Furthermore, using available data on pigeon's classification of hover fly images and also genetic algorithms along with neural network, we identified a reduced set of characteristics that birds may have used to rank the similarity hover fly images to wasps and flies.

Finally, in a behavioural study, I quantitatively compared the sounds produced by species of hymenopteran models and mimetic hover flies, when they were artificially 
attacked. Although I found some similarity in the buzzing sounds produced by bumble bees and their hover fly mimic, E. flavipes, I did not observe this similarity between the other two hymenoptera models (wasps and honeybees) and their presumed mimics. Moreover, all of the tested mimetic hover flies buzzed similarly to one another, independent of the model they resemble. The "buzzing behaviour" was not observed in the tested yellow-jacket wasps. However, all of the tested hoverflies, bumblebees and honeybees emitted a distinctive and quantifiable "buzz" when probed. 


\section{ACKNOWLEDGEMENT}

This thesis project would have been a formidable challenge with out the help of as many as people I am about to name and thank. I appreciate all their support, encouragement, and friendship.

Dr. Tom Sherratt, my supervisor, deserves special thanks for his attention to his graduate students and providing an enjoyable working environment above his many other commitments. I was lucky to have the chance to work with a knowledgeable scientist like Tom and to learn from him. He provided me with immeasurable support during my academic program. I thank Tom for his patience and understanding.

I thank Dr. Mark Forbes, my advisor, for all his support and help over past few years. Mark, I acknowledge that I have been a troublesome student! You believed in my capabilities more than I did myself and took me as a graduate student when I first arrived despite the fact that English was my second language and also I was new to the Canadian lab environment.

I first started to volunteer in Dr. John Arnason's lab at the University of Ottawa. I would like to thank John for accepting me in his lab and letting me to help with one of his ongoing projects. It was a great opportunity for me to experience working in a new environment with a great team and to learn about the other projects that his graduate students were working on.

I also wish to thank Dr. Jeff Skevington from Canadian National Collection of Arthropods who patiently supervised, while I learned molecular techniques. Jeff also 
helped me with a lot of insect identifications for this research and I consider myself lucky to have had him here in Ottawa.

I would like to thank Dr. Jayne Yack for letting me to use the sound recording equipment in her lab. Also many thank to Dr. Jeff Dawson for teaching me to use acoustic equipment.

At Queen's University Biological Station, Frank Phelan and Floyd Connor provided me with a valuable research environment, without which various aspects of the study could not have happened.

Special thanks to Dr. Rod Bain who patiently answered my questions regarding Neural Networks, an area that I knew absolutely nothing about before the project, and tried to make the system even easier to use for us.

I also have to acknowledge that I have learned a lot form my lab-mate Chris Beatty. I would like to thank Chris for all his help.

Finally, I wish to specially thank my parents and also my wife Tirazheh Eslami, who have provided support through out my education, and also my friends and colleagues Yemisi Dare, Hume Douglas, Nahideh Haghighi, Shuyou Han, Imran Khan, Stacey Lee-Jankins, David Lowe, Justin Mahoney, Hannah Mir-Rashed, Tonia Robb, Bin Xang and all others who helped me at different stages and in various forms. 


\section{Table of Contents}

Page

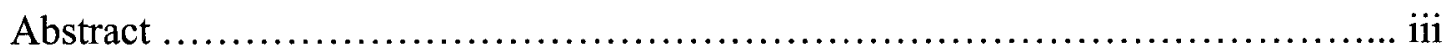

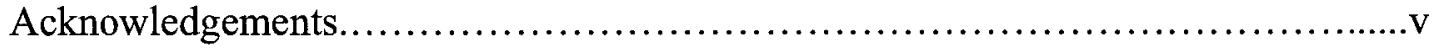

Table of Contents ...........................................................

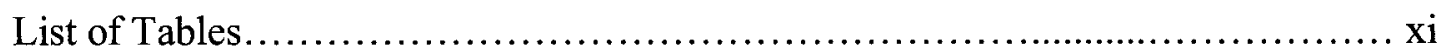

List of Figures...........................................................

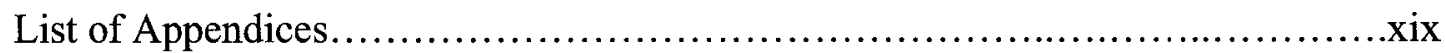

Chapter 1. General Introduction

1.1 Animal Defence..........................................

1.2 Hover Flies...................................................4

1.2.1 Morphology................................5

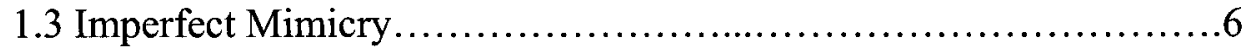

Chapter 2. Prey selection by dragonflies in relation to prey-size and wasp-like colours and patterns

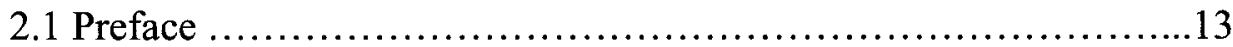

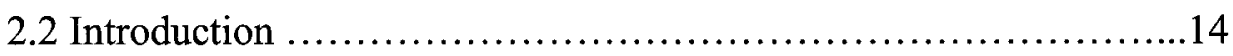

2.3 Methods ................................................17

2.3.1 Large versus Small Prey........................22

2.3.2 Mimetic versus Nonmimetic Prey.................23

2.3.3 Model versus Mimic Prey.......................24

2.4 Results ...................................................24

2.4.1 Large versus Small Prey.........................25

2.4.2 Mimetic versus Nonmimetic Prey.................27

2.4.3 Model versus Mimic Prey.......................29

2.4.4 Dragonfly Species Selectivity...................29

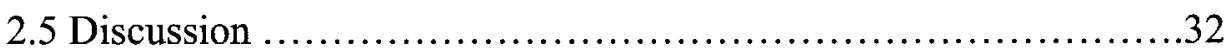

vii 
Chapter 3. Mimicry in hover flies (Diptera: Syrphidae): a field test of the competitive mimicry hypothesis

3.1 Preface............................................................ 38

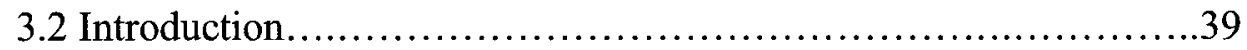

3.3 Methods....................................................... 41

3.3.1 Time and Location of the study...................42

3.3.2 Overall Design...............................42

3.3.3 Pinned Specimens...............................43

3.3.4 Experimental Details..............................44

3.3.4.1 Experiments 1-4: Flowers containing a specimen versus Unoccupied flowers.........45

3.3.4.2 Experiments 5-9: Pinned flowers versus Pinned Flowers...............................45

3.4 Results. .46

3.4.1 Experiments 1-4: Flowers containing a specimen versus Unoccupied flowers...............................46

3.4.2 Experiments 5-9: Pinned flowers versus Pinned flowers.......50

3.4.3 Physical attacks......................................5

3.4.4 Flower Visitors Selectivity...........................56

3.5 Discussion................................................... 58

Chapter 4. Neural Network applications in the Study of Mimicry

4.1 Preface. .64

4.2 Using neural network classifiers to estimate the degree of morphological similarity between mimics and models.............65

4.2 .1 Introduction .............................................65

4.2.2 Methods ....................................................66

4.2.3 Results \& Discussion......................................70

viii 
4.3 A comparison of biological and empirical measures

of the degree of mimicry of hover flies.......................75

4.3 .1 Introduction........................................... 75

4.3.2 Methods................................................ 77

4.3.2.1 Data Collection.................................77

4.3.2.2 Quantitative Assessment of Mimetic

Similarity by Humans...........................79

4.3.2.3 Neural Network Based Measures of

Mimetic Similarity..............................79

4.3.2.4 Numerical Modelling of the

Pigeon Peck Rate.........................80

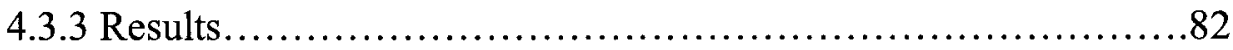

4.3.3.1 Prediction of Wasp Probability By the Neural

Network.

4.3.3.2 Comparison of Orderings of the Morphological

Similarity of Different Hover Fly Species to

Wasps.

4.3.3.3 Salient Predictor Variables in Discriminating

Between Wasps and Flies......................88

4.3.4 Discussion.

Chapter 5. Acoustic signaling following attack: do hover flies (Diptera: Syrphidae)

sound like the Hymenoptera they morphologically resemble?

5.1 Preface $\ldots \ldots \ldots \ldots \ldots \ldots \ldots \ldots \ldots \ldots \ldots \ldots \ldots \ldots \ldots \ldots \ldots \ldots \ldots \ldots . \ldots \ldots$

5.2 Introduction.................................................. 99

5.3 Methods........................................................ 101

5.3.1 Species Investigation........................101

5.3.2 Acoustic Recordings.............................102

5.3.3 Sound Signal Analysis..........................104

ix 
5.4.1 Buzzing Behaviour................................. 107

5.4.2 Do Wasp Mimics Sound Like Wasps on Attack?....110

5.4.3 Do Honeybee Mimics Sound Like Honeybees on Attack?.......................................112

5.4.4 Do Bumble Bee Mimics Sound Like Bumble Bees on Attack?

5.4.5 Do Mimetic Hover Flies Sound Like One Another, Independent of the Model They Resemble?...........116

5.5 Discussion.

Chapter 6. General Discussion and Conclusion.

Literature Cited. 128

Appendices. 141 


\section{List of Tables}

Table

2-1 A summary of the prey the prey types offered and number of replicates in each experiment

2-2 A summary of the flying insects collected in Malaise traps at our study site from 1 July to 10 August

3-1 A summary of the community of arthropods collected by hand nets from flowering stands within the study site from 22 July to 10 August 2005. Standard errors of means, each based on 5 samples, are provided in brackets.

3-2 A summary of the type of specimens presented, results of non- parametric Wilcoxon signed rank tests comparing the number of visits and investigations in each pairwise presentation, and the number of replicate pairwise presentations in each experiment. Where a significant difference (or borderline significance) was detected based on a two-tailed distribution, the direction of the difference is indicated.

3-3 A summary of the chi-square tests of association between taxonomic groups of visitor (Hymenoptera and Diptera) and type of flower presented. In no case did a particular treatment tend to attract disproportionately more of one taxonomic group, compared to the other treatment. "a)" experiments were performed on Goldenrod flowers while "b)" experiments were performed on wild-carrot 


\section{List of Tables}

Table

(continued) flowers. One degree of freedom was involved in each

test.

4-1 Mean predicted wasp probability for each taxonomic group from nnet. Species names: S. ve: Sphecomyia vespiformis; T. ve: Temnostoma vespiforme; C. ca:

Chrysotoxum cautum; X. pe: Xanthogramma pedissequum;

C. bi: Chrysotoxum bicinctum; E. gr: Epistrophe grossulariae;

V. zo: Volucella zonaria; S. ri: Syrphus ribesii; S. py:

Scaeva pyrastri; I. gl: Ischyrosyrphus glaucius; H. pe:

Helophilus pendulus.

4-2 $\quad \mathrm{R}^{2}$ and $\mathrm{P}$-values for relationship between various

Orderings.

5-1 The mean sound characteristics emitted by each species following attack. Standard errors of the means are shown in parentheses. Those species, other than honeybees, with lower dominant frequencies (dominant frequency $<200 \mathrm{~Hz}$ ) did not exhibit buzzing behaviour after simulated attack 108 


\section{List of Figures}

Figure Page

1-1 Some examples of mimetic hover flies; a) good wasp

mimic, Spilomyia sp., b) imperfect wasp

mimic, Epistrophe emarginatus, c) bumble bee

mimic, Mallota bicolor and d) honeybee mimic,

Eristalis tenax

2-1 Proportion of attacks by dragonflies on small (solid bars) and large (open bars) prey types in experiments $1-3$. Experiment

1: Helicobia rapax and Sarcophaga spp. Experiment 2:

pairwise presentations of artificial prey. Experiment 3:

single presentations of artificial prey. Error bars indicate

the exact binomial $95 \%$ confidence intervals

2-2 Proportion of attacks by dragonflies on mimetic (solid bars)

and nonmimetic (open bars) prey types in experiments

4-7. Experiment 4: pairwise presentations of mimetic

Toxoxmerus geminatus and nonmimetic Helicobia rapax

Experiment 5: pairwise presentations of mock-painted and

black-painted Eristalis transversa. Experiments 6a (2003)

and $6 \mathrm{~b}$ (2004): pairwise presentations of black-and-yellow-

painted and black-painted artificial prey. Experiment 7:

single presentations of balck -and-yellow-paintedand black-

painted artificial prey. Error bars indicate the exact binomial

$95 \%$ confidence intervals.

2-3 The relation between the arithmetic mean percentage of dragonfly species observed in the experimental field in each

xiii 


\section{List of Figures (continued)}

Figure

survey and the arithmetic mean percentage of attacks made

by each of the species over our experiments

3-1(a,b) The number of visits from insects to (a) goldenrod flowers and (b) to wild-carrot flowers. Blank boxes indicate the number of visits on pinned flowers. Filled boxes indicate the number of visits on unoccupied flowers. Horizontal thick lines indicate the medians, boxes show the interquartile ranges that contain $50 \%$ of the values and whiskers show the highest and lowest values without any possible outliers ( $>1.5$ box length from the upper or lower edge of the box).

3-2(a,b) The number of times that flower visitors approached and investigated the occupied (blank boxes), and unoccupied inflorescences (filled boxes) on (a) goldenrod and (b) wildcarrot. See fig .1 for graphical notation.

3-3 The number of visits from insects to goldenrod flowers and wildcarrot flowers pinned with a wasp, $D$. arenaria (blank boxes) , and a nonmimetic fly, Sarcophaga spp. (filled boxes). See fig 3.1 for graphical notation.

3-4 The number of visits to inflorescences pinned with a mimetic hover fly, S. longicornis (blank boxes) versus a nonmimetic fly, Sarcophaga spp. (filled boxes), and also black-andyellow painted beads (blank boxes) versus black painted beads (filled boxes) on both goldenrod and wild-carrot 


\section{List of Figures (continued)}

Figure

flowers. See fig 3.1 for graphical notation

4-1 A typical view of the computer screen, showing the neural network classifier software, and data set.

4-2 Graphical depiction of a single-layer feedforward neural network for classification with three Inputs, 2 hidden layer nodes and two output classes. Each line represents one weight and the dotted line represents the skip-layer weight. 68

4-3 An illustration of the effect of the number of training observations on the neural network prediction. When the system was trained with two or more individuals of non-mimetic flies and wasps, each, both flies and wasps were classified 100\% correctly. However , the neural network frequently misclassified hoverflies as wasps. Error barsindicate the standard error of the means.

4-4 An illustration of the effect of the number of training observations on the neural network prediction, when hover flies are included in the training set. Training the system with more than two individuals of each of the groups (non-mimetic flies, mimetic hoverflies and wasps) resulted in $100 \%$ correct classification of all three classes. Error bars indicate the standard error of the means.

4-5(a-d) A comparison of the different measures of similarity of hover flies to wasps. Species names: S. ri: Syrphus ribesii; T. ve: Temnostoma vespiforme; C. ca: Chrysotoxum cautum; $\mathrm{H}$. pe: Helophilus pendulus; E. gr: Epistrophe grossulariae; X. pe: 


\section{List of Figures (continued)}

Figure

Xanthogramma pedissequum; C. bi: Chrysotoxum bicinctum;

S. ve: Sphecomyia vespiformis; V. zo: Volucella zonaria; S. py:

Scaeva pyrastri; I. gl: Ischyrosyrphus glaucius. Wasps and

nonmimetic flies were a mixture of species (see Appendix B).

Graphs compare: (a) human ordering (ranging from 13, most

wasp-like, to 1, most nonmimetic fly-like) and pigeon ordering

(based on Wasp+ data), (b) human ordering and neural network

ordering, (c) neural network ordering and pigeon

ordering based on Wasp + data, (d) mean predicted peck rate from

the REP with cost coefficient $\omega=1$ and observed peck rate based

on Wasp+ data (dashed line represents perfect matching of

predicted and observed values). Additional graphs are provided

in the Appendix E

4-6 Occurrences of retained predictor variables based on each pigeon response set (filled bars based on Wasp+ data, open bars based on Fly+ data). Occurrences are based on the number of times a predictor variable was retained from the 10 simulations each with $\omega=1$ and $\omega=0.1$, based on Wasp + and Fly+ data $(10 \times 2 \times 2$ combinations $)$.

4-7 Mean predicted peck rate for each taxonomic group using REP based on Wasp + data with $\omega=1$ with predictions for novel and excluded species added. Error bars represent \pm one standard deviation for predicted values from the ten data sets. The novel species was Episyrphus balteatus 


\section{List of Figures (continued)}

Figure

Page

5-1 A schematic representation of a power spectrum showing the acoustic parameters measured for our analysis; $\mathrm{Q}_{6 \mathrm{~L}}$

and $\mathrm{Q}_{6 \mathrm{R}}$ indicate the quality factors measured $(\mathrm{Hz})$.

$F_{1}$ frequency indicates the frequency at the first

harmonic $(\mathrm{Hz})$. b) Frequency spectrum of the buzzing sound

produced by a typical honeybee mimic hover fly, Eristalis

arbustorum, immediately after a simulated attack, showing

the dominant pick frequency and the harmonic. The inset

represents the oscillogram.

5-2 Discriminant function analysis of sounds produced after attack, showing the centroids of the measured species

; 1) Apis mellifera, 2) $V$. vulgaris, 3) $V$. germanica, 4)

D. arenaria, 5) B. impatiens, 6) Bombus sp., 7) E. flavipes,

8) E. transversa, 9) E. arbustorum, 10) S. fusca, 11)

S. longicornis , 12) H. fasciatus, 13) C. relictus, 14)

Sarcophaga spp.. Only those species with discriminant

function 1 greater than 0 expressed the buzzing behaviour

when they were artificially attacked

5-3 An illustration of the disriminant function analysis results comparing three wasp-mimic species ( $S$. longicornis, $S$.

fusca and $H$. fasciatus) and other insect species tested in this study. Bars indicate the observed Mahalanobis distance to the other species (low values indicating high similarity) 


\section{List of Figures (continued)}

Figure

5-4 Disriminant function analysis results comparing two honeybee mimic species (E. arbustorum and E. transversa) with other insect species tested in this study. Bars indicate the observed Mahalanobis distance to the other species (low values indicating high similarity)

5-5 Discriminant function analysis results comparing bumble bee and bumble bee mimic species with other insect species tested in this study. Bars indicate the observed Mahalanobis distance of the models, B. impatiens and B. flavipes, and the mimic, E. flavipes, to the other species (low values indicating high similarity).... 


\section{List of Appendices}

Appendix

A. Voucher Numbers for the Plant and Insect Specimens, Deposited at Agriculture and Agri-Food Canada......................................... 141

B. Species List for Images in the Set of 206 (see Dittrich et al. (1993))...............142

C. Description of the Neural Network........................................ 143

D. Description of the Genetic Algorithm..................................... 146

E. Correlation graphs.................................................... 152 


\section{CHAPTER 1}

\section{General Introduction}

This thesis investigates the evolution and maintenance of mimicry. Mimicry frequently forms part of a defensive strategy that some animals use to avoid predation by potential predators. Therefore, I first introduce some of the well-known defense mechanisms based on colours and patterns, highlighting the key terms and concepts. Then, I will move onto hover flies (Diptera: Syrphidae) and their mimetic similarities to their potential defended models (see below). Upcoming chapters will discuss several important questions relating to the evolution and maintenance of mimicry in hover fly species.

\subsection{Animal Defense}

The mechanisms used by animals to avoid detection by predators are varied. Many animals possess colours and patterns that help them blend into their background. This phenomenon is referred to as crypsis or background matching (Endler 1984). Some organisms also resemble an uninteresting element of their surrounding environment, such as a tree branch or a leaf (masquerade) (Allen \& Cooper 1985). Alternatively, the darker coloration on the dorsal side of the body compare to the lighter ventral regions in some animals help them to render their body as less three dimensional to the receiver (countershading) (Thayer 1909). Disruptive coloration is another strategy that animals can adopt to deter recognition by would be predators. In this case, appropriate body 
markings can create false boundaries, or hide existing ones, thereby rendering the detection of the body outline more difficult (Cott 1940).

Some animals and insects use warning coloration to advertise their unpalatability (e.g. bad taste, toxins, possessing stinger) to their potential predators (aposematism) (Wallace 1867; Poulton 1890). Warningly coloured insects usually have patterns in shades of orange, red or yellow, which contrast with their environment. These signals widely thought to be beneficial to both predator and prey since they help predators to learn to avoid unpalatable prey. Several explanations have been offered to explain the forms of these signals. There could be an inbuilt tendency within the vertebrate nervous system to learn rapidly to associate conspicuous colours and patterns with a nasty experience (Turner 1984; Guilford 1990). It has also been suggested that warning coloration takes warning patterns away beyond any possibility of confusion from the green and brown colors of the palatable and/or cryptic prey (Wallace 1867; Fisher 1930; Sherratt \& Beatty 2003).

Although the reasons for protective mimicry are diverse, it is generally referred to as any resemblance in form, colour, pattern and/or behaviour, between a minimum of two organisms in which at least one of them is unpalatable. Examples of protective colouration in insects have played a unique role in shaping the way both academics and the general public think about evolutionary processes. Thus, the theory of mimicry has been described as "perhaps the greatest post-Darwinian application of natural selection" 
(Fisher 1930), while school textbooks regularly showcase adaptation by reference to exquisite examples of prey defence.

The best known forms of protective mimicry are Müllerian and Batesian mimicry that were defined in 1878 and 1862, respectively, by J. F. Müller (1878) and H. W. Bates (1862). In Müllerian mimicry several unpalatable species ("co-models") benefit from less predation by resembling one another by virtue of the fact that the number of different colours and patterns predators are required to learn to avoid are reduced. In this form of mimicry phenotypic variation of the co-models would be a disadvantage since they will be difficult to be identified as inedible and therefore the natural selection ("purifying selection") maintains one or a few colour patterns in the population ("rings") of Müllerian mimics (Gilbert 2005).

In Batesian mimicry a palatable (undefended) mimic resembles an unpalatable model and, therefore, gains protection against potential predators. Batesian mimics are often less abundant than their unpalatable models and therefore predators are more likely to encounter models in nature and as a result they associate the colours and patterns of the model with the nasty experience and avoid such colours and patterns in their future encounters (Mostler 1935). This causes continued selection on mimics to resemble their related models as closely as possible (but see for example Johnstone 2002; Sherratt 2002). In Batesian mimicry a new mimetic form has the advantage because of being rare, however, at high frequency it will be selected against (Gilbert 2005). This frequency 
dependence can cause selection for polymorphism in certain species of Batesian mimics (Gilbert 2005).

I now sound a word of caution with regard to the distinction between Müllerian and Batesian mimicry. Although palatability and unpalatability of the prey are the simplest distinctive characteristics for the two different types of mimicry, it is well known that edibility is not an absolute term (Cott 1940). Some mimics are simply less distasteful than their models. Unpalatability of a potential prey could also depend on the predator species and/or their predatory abilities (Ruxton et al. 2004). An insect prey is not equally distasteful to all predators. The hunger level of the predator could also cause variation in dietary preferences even within species (Sherratt 2003; Ruxton et al. 2004). Therefore it is difficult to draw a line between the two forms of mimicry and instead there may be a 'mimicry spectrum' (Turner 1984; Speed \& Turner 1999). Hereafter in this thesis, the word "mimic" refers to Batesian mimics (palatable) unless otherwise stated.

\subsection{Hover Flies}

Syrphidae, with almost 5400 species, is the most derived Aschiza family and the Pipunculidae is a sister group of it (Rotheray \& Gilbert 1999). There are three subfamilies, which are Syrphinae, Eristalinae and Microdontinae (Vockeroth \& Thompson 1987). Several characteristics make hover flies a suitable insect to study the evolution of mimicry. They are very common flower visitors that can be found in a variety of habitats. Different species of hover flies, which are palatable to their potential predators (Mostler 1935), are thought to mimic colours and patterns of different 
unpalatable and/or stinging models of Hymenoptera including wasps and bees (Fig. 1.1ad). The degree of similarity between hover fly species and their models range from nonmimic/imperfect mimics to near-perfect/ perfect mimics (Gilbert 2005).

\subsubsection{Morphology}

Adult syrphids feed on nectar and pollen (Gilbert 1989) and are small to large in size ( 4 to $25 \mathrm{~mm}$ long). They usually have black bodies, which could be covered by yellow, brown, orange patches and/or strips. These patterns sometimes could cover the head eyes and legs as well. The body could be almost hairless or covered by long hairs or dense short hairs. Sometimes, hairs are flattened or scale like and form dense tomentum (Vockeroth \& Thompson 1987). Distribution of hairs and bristles is an important factor in taxonomy of flies. Distinct bristles or spines are sometimes present on the anepisternum, notopleuron, postalar callus, scutum, and scutellar margin. Another important charcteristic for categorizing the syrphids is wing venation. In Syrphidae the R5 cell is closed and usually a spurious vein crosses $r-m$ between $\mathrm{R} 4+5$ and $\mathrm{M} 1+2$ (longitudinal wing veins: 'radius' (R) and 'media' (M)) (Borrer 1992). Pterostigma could be present and even sometimes wings are totally dark. Calypteres are visible and well developed. Legs are simple and slender. Sometimes femur is swollen and well developed.

The abdomen in syrphids is highly variable in shape and style. Some of them are short and broad. Sometimes elongates and/or forms petiol. In the subfamily of Syrphinae, the male has 5 visible tergites. Females at least have 1-5 tergites and sternites visible (Vockeroth \& Thompson 1987). 


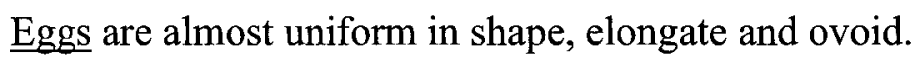

Larvae live in variety of environments based on the species and can be phytophagous, mycophagous, saprophagous and predators (Rotheray \& Gilbert 1999).

Pupation of syrphids occurs close to the larvae habitat. For instance, predacious species pupate on leaves and stems close or inside the prey colony. Species going into diapause usually pupate in leaf litter lust below the soil surface or similar situations.

\subsection{Imperfect Mimicry}

Some adult hover fly species resemble their wasp or bee models very closely (perfect or near-perfect mimicry) (Waldbauer 1988). More frequently however, the hover fly mimics do not appear to closely resemble any particular model species: in this case they are called imperfect (Edmunds 2000) or inaccurate mimics (Johnstone 2002) (Fig 1.1b). Most of the time when people think about mimicry and the evolution of mimicry they consider the evolution of good mimics, although imperfect mimicry is widespread in many Batesian mimetic systems (Gilbert 2005). At first, one might question why natural selection has not caused all hover fly species to resemble their models ever more closely. So far several hypotheses have been presented to explain this phenomenon (see Gilbert 2005 for an excellent review): 
- Curve of protection: Sometimes a very poor resemblance to a very noxious model is enough for predators to avoid feeding on them and there is no further selection beyond this point (Edmunds 2000; Sherratt 2002).

-Multi-Model: Edmunds (2000) suggested that an imperfect mimic which has some similarities to several models is able to live in the combined geographic ranges of all those models and their predators. In this case, these poor mimics could have higher overall protection than the near perfect ones. It has been also suggested that seasonal changes could cause variation in colours and patterns of some poor mimic hover flies and therefore make them mimics of different models in different environmental conditions. For example Ottenheim et al. (1999) studied the effect of temperature on polymorphism in Eristalis tenax (Diptera: Syrphidae) and showed that summer individuals are paler in colour and mimic wasps, which are common later in season, more closely compared to the darker spring individuals that are thought to be honeybee mimics.

-There is no mimicry at all: One other explanation for imperfect mimics or poor mimics is that their color patterns are in fact a kind of aposematic coloration. Independent of mimicry, these kinds of coloration advertise their escape flight agility, so that predators prefer not to pursue them (Pinheiro 1996).

-Mimicry through the eye of beholder: It is possible that an imperfect mimic to our eyes appears to be a perfect mimic in predator eyes (e.g. birds) (Cuthill \& Bennett 1994). The avian color vision differs from that of humans in two respects. The first difference is that birds and insects are able to see well in ultraviolet. And second is that humans possess three types of cones, however bird have four or probably five (Cuthill \& Bennett 1993; 
Church et al. 2004). For example, It has been shown that pigeons see Episyrphus balteatus (Diptera: Syrphidae) as a good mimic of wasps, however, while to human eyes it is not a good mimic (Dittrich et al. 1993). Despite these differences, Dittrich et al. (1993) also showed that pigeons are able to classify images even when the stimuli lack some UV colour information (Cuthill \& Bennett 1993). Moreover, there is no evidence of any UV components to either wasp or hover fly mimetic patterns (Gilbert 2005).

-Imperfect mimicry, an intermediate stage: Imperfect mimics could be considered as a non-equilibrium intermediate stage in the process of evolving into good mimics. The question is why should we have so many species of imperfect mimics in the Syrphidae family? And also if they are in the process of evolution, why we do not see any obvious change toward the model through time? A study by Azmeh et al. (1998) argued that human-induced habitat changes could lead to losing of mimetic patterns, generating poor mimics. 
a.

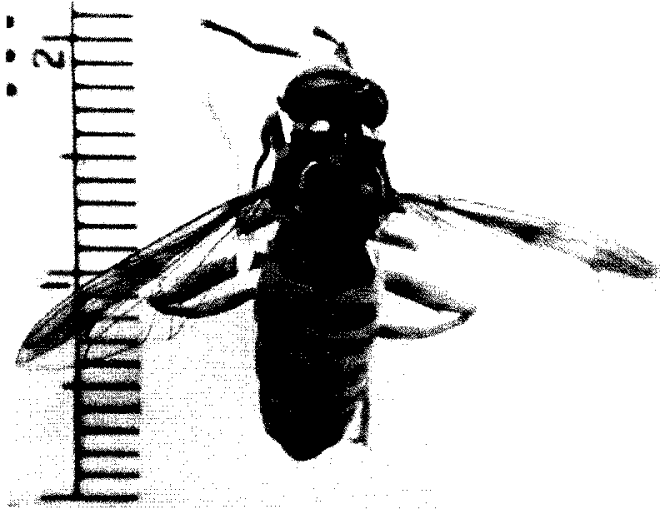

c.

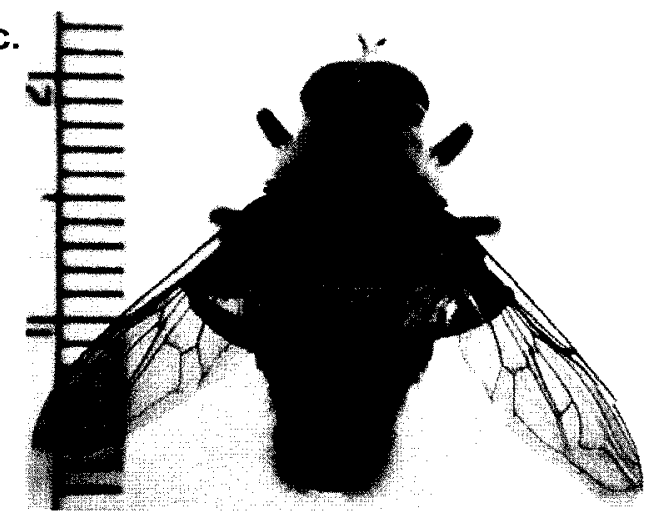

b.

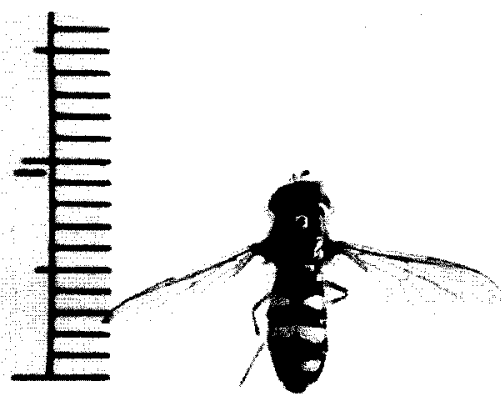

d.

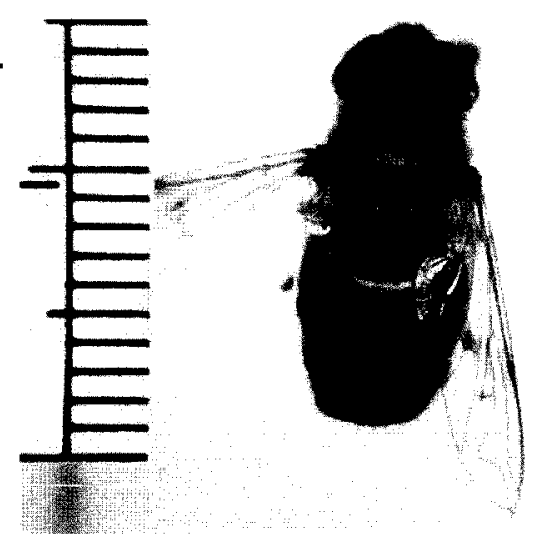

Figure 1.1: Some examples of mimetic hover flies; a) 'good' wasp mimic, Spilomyia sp., b) 'imperfect' wasp mimic, Epistrophe emarginatus, c) bumble bee mimic, Mallota bicolor and d) honeybee mimic, Eristalis tenax. 
The first chapter of this thesis will investigate the effect of invertebrate predation on the evolution of mimicry in wasp mimic hover flies. So far, most of the studies in the field of mimicry have considered vertebrate predators, in particular birds, as the most important agent generating selection for mimicry (e.g. Mostler 1935; Dittrich 1993; Cuthill \& Bennett 1994; Green et al. 1999). However, it is quite possible that predation by insects far exceeds avian predation. I will address this significant shortfall of observations on foraging preferences by invertebrate predators, in the context of evolution of protective coloration. Dragonflies were very abundant in our test area and were likely to be amongst the most common visual predators (see Corbet 1999) on small aerial prey, therefore I chose them as invertebrate predators in my experiments. In so doing my primary questions were: Do insect predators, such as dragonflies, attack wasps? Can other species such as hover flies exploit this learning? Do they respond to warningly coloured prey? What is the effect of prey size on dragonfly preference? In order to address each of these questions, I designed prey- choice experiments to investigate the prey preference of the dragonfly community and their possible role as selective agents in the evolution of mimicry and warning signals.

While most of the hypotheses stated above considered mimicry as a defense against predation, the role of inter-specific competition in the evolution of mimicry has been mentioned only very briefly. Although Nickol (1994) mentioned the possible effect of competition on the evolution and maintenance of mimicry, this idea has never been experimentally tested as a hypothesis. In the second chapter of this thesis I will test the hypothesis that mimetic colours and patterns of hover flies help prevent other flower 
visitors from sharing the same food source or interrupt them while feeding on a food source.

Since each mimic, especially imperfect mimics, usually resembles several models it is very important to assess their degree of similarity in an objective manner. In the third chapter I will introduce a tailor-made neural network classifier as a tool to obtain a quantitative assessment of the degree of mimicry to any possible model. Then I compare the empirical classifier (optimized neural network) to see whether the ranking of mimetic similarity based on the trained neural network would match that of humans and pigeons (as determined by Dittrich et al. 1993). Finally using a genetic algorithm and neural network I have attempted to determine the biometrical features that pigeons might have used in the Dittrich et al. 1993 study to rank different degrees of mimetic similarities.

Most protective mechanisms are not merely a matter of morphology, but of behaviour as well. For instance, camouflage is ineffectual unless the camouflaged creature moves slowly or sits still. When mimetic hover flies possess morphological characteristics of their models it has been shown that some of them also mimic the behaviour of hymenoptrans. For example, while some hover flies possess elongated antennae to mimics the long antennae of yellow jacket wasps (e.g. Sphecomyia vittata and Ceriana signifera), some other hover fly species, such as Spilomyia longicornis and Temnostoma spp., wave their front legs, which unlike other two pairs of legs are darkened to mimic the presence and movement of the antennae of their potential wasp models (Waldbauer 1970). Although the behavioural characteristics are very important 
property of a mimetic insect the idea is a difficult one to test objectively. The final chapter, using a different approach, I will test one of the aspects of behavioural mimicry namely "buzzing behaviour" of mimetic hover flies by comparing the quantitatively measured sound waves and vibration produced by mimics and their hymenopteran models.

Overall, I believe this work expands our knowledge and understanding of mimicry by investigating the potential role of invertebrate predators, by testing a completely different explanation for mimicry in hover flies, by developing tools to assess mimetic similarity and by investigating a suite of behaviours that have been completely ignored in the context of mimicry. 


\section{CHAPTER 2}

\section{Prey selection by dragonflies in relation to prey size and wasp-like colours and patterns}

\subsection{Preface}

In the first chapter I investigate the role of dragonflies as an invertebrate predator in the evolution of mimicry in hover flies. I looked at the size effect as well as the colour and pattern effects on dragonflies prey choice. Do they avoid wasps and wasp-like hover flies? Does prey size affect the dragonfly's choice?

I will present dragonflies with live tethered prey types using both pairwise and single presentation methods. I will then compare my findings with those of other studies and discuss the results. This work has been published in the journal of Animal Behaviour.

Rashed, A., C.D. Beatty, M.R. Forbes \& T.N. Sherratt. 2005. Prey selection by dragonflies in relation to prey size and wasp-like colours and patterns. Animal Behaviour, 70: 1195-1202. 


\subsection{Introduction}

I never saw the flocks of slow-flying Heliconidae in the woods persecuted by birds or Dragonflies, to which they would have been easy prey; nor, when at rest on leaves, did they appear to be molested by Lizards or the predacious

Flies of the family Asilidae, which were very often seen pouncing on Butterflies of other families (H. W. Bates 1862, page 510).

Despite Bates' observations that insect predators may selectively refrain from attacking certain types of prey, birds have long been considered as the primary selective agent involved in the evolution of warning signals (Poulton 1890; Guilford 1990) and mimicry (Bates 1862; Müller 1878; Mallet \& Joron 1999) in insects and other invertebrates. Indeed, given the widespread occurrence of visually hunting insects such as wasps, robber flies and dragonflies, it is remarkable that so few studies have examined the role of such predators in shaping the evolution and maintenance of protective coloration. Shelly \& Pearson (1978) suggested that predatory robber flies (Diptera: Asilidae) may have been responsible in part for the evolution of conspicuous warning signals in chemically defended tiger beetles. A study by Dejean (1988) revealed that hunting workers of an ant species, Odontomachus troglodytes, avoided attacking the chemically defended and warningly coloured larvae of African chrysomeline (Coleoptera: Chrysomelidae) for 28 days after their initial encounter. In perhaps the first formal experimental study of its kind, Berenbaum \& Miliczky (1984) found that the Chinese mantid Tenodera ardifolia sinensis rapidly learned to avoid unpalatable milkweed bugs, Oncopeltus fasciatus, that had been reared on milkweed seeds. Furthermore, of six mantids that had learned to reject milkweed-fed bugs, none attacked palatable sunflower- 
fed bugs when they were offered. Bowdish \& Bultman (1993) confirmed that this species of mantid could learn to avoid attacking unpalatable milkweed bugs, but also found that the mantids attacked natural and stripe-painted milkweed bugs overall less frequently than they did black-painted bugs, which may more closely resemble palatable flies. Thus, Berenbaum \& Miliczky (1984) showed that invertebrate predators may facilitate selection for mimicry, and Bowdish \& Bultman (1993) showed that invertebrate predators could also generate selection in unpalatable prey to evolve particular forms of warning signal.

Most recently, Kauppinen \& Mappes (2003) evaluated the responses of the dragonfly Aeshna grandis to encounters with black natural prey, warningly coloured natural prey (painted flies and wasps) and artificial prey in the field. These prey items were presented to the dragonflies singly, using a fishing rod and line. After observing behavioural responses of the dragonflies towards the prey (e.g. pause but do not touch, touch but do not grab), the authors concluded that black-and-yellow striped flies were 'avoided more' than were black ones and suggested that wasp-like coloration may confer a selective advantage against odonate predators.

The purpose of this study was to continue to address the shortfall of observations on foraging preferences by insects in the context of the evolution of protective coloration, particularly warning signals and mimicry. Similar to Kauppinen \& Mappes' (2003) study, we examined prey selectivity by adult dragonflies in the field. As Kauppinen \& Mappes noted, adult dragonflies are an excellent model group of invertebrate predators for such 
studies because they are voracious, have well-developed visual systems (Yang \& Osorio 1991; Briscoe \& Chittka 2001) and feed on a variety of arthropod prey (Corbet 1999). As Bates observed more than 140 years ago, dragonflies do not always attack prey items that they approach (see also Beatty 1951; Baird 1991). For example, O’Donnell (1996) found that neotropical dragonflies oriented towards wasps but rarely pursued them, and suggested that such behaviour may potentially select for warning signals and mimicry.

Although we have independently used a similar approach to that used by Kauppinen \& Mappes (2003), our study complements that by Kauppinen \& Mappes in several ways. First, we scored responses of several species of (principally libellulid) dragonflies, rather than a single predator species. We chose not to focus on an individual odonate species, because natural prey are exposed to a variety of dragonfly predators. Second, we scored dragonfly responses to artificial and natural prey including hover flies; Kauppinen \& Mappes presented no natural mimics. Third, unlike Kauppinen \& Mappes who admirably controlled for prey size, we have explicitly tested the possibility that dragonflies may be size selective. Fourth, we think that studies aimed at elucidating the advantages of protective coloration require an assessment of the frequency of encounters of predators with different prey types, as well as the nature of predatory behaviour following encounter. Thus, we allowed for potential differences in conspicuousness between prey types by presenting two prey types simultaneously along different ends of a rod, as well as conducting single presentations and recording nonencounters. 


\subsection{Methods}

Our experiments were conducted in two adjoining open meadows (combined area approximately 1.5 ha) near the Queen's University Biological Station, Ontario, Canada $\left(44^{\circ} 34^{\prime} \mathrm{N}, 79^{\circ} 15^{\prime} \mathrm{W}\right)$. All prey choice experiments were performed from 5 June to 10 August in 2003 and 2004, on sunny days during 1100-1530 hours. Air temperature during experiments ranged from 28 to $33^{\circ} \mathrm{C}$; humidity ranged from 70 to $80 \%$. We conducted weekly surveys of dragonflies from mid-June to early August 2004 to identify the adult dragonfly species present in the meadows at the time of the study. Each survey lasted $2 \mathrm{~h}$ and involved an observer walking slowly around the edge of the meadows (where dragonflies tended to perch), and tallying the number of each dragonfly species seen. These surveys allowed us to estimate the presence and relative abundance of potential predator species during our experiments.

Two Malaise traps were set up in the meadows to assess the types and relative proportion of prey items naturally available to our dragonfly predators. These traps were emptied and the contents stored every 5 days from 1 July to 10 August 2004. We recognize that Malaise traps may provide at best a biased sample of the insect community present (Southwood 1978), but they allowed us to ascertain the extent to which various aerial prey species, more or less equally susceptible to trapping, were available to the dragonflies. 
Our experiments were of three main types (Table 2.1). Each replicate of each experiment (16-60 replicates; Table 2.1) consisted of presenting dragonflies encountered in the field with different types of natural or artificial prey. Prey were tethered, pairwise or singly, on 50-cm cotton strings suspended from the end of an Lshaped rod with a 122- $\mathrm{cm}$ handle and a 76-cm support arm. Prey presented in pairs were attached $50 \mathrm{~cm}$ apart on the same support arm.

To present 'prey', an experimenter walked the perimeter of the field with the rod held in front and the support arm horizontal, so that the suspended prey were approximately $1-1.5 \mathrm{~m}$ above the ground. The rod was moved slowly from side to side and up and down to mimic the movement of natural prey. If dragonflies in the proximity made no response, then the experimenter continued walking around the perimeter of the field, presenting the prey to the next dragonfly encountered. Dragonflies frequently attacked natural or artificial prey while the experimenter was simply walking with the rod (50--70\% of attacks; the remainder took place while prey were held in the proximity of dragonflies, with the experimenter standing still). After an attack occurred, the experimenter moved to another part of the field to minimize the probability of testing the same dragonfly twice and performed the next replicate (dragonflies were extremely abundant, and the probability of repeated attack was judged to be extremely small). 
Table 2.1. A summary of the prey types offered and number of replicates in each experiment.

\begin{tabular}{|c|c|c|c|}
\hline Experiments & Prey types & $\begin{array}{l}\text { Presentation } \\
\text { method }\end{array}$ & $\begin{array}{l}\text { Number } \\
\text { of } \\
\text { replicates }\end{array}$ \\
\hline \multirow[t]{3}{*}{$\begin{array}{l}\text { 1-3 (Large vs small } \\
\text { prey (all black-grey)) }\end{array}$} & $\begin{array}{l}\text { (1) Helicobia rapax vs Sarcophaga } \\
\text { spp.* }\end{array}$ & Pairwise & 16 \\
\hline & $\begin{array}{l}\text { (2) Large artificial prey vs small } \\
\text { artificial prey }\end{array}$ & Pairwise & 21 \\
\hline & $\begin{array}{l}\text { (3) Large artificial prey vs small } \\
\text { artificial prey }\end{array}$ & Single & 30 plus 30 \\
\hline \multirow[t]{5}{*}{$\begin{array}{l}4-7 \text { (Mimetic vs non } \\
\text { mimetic prey) }\end{array}$} & $\begin{array}{l}\text { (4) Toxomerus geminatus (mimetic } \\
\text { hover fly) vs H. rapax }\end{array}$ & Pairwise & 38 \\
\hline & $\begin{array}{l}\text { (5) Black-painted Eristalis } \\
\text { transvera vs mock-painted } E \text {. } \\
\text { transversa }\end{array}$ & Pairwise & 47 \\
\hline & $\begin{array}{l}\text { (6a) Black-and-yellow-striped } \\
\text { artificial prey vs black artificial } \\
\text { prey }(2003)\end{array}$ & Pairwise & 30 \\
\hline & $\begin{array}{l}\text { (6b) Black-and-yellow-striped } \\
\text { artificial prey vs black artificial } \\
\text { prey (2004) }\end{array}$ & Pairwise & 52 \\
\hline & $\begin{array}{l}\text { (7) Black-and-yellow-striped } \\
\text { artificial prey vs black artificial } \\
\text { prey }\end{array}$ & Single & 30 plus 30 \\
\hline \multirow[t]{2}{*}{$8-9$ (Model vs. mimic) } & $\begin{array}{l}\text { (8) Black-painted Dolichovespula } \\
\text { arenaria vs mock-painted } \\
\text { Dolichovespula arenaria }\end{array}$ & Pairwise & 20 \\
\hline & $\begin{array}{l}\text { (9) Dolichovespula arenaria vs } \\
\text { Toxomerus geminatus }\end{array}$ & Pairwise & 20 \\
\hline
\end{tabular}

* The majority of Helicobia flies (small and dark) were identified as H. rapax (Walker), and the majority of the Sarcophaga flies were identified as S. bullata (Parker) (Appendix A). 
Natural prey items used in these experiments were collected by hand nets from within our field sites. In all experiments, the presented items were replaced with fresh specimens (either with natural colours and patterns or with painted colours and patterns) of the same species immediately after an attack or, if no attack occurred, after $8 \mathrm{~min}$. To avoid bias in pairwise presentations, we switched the position of the two prey on the rod after each replicate. Similarly, the prey types presented singly in an experiment were always presented at the same time by different researchers who swapped the prey type they were presenting after each replicate. Presentations continued until a prey item was attacked (measured as a physical grasp) or until 8 min elapsed. If an attack was made, we recorded the prey type, predator species and duration of attack up to a maximum of 4 min (dragonflies often remained suspended on the string consuming natural prey). All of the natural potential prey used in our experiments were abundant at the experimental site (Table 2.2) and were tethered alive; they often attempted to fly when tied to the string, although they were clearly restricted in movement. 
Table 2.2. A summary of the flying insects collected in Malaise traps at our study site from 1 July to 10 August 2004.

\begin{tabular}{|c|c|c|c|c|}
\hline Order & Family & $\begin{array}{c}\text { Percentage } \\
\text { (by } \\
\text { number) }\end{array}$ & $\begin{array}{l}\text { Percentage of the insect } \\
\text { order (by number) }\end{array}$ & $\begin{array}{l}\text { Standard } \\
\text { error }(n= \\
9 \text { samples })\end{array}$ \\
\hline \multicolumn{2}{|c|}{ Diptera } & 52.58 & & 7.69 \\
\hline & Tabanidae & & 54.58 & 8.91 \\
\hline & Bombyliidae & & 9.34 & 1.97 \\
\hline \multicolumn{5}{|c|}{ Sarcophagidae } \\
\hline & Sarcophaga spp. & & 6.1 & 1.31 \\
\hline & Helicobia rapax & & 5.15 & 1.47 \\
\hline & Asilidae & & 1.36 & 0.3 \\
\hline \multicolumn{5}{|c|}{ Syrphidae } \\
\hline & Syritta sp. & & 1.95 & 0.96 \\
\hline & Syrphus rebesii & & 0.39 & 0.19 \\
\hline & Toxomerus geminatus & & 10.12 & 2.04 \\
\hline & Eristalis spp. & & 0.37 & 0.19 \\
\hline & Others & & 10.48 & 3.87 \\
\hline \multicolumn{2}{|c|}{ Lepidoptera } & 35.56 & & 8.26 \\
\hline \multicolumn{5}{|c|}{ Hesperidae } \\
\hline & Euphyes sp. & & 23.89 & 6.34 \\
\hline & Thymelicus sp. & & 52.07 & 6.21 \\
\hline & Others & & 23.76 & 5.78 \\
\hline \multicolumn{2}{|c|}{ Hymenoptera } & 11.6 & & 5.36 \\
\hline & Black-and-yellow wasps & & & 1.94 \\
\hline & (including Vespidae) & & 11.55 & 8.81 \\
\hline & Other wasps & & 41.39 & 9.16 \\
\hline & Bees & & 47.04 & \\
\hline \multicolumn{2}{|c|}{ Orthoptera } & 0.04 & & 0.024 \\
\hline
\end{tabular}


Water-based colours (Ultra Gloss acrylic enamel, DecoArt, Stanford, KY) were used to paint artificial prey types and natural prey items as required. A fine-bristled paint brush was used to paint different prey types (artificial and natural). Mock-painted hover flies and wasps received a similar amount of paint as individuals in their comparison groups, but were painted so that they retained much of their former appearance (yellow stripes and patches on the thorax and abdomen were painted yellow; black segments and areas were painted black). Although the paints used were not different from the natural coloration of wasps to our eyes, we measured the reflectance of both the black and yellow paints using an Ocean Optics USB2000 spectrometer (Dunedin, Florida, U.S.A.) and a 200-micron reflection probe at a $45^{\circ}$ angle from the sample surface. Illumination was provided via a (PX-2, pulsed xenon) light source. Spectra were recorded at 1-nm intervals from 350 to $700 \mathrm{~nm}$ and measured relative to a Labsphere $98 \%$ reflection standard (OOIIrrad software ver. 2.04, Ocean Optics, Dunedin, FL). The peak reflectance for the yellow paint was around $610 \mathrm{~nm}$ and the black paint showed a flat curve. These measurements are very close to those observed in vespid wasps (Kauppinen \& Mappes 2003), which are considered to be the model for the mimetic hover flies. We detected no ultraviolet (UV) reflectance in our paints.

\subsubsection{Large versus Small Prey (Experiments 1-3)}

We conducted three experiments to examine whether dragonflies were size selective. We used pairwise presentations of small natural prey (Helicobia rapax) and larger natural prey (Sarcophaga spp.) (experiment 1), pairwise presentations of artificial prey of different sizes (experiment 2), and single presentations of artificial prey of 
different sizes (experiment 3). For the first experiment, the Sarcophaga spp. presented ranged from 13 to $15 \mathrm{~mm}$ in total body length and the $H$. rapax ranged from 5 to $7 \mathrm{~mm}$. Members of these fly genera are naturally grey-black and are not considered wasp mimics. For pairwise and single presentations of artificial prey, the small prey consisted of two ellipsoid plastic beads, each $3 \times 4 \mathrm{~mm}$ (diameter $\mathrm{x}$ length), and the large prey consisted of two ellipsoid beads, one $3 \times 4 \mathrm{~mm}$ and the other one $6 \times 11 \mathrm{~mm}$. The two beads used for each prey type were attached using a piece of wire as a central axis. We chose to use the above dimensions and shape to mimic the general size and shape of a potential natural prey as closely as possible. In these latter two experiments, the artificial prey were painted black (Table 2.1).

\subsubsection{Mimetic versus Nonmimetic Prey (Experiments 4-7)}

We then performed a series of four experiments to determine whether dragonflies were less likely to attack prey with wasp-like colours and patterns, while controlling for prey size. For experiment 4, we made pairwise presentations of natural mimics (Toxomerus geminatus) and nonmimetic flies of the same size (H.rapax). Although Toxomerus geminatus is similar to $H$. rapax only in size $(6-7 \mathrm{~mm}$ long), T. geminatus resembles a wasp in many attributes except body size (as above). For experiment 5 , we used individuals of a larger syrphid species, Eristalis transversa $(11-12 \mathrm{~mm}$ in body length). This wasp mimic was relatively common at our study site and was selected as an experimental species because it was large enough to be painted with relative ease. Using pairwise presentations we evaluated the attack responses of dragonflies to mock-painted individuals of $E$. transvers $a$ and conspecifics that were painted entirely black 
(nonmimetic). For experiments 6 and 7, we compared dragonfly responses to pairwise and single presentations of nonmimetic (black-painted) versus wasp-like (black-and yellow-painted) artificial prey of the same size (diameter $\times$ length $=3 \times 8 \mathrm{~mm}$ ). Artificial prey consisted of two attached beads (each $3 \times 4 \mathrm{~mm}$ ). To make the artificial prey a wasp mimic, we applied three stripes of yellow paint, approximately $1 \mathrm{~mm}$ wide (one on the first bead and two on the second bead), on a black painted prey. We conducted two separate runs of experiment 6 using pairwise presentations of artificial prey: one in 2003 (experiment 6a) and one in 2004 (experiment 6b). In experiment 7, we presented each type of artificial prey singly.

\subsubsection{Model versus Mimic Prey (Experiments 8, 9)}

In our final two experiments, we tested the attack responses by dragonflies to mock-painted wasps, Dolichovespula arenaria (Fabricius) (appendix A) (body length = $14-15 \mathrm{~mm}$ ) and wasps painted black (nonmimetic) in pairwise trials (experiment 8 ) and to small mimetic hover flies, $T$. geminatus, and large wasps, $D$. arenaria, in pairwise trials (experiment 9).

\subsection{Results}

Weekly surveys revealed that the most common dragonflies present in the field were Sympetrum spp. (meadowhawks), Libellula luctuosa Burmeister (widow skimmer), $L$. pulchella Drury (twelve-spotted skimmer), L. quadrimaculata L. (four-spotted skimmer), Plathemis lydia Drury (common whitetail), Leucorrhinia intacta Hagen (dot-tailed whiteface), L. proxima Calvert (red-waisted whiteface), Erythemis simplicicollis Say 
(eastern pondhawk), Aeshna canadensis Walker (Canada darner), Anax junius Drury (common green darner), Ladona julia Uhler (chalk-fronted corporal) and Pachydiplax longipennis Brumeister (blue dasher). Data collected from the Malaise traps on nine occasions indicated that the flying insect community at the experimental site included nonmimetic and mimetic flies, as well as wasps and bees (Table 2.2).

\subsubsection{Large versus Small Prey (Experiments 1-3)}

Dragonflies preferred small prey over large prey. In experiment 1 , using small $H$. rapax flies and large Sarcophaga spp. flies, dragonflies attacked the Helicobia in 15 of 16 pairwise presentations (sign test: $P=0.0005$; Fig. 2.1). In experiment 2 , using nonmimetic small and large artificial prey, dragonflies attacked the smaller prey in 19 of 21 pairwise presentations (sign test: $\mathrm{P}=0.0002$; Fig. 2.1 ). In experiment 3 , in which nonmimetic small and large artificial prey were presented singly in an 8-min period, dragonflies attacked small prey in 26 of 30 trials and attacked large prey in 8 of 30 trials (G test: $G_{1}=23.75, \mathrm{P}<0.001$; Fig. 2.1). Furthermore, for the subsets of small and large prey that were attacked, the median time to attack was significantly shorter for smaller than for larger prey (Mann-Whitney $U$ test: $U=52.5, N_{1}=26, N_{2}=8, \mathrm{P}=0.03$ ). 


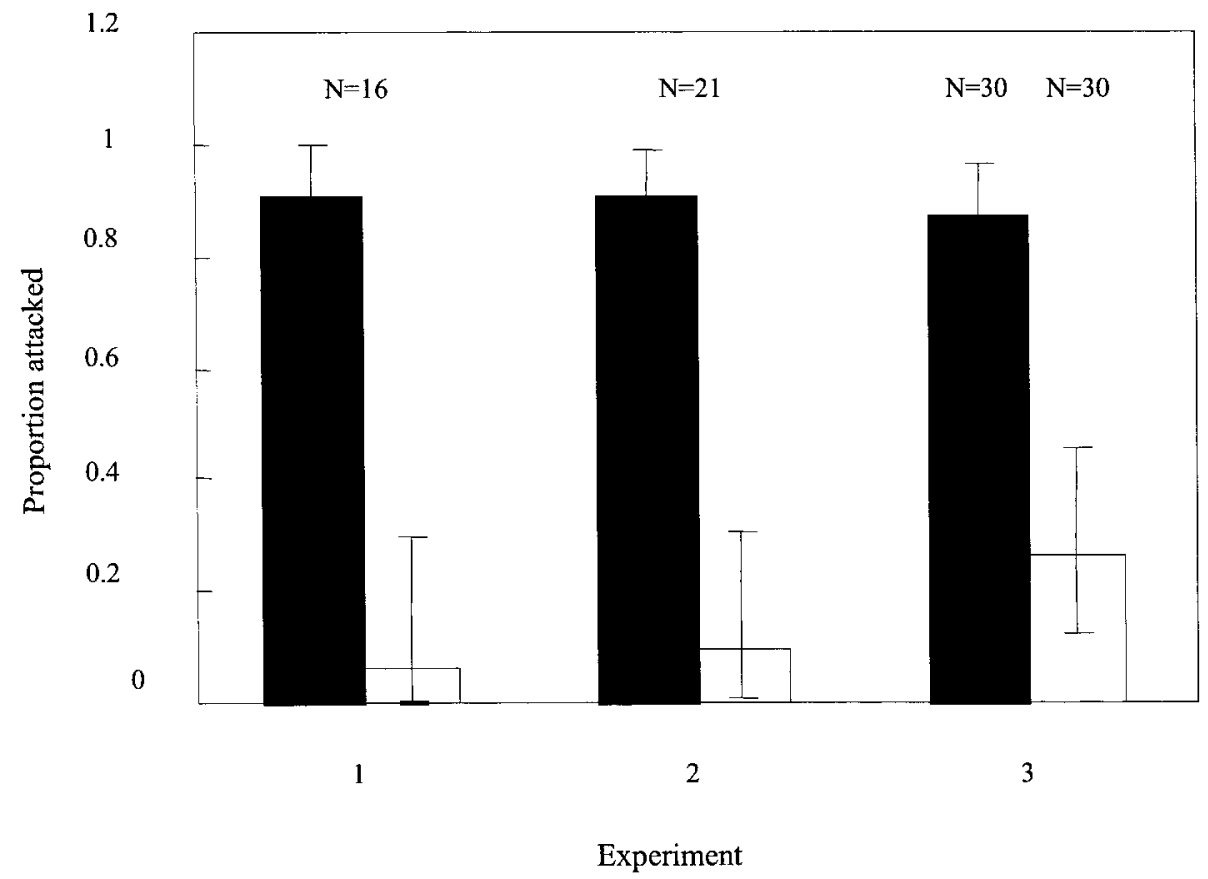

Figure 2.1: Proportion of attacks by dragonflies on small (solid bars) and large (open bars) prey types in experiments $1-3$. Experiment 1: Helicobia rapax and Sarcophaga spp. Experiment 2: pairwise presentations of artificial prey. Experiment 3: single presentations of artificial prey. Error bars indicate the exact binomial $95 \%$ confidence intervals. 


\subsubsection{Mimetic versus Nonmimetic Prey (Experiments 4-7)}

Dragonflies did not avoid wasp-like colours and patterns. In experiment 4, we recorded a nonsignificant tendency for dragonflies to attack $T$. geminatus wasp mimics (23 of 38 pairwise presentations) more than similar sized nonmimetic $H$. rapax flies (15 of 38 pairwise presentations; sign test: $\mathrm{P}=0.25$; Fig. 2.2). Furthermore, we found no difference between the median times that dragonflies spent feeding on hover flies and on nonmimetic flies (Mann-Whitney $U$ test: $U=147, N_{1}=23, N_{2}=15, \mathrm{P}=0.46$ ).

In experiment 5, using mock-painted and black-painted E. transversa, dragonflies directed 24 first attacks at mock-painted hover flies and 23 first attacks at individuals of the same species painted to look nonmimetic (sign test: $P=1$; Fig. 2.2). In both experiments 6a (2003) and 6b (2004), dragonflies attacked black-painted artificial prey and yellow-and-black-painted artificial prey at approximately the same rates (experiment 6a: 14 versus 16 , respectively, sign test: $P=0.85$; experiment $6 \mathrm{~b}: 30$ versus 22 , respectively, sign test: $\mathrm{P}=0.33$; Fig. 2.2). Similarly, in experiment 7 (single presentations of artificial prey during 8-min trials), dragonflies attacked black artificial prey in 28 of 30 trials and attacked yellow-and-black artificial prey in 27 of 30 trials (G test: $G_{1}=0.22, \mathrm{P}$ $=0.64 ;$ Fig. 2.2). The duration before the attacks also did not differ significantly between black and yellow versus black artificial prey (Mann-Whitney $U$ test: $U=358, N_{1}=28$, $\left.N_{2}=27, \mathrm{P}=0.73\right)$. 


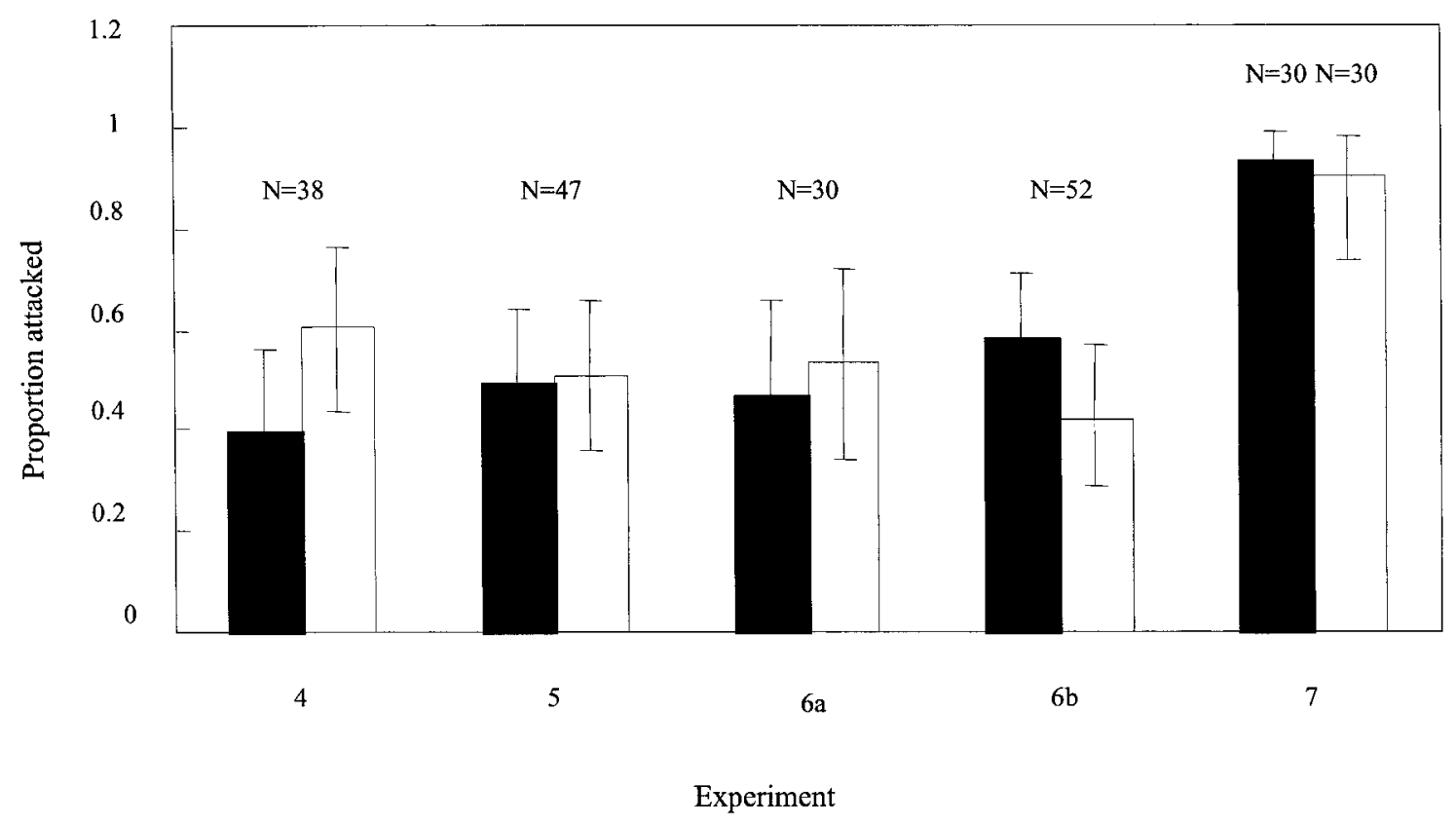

Figure 2.2: Proportion of attacks by dragonflies on mimetic (solid bars) and nonmimetic (open bars) prey types in experiments 4-7. Experiment 4: pairwise presentations of mimetic Toxoxmerus geminatus and nonmimetic Helicobia rapax Experiment 5: pairwise presentations of mock-painted and blackpainted Eristalis transversa. Experiments 6a (2003) and 6b (2004): pairwise presentations of black-and-yellow-painted and black-painted artificial prey. Experiment 7: single presentations of black -and-yellow-painted and blackpainted artificial prey. Error bars indicate the exact binomial $95 \%$ confidence intervals. 


\subsubsection{Model versus Mimic Prey (Experiments 8, 9)}

In experiment 8 , neither black-painted nor mock-painted wasps, D. arenaria, were attacked in any of the 20 pairwise 8-min trials. However, in experiment 9 , when dragonflies were presented with a choice of a wasp, D. arenaria and a hover fly, $T$. geminatus, they took only hover flies (20 attacks out of 20 pairwise presentations).

\subsubsection{Dragonfly Species Selectivity}

Overall, we observed a significant positive correlation between the mean proportion of times that a given dragonfly species was recorded in surveys and the proportion of attacks that that species made during our experiments (Spearman rank correlation: $r_{\mathrm{s}}=$ $0.724, N=14, \mathrm{P}=0.003$; Fig. 2.3 ). We also conducted a series of chi- square tests to evaluate whether certain prey types (such as hover flies or flies) were attacked more frequently by certain size classes and/or species of dragonflies in our pairwise experiments. To do so, we categorized dragonfly species by total body length: small-size, 25.4- $41 \mathrm{~mm}$ : Celithemis eponina, Leucorrhinia intacta, L. proxima and Sympetrum spp.; and medium 43-51 mm: Gomphus sp., Ladona julia, Libellula luctuosa, L. pulchella, L. quadrimaculata, Pachydiplax longipennis and Plathemis lydia). We did not observe any attacks from large-sized dragonflies in the pairwise experiments. In experiments 4 (T. geminatus versus Helicobia rapax) and 5 (E. transversa), there was no relation between small and medium dragonfly size classes and the type of prey they attacked (chi-square test: experiment $4: X^{2}{ }_{1}=0.008, \mathrm{P}=0.927$; experiment $5: X^{2}{ }_{1}=$ $0.508, \mathrm{P}=0.476$ ). We analysed the results of experiments $6 \mathrm{a}$ (black and yellow versus 
black artificial prey, 2003) and 6b (black and yellow versus black artificial prey, 2004) separately. Only Sympetrum spp. and Libellula luctuosa attacked the prey types in experiment $6 \mathrm{a}$ and none attacked one prey type over another $\left(2003: X^{2}{ }_{1}=0.053, \mathrm{P}=\right.$ $\left.0.818 ; 2004: X_{1}^{2}=1.883, \mathrm{P}=0.17\right)$. 


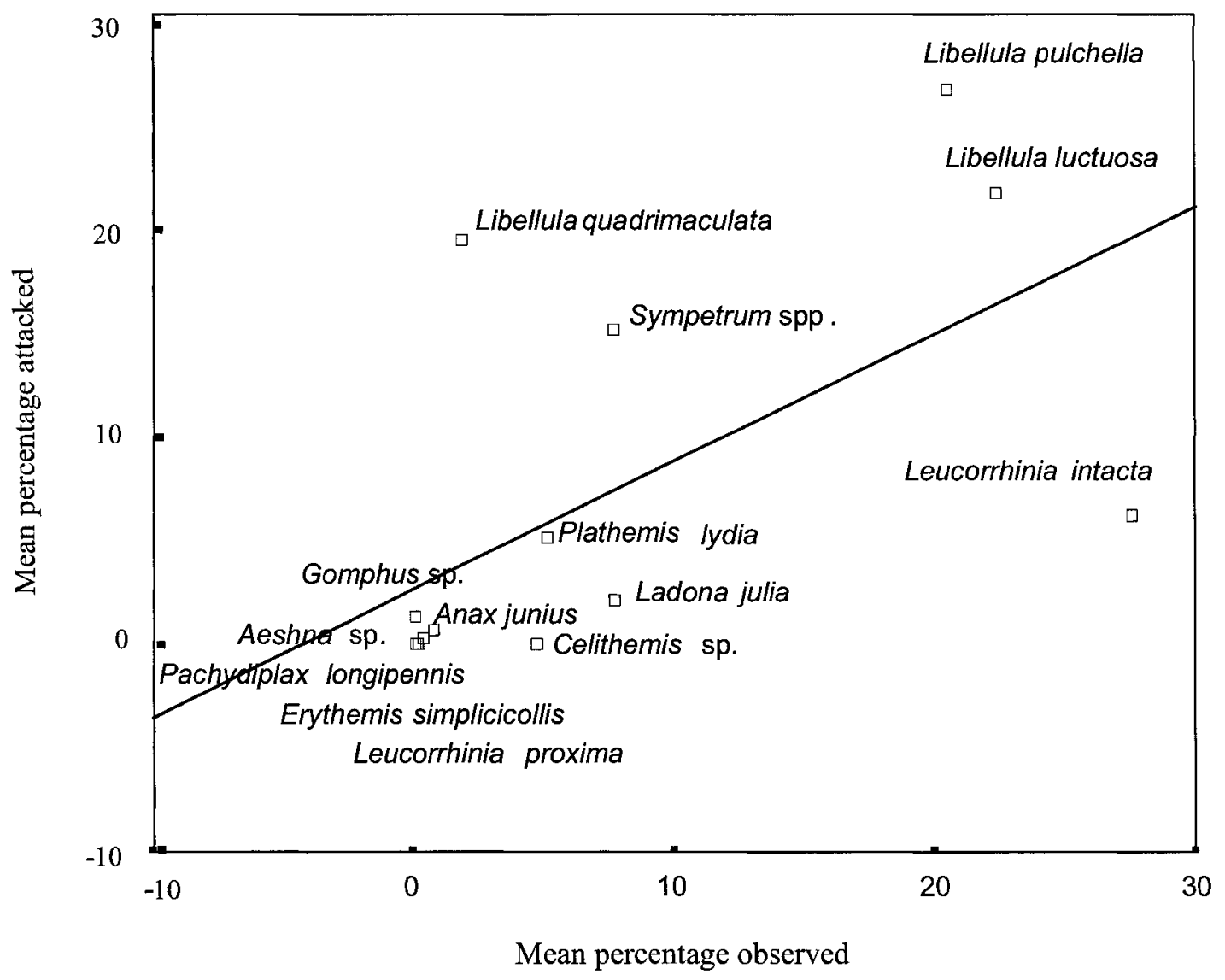

Figure 2.3: The relation between the arithmetic mean percentage of dragonfly species observed in the experimental field in each survey and the arithmetic mean percentage of attacks made by each of the species over our experiments. 


\subsection{Discussion}

Dragonflies were abundant in our test area and were likely to be amongst the most common predators on small aerial insects. The potential prey in our test area (collected in our Malaise-trap samples) included mimetic and nonmimetic flies as well as a variety of warningly coloured Hymenoptera. Thus, the types of natural prey items presented in our experiments were common at the site during our study, indicating that the dragonflies were likely to have previous experience with these species.

Our first set of experiments $(1-3)$ revealed that dragonflies preferred small flies (Diptera) to large flies. This result is contrary to what one would expect if dragonflies were simply attacking the most detectable prey or seeking the largest potential meal. This preference for smaller prey may be due to ease of prey handling or lower energy costs to the predator in subduing the prey. Since different species of nonmimetic flies were used in this experiment, there could have been a species bias in dragonflies' prey choice; however, using artificial prey, the same results were found. Although this is the first controlled measure of size-based prey preference for adult dragonflies, our results are consistent with earlier observations. Pritchard (1964) examined the guts of 293 dragonflies and reported small Diptera as the largest part of their diet. Corbet (1999) also listed small flies as a large component of dragonflies' diet. These data support Kauppinen \& Mappes' (2003) efforts to control for prey size and may help to explain why they reported so few physical attacks on large flies and wasps in their study, as we also found. 
Most importantly, experiments $4-7$ showed that there was no tendency for dragonflies to avoid attacking wasp mimic hover flies or brightly coloured artificial prey. Thus, when we presented the small mimetic hover fly $T$. geminatus together with small flies (Helicobia rapax) to dragonflies, our results indicated no significant difference between the number of dragonfly attacks on the two prey types. To control for a possible species effect, we recorded the attack rate of dragonflies on mock-painted versus blackpainted hover flies of the same species. Dragonflies did not preferentially attack either of the two prey types. Similarly, dragonflies showed no significant difference between the number of attacks on small black-and-yellow-striped artificial prey compared to small black-painted artificial prey. These combined data indicate that small mimetic hover flies gain no clear advantage from their yellow and black pattern in the context of predation by dragonflies.

One possible argument against presenting prey types experimentally in a pairwise manner is that in nature predators might not encounter the two prey types in proximity. However, the single-presentation method might be more prone to experimenter bias. We therefore used both single and pairwise presentations in the experiments with artificial prey. The results using both presentation methods showed a significant difference between the number of attacks on large and small artificial prey, regardless of whether the dependent variable was mean time to attack or proportion of prey attacked. We also found no significant difference between the number of attacks on black-and-yellow 
artificial prey and the number of attacks on black artificial prey either using the single presentation method or the pairwise method.

Our failure to reject the null hypothesis of no selectivity in our experiments with wasp-like prey may have resulted from low sample sizes, small effect sizes or both (Thomas \& Juanes 1996). With high power (0.8) effect sizes of 70\% attacks on one prey species (a 20\% departure from the null hypothesis) would be detected after 47 replicates of our pairwise presentations (Minitab version 14, Minitab, State College, PA). Our experiments using mock-painted versus black-painted hover flies, E. transversa, and black-and-yellow-painted artificial prey versus black artificial prey both had at least this power, which is considered acceptable for most scientific purposes (Cohen 1988). Of course, these values represent power estimates for the detection of a relatively large effect; a smaller effect would require greater replication to detect with high probability. Some authors have proposed that it is more informative to cite the confidence interval of the difference when summarizing a nonsignificant result, rather than the statistical power per se (Hoenig \& Heisey 2001; Colegrave \& Ruxton 2003). In our study, the observed difference in the sample means between the two single presentation treatments, using black and yellow versus black artificial prey, was only 0.033 , but the $95 \%$ confidence limits for this difference (based on the normal approximation to the binomial) were from -0.109 to 0.175 , with a zero effect size occurring in the central portion of the distribution. Although all statistics are based on probabilistic assessments, the most conservative explanation for our results is that dragonflies are relatively undeterred by yellow and black markings. 
In experiment 8, dragonflies avoided equally mock-painted and black-painted $D$. arenaria. One explanation for this result is that dragonflies might not be active at the time the experiment took place. However, in experiment 9 ( $T$. geminatus versus $D$. arenaria), which was conducted at the same time, dragonflies rapidly attacked the hover flies but left the wasps untouched. Although increasing the size of aposematic prey might increase the effect of the warning signal (Gamberale \& Tullberg 1996), in our study dragonflies avoided large prey that were both warningly coloured and not warningly coloured (experiment 8). Thus, prey size and not the black and yellow patterns appears to be the main factor prohibiting dragonflies from attack.

It is conceivable that certain species of hover fly are unpalatable to invertebrate predators (i.e. they are aposematic rather than mimetic; Gilbert 2005). However, dragonflies attacked, and spent approximately equal times feeding on hover flies and small flies, which indicates that the hover fly species $T$. geminatus was palatable to dragonflies. Of course, if hover flies were completely free flying, then they may elicit a different response from predators than if they were tethered. Moreover, dragonflies might also use specific characteristics such as antennae length or general body shape to detect potential prey. Such hypotheses need to be tested, but our results suggest that colour cues themselves do not appear sufficient to inhibit attack.

Either the lack of a UV component or possible odour from the paints could also have biased our results. However, there is no empirical evidence of a UV component in the colour pigments of either wasps or hover flies (Gilbert 2005). Moreover, dragonflies 
mainly use visual cues to detect their prey, so it is unlikely that the smell of the prey types affected the dragonflies' preference (Corbet 1999).

Although we observed no significant associations between dragonfly size and/or species and their feeding preferences, we were aware of possible seasonal effects during our experiments. For instance, towards the end of the season, dragonflies of the genus Libellula (medium-sized dragonfly) declined in numbers and were replaced by Sympetrum spp. (small-sized dragonfly). However, each prey-choice experiment was conducted for a relatively short period (maximum duration of 5 days), and the dragonfly community was the same within each experiment, so it is unlikely that seasonal effects could bias our interpretation in any individual experiment. Nevertheless, the possibility of seasonal effects requires caution when comparing preferences between experiments.

Our results suggest that yellow-and-black flies are at no selective advantage compared to black flies in the context of odonate predation, but Kauppinen \& Mappes (2003) concluded the opposite. However, the two studies are not necessarily contradictory. Our work focused on smaller flies; we explicitly controlled for encounter, and we considered only the number of actual physical attacks by dragonflies. In contrast, Kauppinen \& Mappes investigated the response of dragonflies to larger flies and wasps after encounter, and they considered a much broader suite of response behaviours (not all of which may influence selection on prey coloration). Another potential explanation for the differences between the two studies in the dragonflies' responses towards black-and- 
yellow prey types might lie in temporal and spatial differences. Under natural environmental conditions, the proportion of predators that find wasps unprofitable may vary in both time and space (Endler \& Mappes 2004). The predator species used by Kauppinen \& Mappes (2003), Aeshna grandis, is a midair forager (Corbet 1999), and it is possible that this species incorporates larger prey items into its diet. Although individuals of the genera Aeshna and Anax (Aeshnidae) were among the largest dragonflies present in the field during our experiments, these dragonflies made very few attacks. Furthermore, the dragonfly species that attacked the prey types in our experiments were mainly 'perchers' (i.e. sit-and-wait predators that take flight after they have spotted a potential prey). Differences in these predators between studies may therefore account for differences in prey choice.

Our results indicate that, although dragonflies tend to prefer attacking small prey over large prey, they are not inhibited by the yellow-and-black patterns sometimes shown by aposematic and mimetic prey. Although our study suggests that dragonflies may not select for protective coloration in aerial insect prey, we cannot rule out the effect of other insect predators in the evolution of mimetic patterns in invertebrates. Researchers have only begun to address this phenomenon, and there is a need for more experimental studies of the potential effect of other invertebrate predators in shaping warning signals and mimicry. 


\section{Chapter 3}

\section{Mimicry in hover flies (Diptera: Syrphidae): a field test of the competitive mimicry hypothesis}

\subsection{Preface}

In the first chapter I investigated the role of invertebrate predators in the evolution mimicry in hover flies. Although dragonflies were size selective they did not avoid brightly coloured prey. These findings led me to test other possibilities for the existence of wasp-like colours and patterns in hover flies. In the second chapter I looked at the effect of competition on the evolution of mimicry.

Food source competition is a common phenomenon in nature. Since wasps are predators and feed on other flower visitors, it is conceivable that pollinators will avoid flowers occupied by a wasp. Moreover, wasp-mimic hover flies might benefit from their wasp-like appearance by not sharing the flower resource with another pollinator. I have done multiple, well replicated experiments, to test this hypothesis further and have discussed the results. This chapter has recently been submitted for publication.

Rashed, A. \& Sherratt, T. N. 2006. Mimicry in hover flies (Diptera: Syrphidae): A field test of the competitive mimicry hypothesis, submitted. 


\subsection{Introduction}

The resemblance of a palatable (edible) species to an unpalatable (or otherwise defended) species is referred to as Batesian mimicry (Bates 1862; Edmunds 1974). While the phenomenon of mimicry is one of the most celebrated examples of the power of natural selection, there are still many outstanding questions and a recognized shortage of field studies, particularly on nonlepidopteran groups (Ruxton et al. 2004).

Many species of hover fly (Diptera: Syrphidae) are palatable to their potential avian predators (Mostler 1935) and mimic noxious hymenopteran models (Gilbert 2005). One of the most popular explanations to date is that this resemblance helps deter predation by vertebrate (e.g. Mostler 1935; Dittrich et al. 1993; Green et al. 1999) and invertebrate predators (Kauppinen \& Mappes 2003; see also Rashed et al. 2005). However, adult hover flies frequently visit flowers for nectar and pollen (Gilbert 1981; Branquart \& Hemptinne 2000) so it is conceivable that the resemblance to a wasp or bee also serves to reduce the frequency and intensity of competitive interactions on inflorescences, a phenomenon we have called 'competitive mimicry'. In employing signals to gain access to resources rather than to avoid predation, competitive mimicry, if substantiated, may be closer to the definition of "aggressive mimicry" than Batesian mimicry (Ruxton et al. 2004), although both forms of mimicry involve exploitation of the signal receivers (Hölen \& Johnstone 2004).

There are numerous examples of conspecifics or heterospecifics reducing the reproductive success of an individual either by directly interfering with the individual's 
ability to obtain resources, or by causing it to expend energy in responding to these competitors (Schoener 1974). Several studies have shown that flower visitors, particularly social bees and wasps, actively compete with other flower visitors over resources. For example, it has been suggested that food source competition and aggressive encounters among the bee species Trigina conifrons, T. fimbriata, T. apicalis and T. melina (Apidae, Meliponinae), has resulted in the separation of these species in time and space (Nagamitsu \& Inoue 1997). Similarly, Biesmeijer et al. (1999) reported interspecific food source competition between the two species of stingless bees (Hymenoptera: Apidae), Melipona beecheii and M. fasciata, noting that M. beecheii tended to avoid landing close to M. fasciata on artificial feeders. Parrish \& Fowler (1983) experimentally showed that when wasp species, Vespula maculifrons and Vespula germanica encountered one another on a food resource, their aggressiveness towards heterospecifics was higher than that directed toward conspecifics.

Of course, many species of Hymenoptera, such as social vespid wasps, are active generalist predators (see Richter 2000), which raises the possibility that mimetic hover flies could gain improved access to resources not only through their resemblance to a vigorous competitor, but also to a predator. It is now well known that the behaviour of insects when visiting flowers is sensitive to risk. For example, even Hymenoptera such as honey bees (Dukas 2001) and smaller sized bumble bees (Dukas \& Morse 2003) prefer to visit "safe flowers" without potential predators compared to equally rewarding flowers that could pose a potential danger. Similarly, Howarth and colleagues (2004) noted a 
significant inverse relationship between the number of an imperfect wasp mimic, Helophilus pendulus, and the number of wasps observed, and suggested that these hover flies avoid flowers with wasps on them to minimize their predation risk.

Although Hymenoptera are known to be competitive flower foragers, we are not aware of any test of whether the mimicry of a noxious hymenopteran model provides any form of competitive advantage. Nickol (1994) treated flower-visiting Hymenoptera as competitors for the hover fly, Volucella zonaria (Poda), and considered them as possible receivers for the mimicry signals, but his theory remains untested. If resource competition occurs in the field then flower visitors avoid landing on the flowers occupied by a specimen more frequently compared to an unoccupied flower. If mimicry provides any form of competitive advantage then one might expect that pollinators occupying the same inflorescence would come into physical contact with mimics less frequently than with similar-sized specimens that were not warningly coloured. We set out to test these predictions using replicated field experiments.

\subsection{Methods}

We experimentally investigated the rate of visitation of insects, and their subsequent behaviour, when landing on inflorescences of both goldenrod (Solidago canadensis L., Asteraceae [Compositae]) and wild-carrot (Daucus carota L., Apiaceae [Umbelliferae]) (appendix A). 


\subsubsection{Time and Location of Study}

Our study was conducted at Ottawa's Central Experimental Farm in two connected open fields near Carleton University, Canada $\left(44^{\circ} 34^{\prime} \mathrm{N}, 79^{\circ} 15^{\prime} \mathrm{W}\right)$. Experiments on goldenrod flowers were performed from 10 August to 20 September in both 2004 and 2005. Due to earlier flowering times, experiments on wild-carrot flowers were conducted from 22 June to 5 August, 2005. All experiments took place on warm (temperature range $27-33 \mathrm{C}^{\circ}$ ) sunny days between $1000-1300$ hours local time. We also conducted weekly surveys to identify other insect species present in our experimental field. Each survey involved an experimenter crossing the field four times in a zigzag manner, for approximately 4-5 min, while swiping a hand-held net into the inflorescences. This allowed us to record the presence, and estimate the relative abundance, of the potential flower visitors in our study area.

\subsubsection{Overall Design}

Each replicate consisted of simultaneously observing two randomly chosen flowers of the same species in the same condition (same size, same exposure to pollinators, etc), and at least $1 \mathrm{~m}$ apart, in the field for 10 consecutive minutes. All observations were made from at least a $2 \mathrm{~m}$ distance to minimize the effect of the experimenter's presence on flower visitations. Depending on the design of each experiment, either both of the chosen flowers were pinned with a single specimen (such as a mimetic hover fly and a nonmimetic fly), or only one of them (chosen at random) was pinned with a specimen and the other one was left unoccupied (see below). A variety of events, including the 
number of visits by different species (landing on the flower), the timing of visits, the length of time visitors spent on each flower and any behavioural interactions were recorded. We also recorded the number of investigations not resulting in physical contact with the flowers ('investigations' were defined as independent inspections made by flower visitors within $10 \mathrm{~cm}$ - repeated movements by the same individual closer to the flower were treated as a single inspection). The taxonomic level to which visiting insects were ascribed varied between taxonomic groups, but in all cases it was to at least family, and often genus.

\subsubsection{Pinned Specimens}

Both natural and artificial specimens were pinned out onto flowers in our experiments. All natural prey items were used only once, so that each replicate involved a new specimen. All of our natural specimens had been killed, dried and kept in the fridge (at $4{ }^{\circ} \mathrm{C}$ ) for at least four weeks prior to each experiment, to reduce the potential odour effect on the experimental results (see Gamboa et al. 1996). All species used in the study had a similar total body size range (measured from forehead to the tip of the last visible segment of the abdomen, they were all 10 to $13 \mathrm{~mm}$ in length), although their shapes differed. Our artificial specimens consisted of two ellipsoid plastic beads, each 3 x $5 \mathrm{~mm}$ (diameter x length). We painted the two beads either black or black-and-yellow striped and attached them using an insect pin as a central axis. We chose to use the above dimensions and shape so as to resemble the general shape of a live flower-visiting insect. 
Water-based colours (Crafter's Acrylic, DecoArt, Stanford, KY) were used to paint artificial prey types and natural prey items as required. Mock-painted hover flies, Spilomyia longicornis (Leow) (Appendix A), received a similar amount of paint as individuals in their comparison groups, but were painted so that they retained much of their former appearance (yellow stripes and patches on the thorax and abdomen). To make the hover flies black we painted the yellow stripes with black colour. Although the paints used were not different from the natural coloration of wasps to our eyes, we measured the reflectance of both the black and yellow paints using an Ocean Optics USB2000 spectrometer (Dunedin, Florida, U.S.A.) and a 200-micron reflection probe at a $45^{\circ}$ angle from the sample surface. Illumination was provided via a pulsed xenon (PX-2) light source. Spectra were recorded at 1-nm intervals from 350 to $700 \mathrm{~nm}$ and measured relative to a Labsphere $98 \%$ reflection standard (OOIIrrad software ver. 2.04). The peak reflectance for the yellow paint was around $610 \mathrm{~nm}$ and the black paint showed a flat curve. These measurements are very close to those observed in vespid wasps (Kauppinen \& Mappes 2003), which are considered to be the model for the mimetic hover fly, $S$. longicornis. We detected no ultraviolet (UV) reflectance in our paints.

\subsubsection{Experimental Details}

Overall, we ran 8 separate experiments on wild-carrot and 9 experiments on goldenrod using both natural and artificial specimens. Each experiment was repeated 12 to 28 times, reflecting a combined total of approximately 57 hours of continual observation. 


\subsubsection{Experiments 1-4: Flowers containing a specimen versus Unoccupied flowers}

In the first set of four experiments on goldenrod (experiments 1a- 4a) and wildcarrot (experiments $1 b-4 b$ ), one of the two flowers was pinned with a specimen while the other one was left unoccupied. Thus, in experiment $1(a, b)$ one of the flowers contained a pinned wasp, Dolicovespula arenaria (Farbricius), in experiment $2(a, b)$ one of the flowers had a pinned wasp-mimetic hover fly, S. longicornis and in experiment 3(a, b) one of the flowers held a pinned nonmimetic fly, Sarcophaga spp. (Appendix A)- no specimen was pinned on the matching flower in each case. In experiment $4(a, b)$ we placed a black-painted artificial specimen on one flower and left the other one unoccupied.

\subsubsection{Experiments 5-9: Pinned flowers versus Pinned flowers}

In our second set of five experiments we compared events on two flowers, each harbouring a different artificial or natural dried specimen. Experiments 5-8 were again conducted on both goldenrod (5a-8a) and wild-carrot (5b-8b) flowers. Experiment 9 was conducted on goldenrod flowers only (the restricted flowering period for carrot prevented us from conducting this final experiment on this species).

In experiment $5(\mathrm{a}, \mathrm{b})$, one of the flowers was pinned with a nonmimetic fly, Sarcophaga spp., and the other flower was pinned with a black and yellow wasp specimen, $D$. arenaria. In experiment $6(\mathrm{a}, \mathrm{b})$, we presented a flower pinned with a nonmimetic fly, Sarcophaga spp., and a flower pinned with mimetic hover fly, $S$. longicornis. In experiment $7(\mathrm{a}, \mathrm{b})$ one of the flowers was pinned with a wasp, $D$. 
arenaria and the other was pinned with a wasp-mimic hover fly, S. longicornis. In experiment $8(a, b)$ one of the experimental flowers contained a black painted artificial specimen and the other contained a black-and-yellow painted artificial specimen. Finally, Experiment 9a (conducted only on goldenrod flowers) involved comparing events on flowers pinned with a black painted hover fly, S. longicornis, to events on flowers pinned with a mock-painted hover fly, S. longicornis.

\subsection{Results}

Weekly surveys revealed that the most common flower visitors present in and around flowers on the experimental field belonged to the order of Hymenoptera, particularly from the family of Apidae (honey bees and bumble bees). Mimetic hover flies (Syrphidae), nonmimetic flies (e.g. Sarcophaga spp.) and black-and-yellow wasps (e.g. Vespidae) were also among the common species present in our study site (Table 3.1).

\subsubsection{Experiments 1-4: Flowers containing a specimen versus Unoccupied flowers}

In both experiments $1 \mathrm{a}$ and $1 \mathrm{~b}$ significantly more insects visited unoccupied flowers than flowers pinned with a wasp in the 10 min observation period (Table 3.2) (Fig. 3.1a and b). Likewise, goldenrod flowers pinned with the mimetic hover fly $S$. longicornis received significantly fewer insect visitors in the observation period than goldenrod not containing a specimen (Table 3.2) (Fig. 3.1a). Wild-carrot pinned with the hover fly $S$. longicornis similarly received overall fewer visitors than wild-carrot flowers not containing a specimen, although the difference was of borderline statistical significance in a two-tailed test (Table 3.2) (Fig. 3.1b). 
Table 3.1. A summary of the community of arthropods collected by hand nets from flowering stands within the study site from 22 July to 10 August 2005. Standard errors of means, each based on 5 samples, are provided in brackets.

\begin{tabular}{|c|c|c|c|}
\hline Order & Family & $\begin{array}{l}\text { Percentage (by } \\
\text { number) }\end{array}$ & $\begin{array}{l}\text { Percentage of the } \\
\text { insect order and } \\
\text { spider class (by } \\
\text { number) }\end{array}$ \\
\hline Diptera & $\begin{array}{l}\text { Syrphidae } \\
\text { Sarcophagidae } \\
\text { Calliphoridae } \\
\text { Others }\end{array}$ & $\begin{array}{l}32.5(11.0) \\
43.8(8.7) \\
4.9(3.1) \\
18.9(4.0)\end{array}$ & $23.3(7.7)$ \\
\hline Hymenoptera & $\begin{array}{l}\text { Apidae } \\
\text { Black-and-yellow } \\
\text { wasps (including } \\
\text { Vespidae) } \\
\text { Others }\end{array}$ & $\begin{array}{l}63.8(9.1) \\
14.1(1.4) \\
23.1(8.4)\end{array}$ & $33.2(3.3)$ \\
\hline Coleoptera & $\begin{array}{l}\text { Cantharidae } \\
\text { Others }\end{array}$ & $\begin{array}{l}39.9(20.4) \\
60.1(20.4)\end{array}$ & $20(8.0)$ \\
\hline Hemiptera & & & $20.4(5.0)$ \\
\hline Spiders (Arenae) & & & $3.1(1.9)$ \\
\hline
\end{tabular}


Table 3.2. A summary of the type of specimens presented, results of non-parametric Wilcoxon signed ranks tests comparing the number of visits and investigations in each pairwise presentation, and the number of replicate pairwise presentations in each experiment. Where a significant difference (or borderline significance) was detected based on a two-tailed distribution, the direction of the difference is indicated.

\begin{tabular}{|c|c|c|c|c|}
\hline \multirow[t]{2}{*}{ Experiment } & \multicolumn{2}{|c|}{ goldenrod } & \multicolumn{2}{|c|}{ wild-carrot } \\
\hline & No. of visits & $\begin{array}{l}\text { No. of } \\
\text { investigations }\end{array}$ & No. of visits & No. of investigations \\
\hline $\begin{array}{l}\text { Wasp vs } \\
\text { Unoccupied } \\
\text { (experiment } 1 \mathrm{a}, \mathrm{b} \text { ) }\end{array}$ & $\begin{array}{l}Z=-3.248 \\
P<0.001 \\
N=20 \\
\text { Wasp }< \\
\text { Unoccupied }\end{array}$ & $\begin{array}{l}Z=-2.588 \\
P=0.010 \\
N=20 \\
\text { Wasp }> \\
\text { Unoccupied }\end{array}$ & $\begin{array}{l}Z=-2.447 \\
P=0.013 \\
N=24 \\
\text { Wasp }<\text { Unoccupied }\end{array}$ & $\begin{array}{l}Z=-1.807 \\
P=0.071 \\
N=24 \\
\text { Wasp }>\text { Unoccupied }\end{array}$ \\
\hline $\begin{array}{l}\text { Mimetic hover fly } \\
\text { vs Unoccupied } \\
\text { (experiment } 2 a, b \text { ) }\end{array}$ & $\begin{array}{l}Z=-3.024 \\
P=0.001 \\
N=21 \\
\text { Hover fly }< \\
\text { Unoccupied }\end{array}$ & $\begin{array}{l}Z=0 \\
P=1 \\
N=21\end{array}$ & $\begin{array}{l}Z=-1.868 \\
P=0.063 \\
N=20 \\
\text { Hover fly }< \\
\text { Unoccupied }\end{array}$ & $\begin{array}{l}Z=-2.667 \\
P=0.008 \\
N=20 \\
\text { Hover fly }>\text { Unoccupied }\end{array}$ \\
\hline $\begin{array}{l}\text { Nonmimetic fly vs } \\
\text { Unoccupied } \\
\text { (experiment } 3 a, b \text { ) }\end{array}$ & $\begin{array}{l}Z=-1.757 \\
P=0.083 \\
N=20 \\
\text { Nonmimetic fly }< \\
\text { Unoccupied }\end{array}$ & $\begin{array}{l}Z=-1.823 \\
P=0.061 \\
N=20 \\
\text { Nonmimetic fly }> \\
\text { Unoccupied }\end{array}$ & $\begin{array}{l}Z=-2.017 \\
P=0.054 \\
N=20 \\
\text { Nonmimetic fly }< \\
\text { Unoccupied }\end{array}$ & $\begin{array}{l}Z=0 \\
P=1 \\
N=20\end{array}$ \\
\hline $\begin{array}{l}\text { Black-painted } \\
\text { bead vs } \\
\text { Unoccupied } \\
\text { (experiment } 4 a, b)\end{array}$ & $\begin{array}{l}Z=-3.52 \\
P<0.001 \\
N=20 \\
\text { Artificial black }< \\
\text { Unoccupied }\end{array}$ & $\begin{array}{l}Z=-2.456 \\
P=0.014 \\
N=20 \\
\text { Artificial black }> \\
\text { Unoccupied }\end{array}$ & $\begin{array}{l}Z=-2.950 \\
P=0.002 \\
N=21 \\
\text { Artificial black < } \\
\text { Unoccupied }\end{array}$ & $\begin{array}{l}Z=-2.539 \\
P=0.011 \\
N=21\end{array}$ \\
\hline $\begin{array}{l}\text { Wasp vs } \\
\text { Nonmimetic fly } \\
\text { (experiment 5a,b) }\end{array}$ & $\begin{array}{l}Z=-2.307 \\
P=0.022 \\
N=20 \\
\text { Wasp }< \\
\text { Nonmimetic fly }\end{array}$ & $\begin{array}{l}Z=0 \\
P=1 \\
N=20\end{array}$ & $\begin{array}{l}Z=-1.842 \\
P=0.061 \\
N=20 \\
\text { Wasp }<\text { Nonmimetic } \\
\text { fly }\end{array}$ & $\begin{array}{l}Z=0 \\
P=1 \\
N=20\end{array}$ \\
\hline $\begin{array}{l}\text { Mimetic hover fly } \\
\text { vs Nonmimetic fly } \\
\text { (experiment } 6 a, b)\end{array}$ & $\begin{array}{l}Z=-1.248 \\
P=0.233 \\
N=18\end{array}$ & $\begin{array}{l}Z=-0.302 \\
P=0.763 \\
N=18\end{array}$ & $\begin{array}{l}Z=-0.467 \\
P=0.677 \\
N=21\end{array}$ & $\begin{array}{l}Z=-0.723 \\
P=0.47 \\
N=21\end{array}$ \\
\hline $\begin{array}{l}\text { Wasp vs Mimetic } \\
\text { hover fly } \\
\text { (experiment } 7 \mathrm{a}, \mathrm{b} \text { ) }\end{array}$ & $\begin{array}{l}Z=-0.058 \\
P=0.992 \\
N=18\end{array}$ & $\begin{array}{l}Z=0 \\
P=1 \\
N=\mathbf{1 8}\end{array}$ & $\begin{array}{l}Z=-0.741 \\
P=0.507 \\
N=28\end{array}$ & $\begin{array}{l}Z=-0.707 \\
P=0.48 \\
N=28\end{array}$ \\
\hline $\begin{array}{l}\text { Black-and-yellow } \\
\text { vs Black } \\
\text { (experiment 8a, b) }\end{array}$ & $\begin{array}{l}Z=0 \\
P=0.519 \\
N=20\end{array}$ & $\begin{array}{l}Z=0 \\
P=1 \\
N=20\end{array}$ & $\begin{array}{l}Z=-0.591 \\
P=0.559 \\
N=20\end{array}$ & $\begin{array}{l}Z=-0.907 \\
P=0.365 \\
N=20\end{array}$ \\
\hline $\begin{array}{l}\text { Mock-painted vs } \\
\text { Black-painted } \\
\text { hover fly } \\
\text { (experiment 9a) }\end{array}$ & $\begin{array}{l}Z=-1.558 \\
P=0.148 \\
N=12\end{array}$ & $\begin{array}{l}Z=-1.890 \\
P=0.059 \\
N=12\end{array}$ & & \\
\hline
\end{tabular}



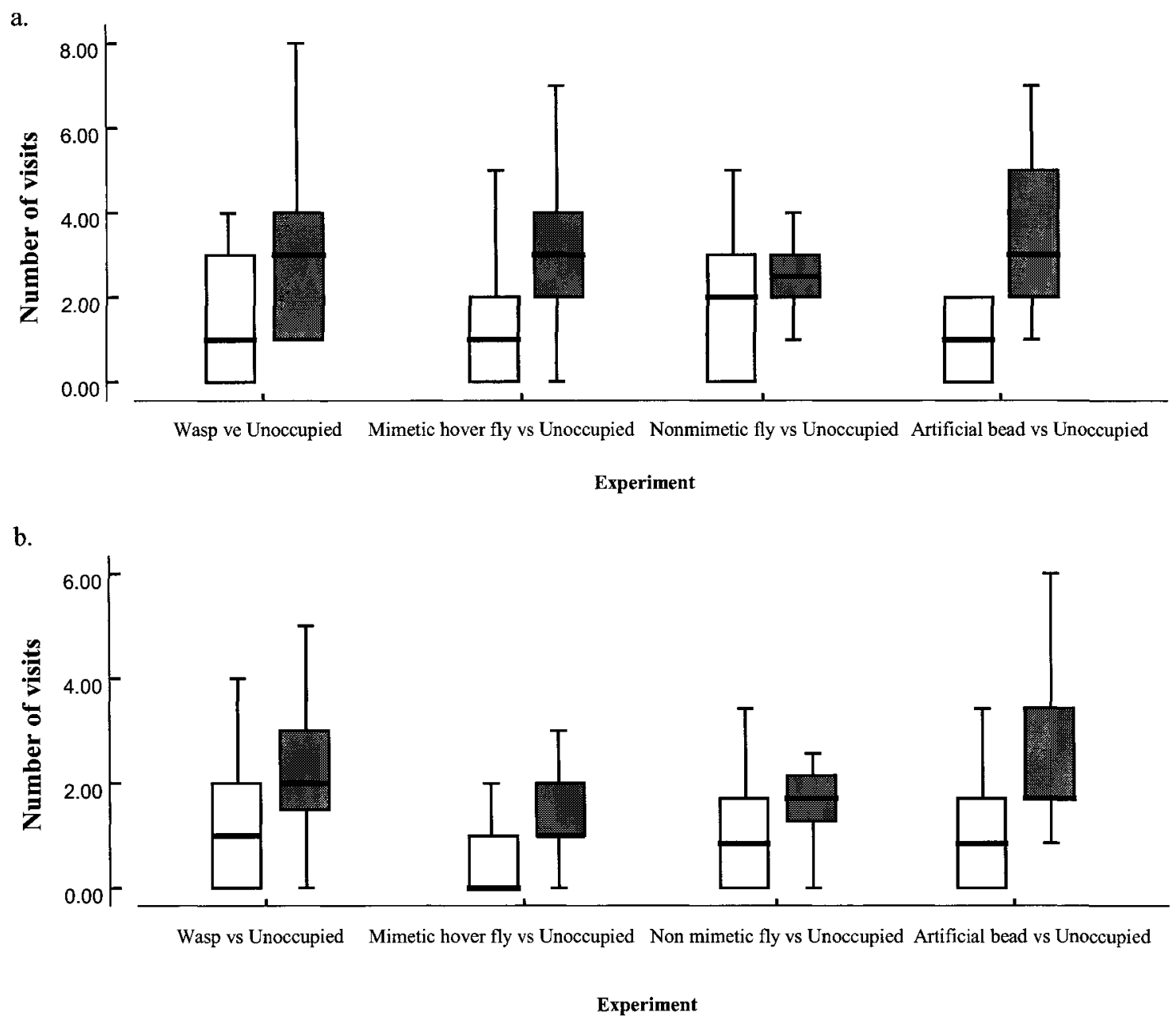

Figure 3.1a, b: The number of visits from insects to (a) goldenrod flowers and (b) to wildcarrot flowers. Blank boxes indicate the number of visits on pinned flowers. Filled boxes indicate the number of visits on unoccupied flowers. Horizontal thick lines indicate the medians, boxes show the interquartile ranges that contain $50 \%$ of the values and whiskers show the highest and lowest values without any possible outliers ( $>1.5$ box length from the upper or lower edge of the box). 
In experiment $3(a, b)$ there was no significant difference between the number of visits on unoccupied versus the number of visits of the flowers pinned with the nonmimetic fly, Sarcophaga spp. on both goldenrod and wild-carrot flowers (Table 3.2) although a strong trend towards visiting unoccupied flowers still existed (Fig. 3.1a and b). In the experiment $4(a, b)$, flower visitors showed a significant tendency toward visiting unoccupied flowers compared to the flowers harbouring black-painted artificial specimens (Table 3.2) (Fig. 3.1a and b).

Our observations revealed that pollinators tended to frequently hover around and inspect flowers pinned with a specimen without making any physical contact with either the flower or the specimen. We conducted a parallel series of nonparametric analyses (Wilcoxon signed ranks) to compare the number of investigations made by flower visitors. These analyses indicated that visitors investigated the pinned flower in the pair significantly more frequently than the unoccupied flower (Table 3.2) (Fig. 3.2a and b).

\subsubsection{Experiments 5-9: Pinned flowers versus Pinned flowers}

In experiment 5a there were significantly fewer visits of other insects to goldenrod pinned with the wasp, D. arenaria compared to flowers pinned with the nonmimetic fly, Sarcophaga spp. (Table 3.2) (Fig. 3.3). A similar trend was observed on wild-carrot (experiment $5 b$ ), although the difference was of borderline statistical significance (Table 3.2) (Fig 3.3). 
a.

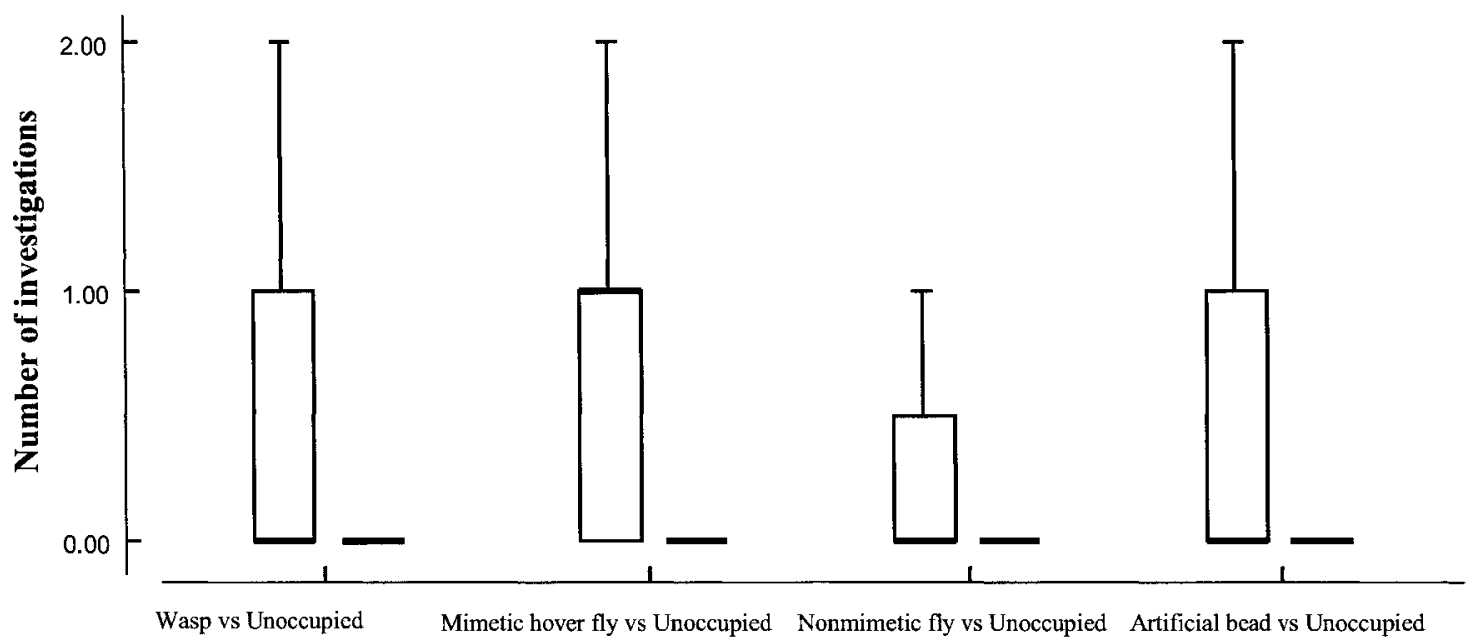

b.

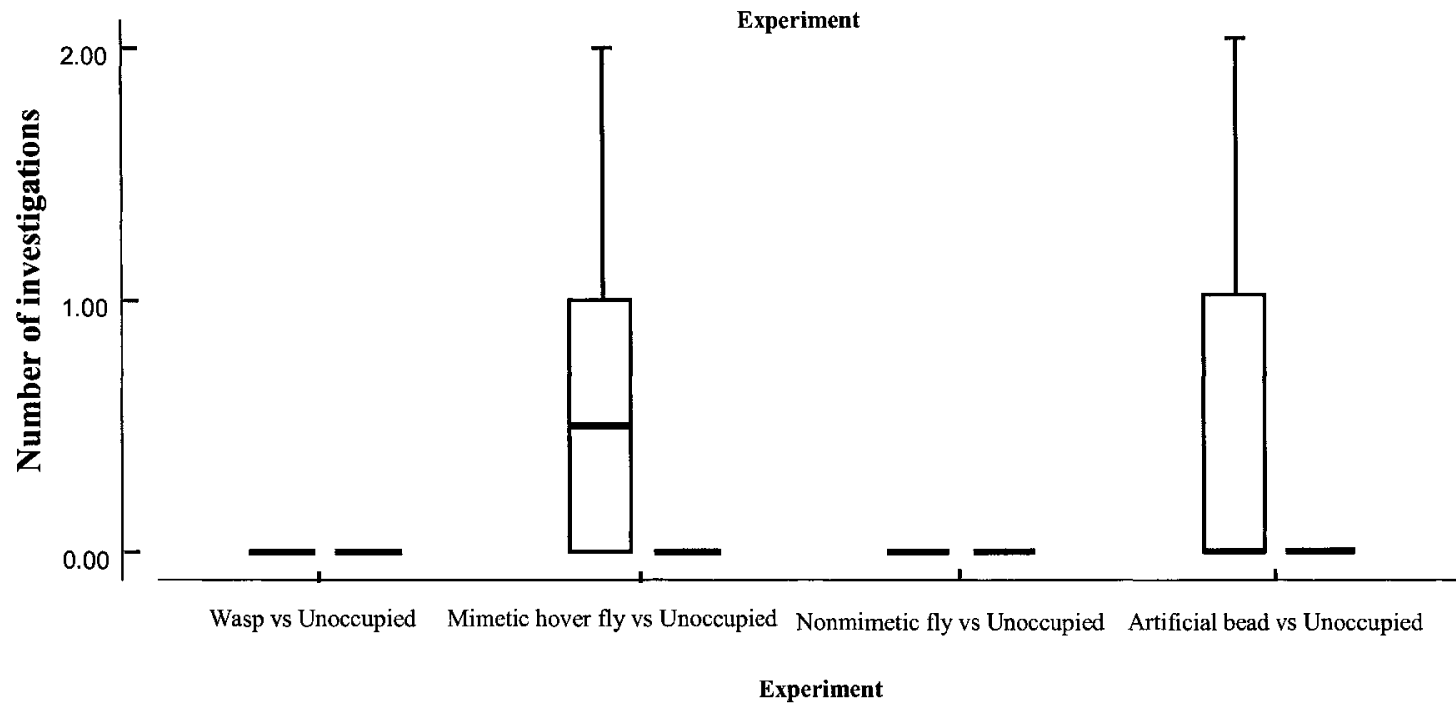

Figures $3.2 \mathrm{a}, \mathrm{b}$ : The number of times that flower visitors approached and investigated the occupied (blank boxes), and unoccupied inflorescences (filled boxes) on (a) goldenrod and (b) wild-carrot. See fig 3.1 for graphical notation. 


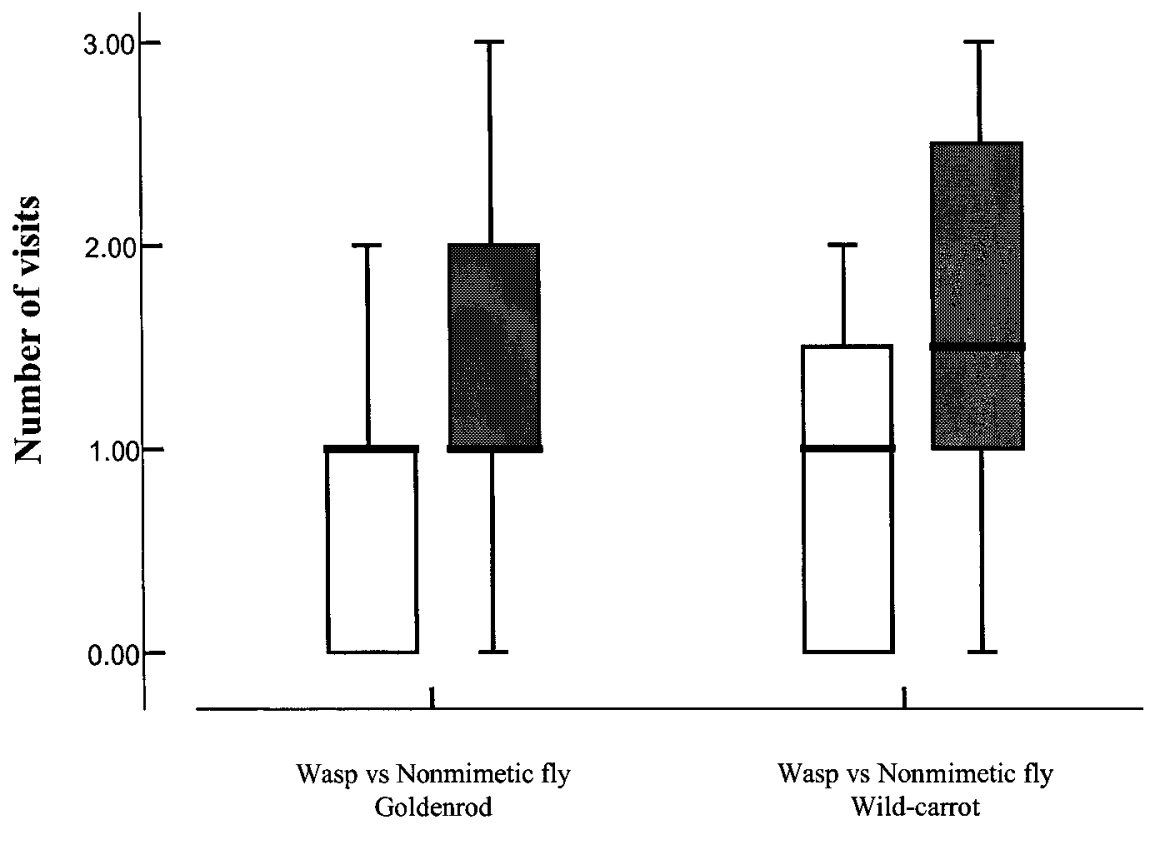

Experiment

Figure 3.3: The number of visits from insects to goldenrod flowers and wild-carrot flowers pinned with a wasp, D. arenaria (blank boxes), and a nonmimetic fly, Sarcophaga spp. (filled boxes). See fig 3.1 for graphical notation. 
Crucially, in experiment $6(a, b)$ the number of visits to the flowers pinned with a mimetic hover fly, S. longicornis, was not significantly different from the number of visits to the flowers pinned with a nonmimetic specimen, Sarcophaga spp. (Table 3.2) (Fig. 3.4). Our results from experiment 7, on both goldenrod (7a) and wild-carrot (7b), similarly indicated no significant difference between the number of visits to the flowers pinned with a wasp specimen, $D$. arenaria and flowers pinned with the mimetic hover fly S. longicornis (Table 3.2). Likewise, in experiment 8(a,b), we observed no significant difference between the number of visits to black-painted beads and the number of visits to black-and-yellow painted beads (Table 3.2) (Fig. 3.4). Finally, the results from experiment $9 \mathrm{a}$, also indicated no difference between the number of visits to flowers pinned with a mock-painted hover fly, S. longicornis, and the number of visits to flowers pinned with a black-painted hover fly (Table 3.2).

Our observations indicated that pollinators inspected both occupied flowers at approximately the same frequency without making any physical contact with the food source, and regardless of the type and the colour of the pinned specimen. Thus, Wilcoxon tests showed no evidence that any of pairs of flowers were investigated more often by flower visitors (see Table 3.2).

\subsubsection{Physical attacks}

We regularly observed large-sized Vespula maculata, Polistes fuscatus and even a hover fly, S. sayi, physically attacking our pinned specimens and other flower visitors when they were feeding on the inflorescences. On a few occasions $V$. maculata and $P$. 
fuscatus even tried to remove the pinned nonmimetic fly, Sarcophaga spp. from the flower in an aggressive manner. By contrast, and despite many hours of observation, we did not record any such behaviour towards pinned wasps. Incidental touching of the flower visitors to the pinned specimens sometimes occurred but the overall frequency of physical attacks (typically 2-3 attacks over 20 or so replicates in any given experiment) were too few to allow detailed statistical analysis. 


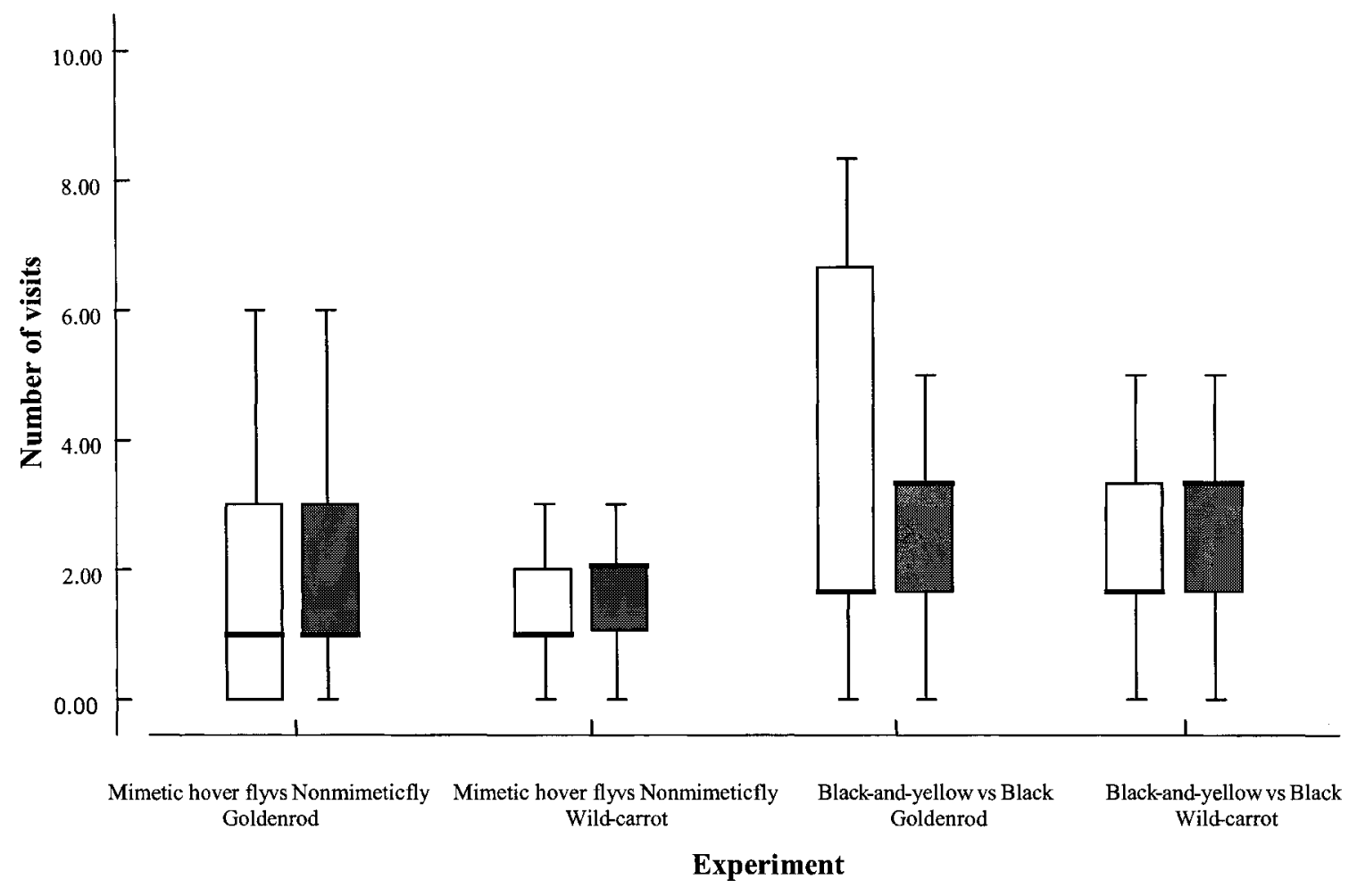

Figure 3.4: The number of visits to inflorescences pinned with a mimetic hover fly, $S$. longicornis (blank boxes) versus a nonmimetic fly, Sarcophaga spp. (filled boxes), and also black-and-yellow painted beads (blank boxes) versus black painted beads (filled boxes) on both goldenrod and wild-carrot flowers. See fig 3.1 for graphical notation. 


\subsubsection{Flower Visitors Selectivity}

We conducted a series of chi-squared tests of association to evaluate whether unoccupied flowers or flowers pinned with a certain specimen were visited relatively more frequently by a certain taxonomic group of flower visitors (Hymenoptera and/or Diptera - the majority of flower visitors). Such tests necessarily involved combining the number of visits by taxonomic groups within a given experiment, assuming that the data were independent. Separate analyses of the results of individual experiments gave no evidence that a particular insect order (Hymenoptera or Diptera) visited one of the two flower types over the other (Table 3.3), although expected counts were frequently less than 5 so the results should be treated with some caution (Sokal \& Rohlf 1995). 
Table 3.3. A summary of the chi-square tests of association between taxonomic groups of visitor (Hymenoptera and Diptera) and type of flower presented. In no case did a particular treatment tend to attract disproportionately more of one taxonomic group, compared to the other treatment. "a)" experiments were performed on Goldenrod flowers while "b)" experiments were performed on wild-carrot flowers. One degree of freedom was involved in each test.

\begin{tabular}{lllc}
\hline Experiment & $\mathrm{X}^{2}$ & $\mathrm{P}$ & $\begin{array}{c}\text { Expected counts } \\
\text { less than 5 }\end{array}$ \\
\hline 1a) Wasp vs Unoccupied & 1.046 & 0.306 & 2 \\
1b) Wasp vs Unoccupied & 3.136 & 0.077 & 0 \\
2a) Hover fly vs Unoccupied & 0.656 & 0.418 & 1 \\
2b) Hover fly vs Unoccupied & 1.154 & 0.283 & 1 \\
3a) Wasp vs Unoccupied & 2.817 & 0.093 & 2 \\
4a) Artificial vs Unoccupied & 0.617 & 0.432 & 1 \\
4b) Artificial vs Unoccupied & 2.256 & 0.133 & 0 \\
5a) Wasp vs Nonmimetic fly & 0.05 & 0.824 & 1 \\
5b) Wasp vs Nonmimetic fly & 0.291 & 0.59 & 1 \\
6b) Hover fly vs Nonmimetic fly & 0.854 & 0.355 & 0 \\
7a) Hover fly vs Nonmimetic fly & 0.055 & 0.815 & 2 \\
7b) Wasp vs Hover fly & 1.276 & 0.259 & 2 \\
8b) Artificial black-and-yellow vs Black & 0.149 & 0.7 & 0 \\
\hline
\end{tabular}




\subsection{Discussion}

Goldenrod and wild-carrot were the most common flowering species present in the sites during our study period. These two plant species were very attractive to insects and were frequently visited by a variety of species from the orders Diptera and Hymenoptera and sometimes Coleoptera, Hemiptera and Lepidoptera. The results of our weekly surveys indicated that species of the pinned specimens we used in our pairwise experiments were common at the sites where the study took place, indicating that flower visitors were likely to have had previous encounters with the species that we used as pinned specimens (Table 3.1). Using the two types of natural flower with different colours and shapes also enabled us to look at the consistency of our results (goldenrod inflorescences are more or less cone shaped and larger compared to wild-carrot inflorescences, which are arranged on a flat disc-like form). Furthermore, our incidental observations of aggression exhibited by wasps such as $V$. maculata and P. fuscatus as the experiments progressed gave us good reason to wonder whether hover flies might benefit in any competitive sense by resembling a wasp.

Overall our results indicated that flower visitors visited unoccupied goldenrod flowers significantly more frequently than goldenrod flowers occupied by a wasp, mimetic hover fly or an artificial specimen (experiments 1a, 2a and 4a). A very similar pattern was observed for experiments with wild-carrot flowers except that only experiments $1 \mathrm{~b}$ and $4 \mathrm{~b}$ resulted in a significant difference between the number of visits. It is important to note that even though the results of experiments $3 \mathrm{a}$ for goldenrod also $2 \mathrm{~b}$ 
and $3 \mathrm{~b}$ for wild-carrot were nonsignificant, they were close to significance and in the same direction (in fact, had we employed a one-tailed test on the basis of our prior expectation they would have been significant). The overall mean number of visitors tended to be less to wild-carrot (partly a result of their smaller size), which may render each of our comparisons less sensitive to a treatment effect in this particular plant species.

It has been shown that the presence and size of the occupier influences the flower choice of foragers, although the type of the response to these visual cues varies with species. For example, Richter \& Tisch (1999) showed that while Vespula maculifrons, $V$. vidua and $V$. consobrina avoid flowers pinned with a wasp specimen, $V$. germanica and Polistes fuscatus were attracted to the flowers that were occupied by a wasp specimen. Parrish \& Fowler (1983) similarly observed that $V$. maculifrons tended to avoid pinned specimens and artificially painted drawing pins, whereas $V$. germanica preferred to feed on the resources that are occupied by a greater number of foragers. Although their results indicate that different species of foragers could have different preferences for the food source, we chose to focus on a community response because a variety of potential competitors may in theory facilitate selection for mimicry in hover flies.

Our analysis also clearly indicated that flower visitors investigated and hovered around the occupied flowers more often compared to unoccupied flowers. Three explanations can be offered for investigating the occupied inflorescence by flower 
visitors and avoiding any physical contact with the pinned specimen, although they are not mutually exclusive. First, flower visitors may perceive the presence of another species as potential danger. Previous studies have also shown that flower visitors avoid visiting potentially dangerous flowers (Dukas \& Morse 2000; Dukas 2001). The second possibility is that flower visitors prefer not to share a food resource with another insect. Thirdly, it is possible that the presence of another visitor on a flower is an indicator for the quality of the resource and therefore flower visitors assess the chance of sharing the food source with, or even the possibility of winning an aggressive encounter with the occupier. The fact that the number of inspections is significantly higher for pinned specimens compared to unoccupied flowers clearly suggests that such decisions are made at close quarters rather than from a distance.

Intriguingly, our results revealed that flower visitors have a tendency to avoid landing on flowers pinned with a wasp compared to flowers pinned with a nonmimetic fly. By contrast, visitors arrived at flowers pinned with hover flies at an approximately equal rate compared to similar flowers pinned with nonmimetic flies (experiments $6 a, b)$. Indeed, goldenrod with mock-painted and black-painted hover flies attracted visitors at similar rates (experiment 9a) and a similar result was observed for black painted and yellow painted beads (experiments $8 \mathrm{a}, \mathrm{b}$ ). Collectively this suggests that while insects may be dissuaded from landing on flowers that contain another individual, and they may show particularly strong avoidance of wasps (quite possibly because of their distinctive shape or antennae length, see Dukas 2001; Kauppinen \& Mappes 2003), the yellow and 
black stripes of a hover fly do not appear to protect an individual from competition in terms of reducing the rates of arrival of potential competitors.

While non-significant results can arise due to insufficient replication, each of the above experiments was well replicated and therefore capable of detecting modest differences with reasonable power. To address this issue in more detail, we have followed the guidelines proposed by Colegrave \& Ruxton (2003), who argue that confidence intervals are a more useful complement to nonsignificant tests than post-hoc power tests (see also Johnson 2005, Colegrave \& Ruxton 2005). In all of the central non-significant comparisons to test for the effectiveness of yellow and black markings in reducing competititon, the mean difference in the number of visits between the two types of flower was always less than 1 (and generally less than 0.5 ) with the $95 \%$ confidence intervals (assuming approximate normality) for this difference always having an upper limit of less than 2 visits (in detail - black painted beads vs black and yellow painted beads: goldenrod, mean difference -0.05 visits $[95 \% \mathrm{CI}-0.90 \rightarrow 0.80]$; carrot, mean difference 0.2 visits [95\% C.I. $-0.78 \rightarrow 1.18]$; nonmimetic fly vs mimetic hover fly: goldenrod, mean difference 0.56 visits $[95 \% \mathrm{CI}-0.86 \rightarrow 1.97]$; carrot, mean difference 0.29 visits [ $95 \%$ CI $-0.63 \rightarrow 1.20]$; black-painted vs mock painted hover fly: goldenrod, mean difference 0.83 visits [ $95 \% \mathrm{CI}-0.21$ to 1.88 ). Of course, like all non-significant experiments, we cannot exclude the possibility that black and yellow patterns provide some competitive benefit to hover flies but we believe, after repeated non-significant tests, that we are safe 
in concluding that our data in themselves provide no convincing evidence for a competitive benefit from mimicry in hover flies.

It is possible that alternative designs may have given different answers. For example, some hover flies possess elongated antennae (e.g. Sphecomyia vittata and Ceriana signifera) — presumably to mimic the long antennae of yellow-jacket waspswhile some other hover fly species, such as $S$. longicornis and Temnostoma spp., wave their darkened front legs to mimic the presence and movement of the antennae of their potential wasp models (Waldbauer 1970). Moreover, good mimetic hover flies also wag their wings to mimic wasp's movements (Waldbauer 1988) or they fly in a similar manner as their related models do (Golding \& Edmunds 2000; Golding et al. 2001). Behavioural similarities are potentially important in improving the quality of mimicry to the receivers and in our case to potential competitors. However, in using pinned specimens, we limited ourselves to elucidating benefits of morphological mimicry. Further studies need to be done to test the possibility that behavioural mimicry is necessary before benefits of reduced competition can be realized.

Studies have also shown that some flower visitors like honey bees and bumblebees (Goulson et al. 2000) and even hover flies (Reader et al. 2005) use short term olfactory cues to mark flowers that they have already visited and possibly to mediate interaction between species competing for flower resources. Although this could potentially affect the results of some experiments, the 10 min observation time allowed us to record frequent flower visits for our experiments. Furthermore, the two flower choices in each 
trial were presented in a pairwise manner and they were equally exposed to flower visitors including honey bees and bumblebees.

Although our experiments did not show any direct competitive advantage for mimetic colours and patterns in hover flies, it is possible that competitive interactions could facilitate the evolution of mimicry indirectly. Larger flower visitors are usually the winner of any physical interactions on the flower resources (Gilbert 2005). In our study we also observed that larger species (mainly bumble bees) remained on an inflorescence despite interruption by small halictid bees, small nonmimetic flies or smaller bumble bees. If the larger species remain on flowers longer due to their superior competitive abilities, then they should have good means to actively defend themselves from predators or seek to escape predation via mimicry (Gilbert 2005). Gilbert (2005) suggests this as a potential explanation for the positive correlation between the size and degree of mimetic similarity in some hover fly species.

The idea of competitive mimicry is an intriguing one and merits further empirical testing. Our study has revealed very clear evidence that flower choice by pollinators is sensitive to whether flowers are occupied, and it has provided some evidence to suggest that flowers containing wasps are preferentially avoided by pollinators compared to flowers with nonmimetic flies. Nevertheless, we have found no compelling evidence that floral competition is reduced through the adoption of yellow and black markings per se, using both artificial prey and natural prey on two different flowering species. 


\section{CHAPTER 4}

\section{Neural Network Applications in the Study of Mimicry}

\subsection{Preface}

In the first two chapters I experimentally tested two potential selective factors that could facilitate the evolution of morphological mimicry in hover flies. In this chapter I use a numerical modeling approach to assess the degree of this similarity to the potential model. As previously introduced, the similarity between the mimics and the models is not always perfect. More often this similarity is imperfect.

In this chapter, first I present the use of a neural network model to help measure the degree of similarity in an objective manner. In the following section I compare the classification of hover fly images by a neural network to the classifications made by both humans and pigeons. Furthermore, using a genetic algorithm along with the neural network, we have "reverse engineered" the pigeon's classification of wasp, nonmimetic fly and hover fly images to determine the most important predictor variables birds use to classify morphological mimicry. Dr. Rod S. Bain who wrote the neural network program took the lead in writing the manuscript (second part of this chapter) and I incorporated the biological component of the project, and took part in the data collection (including evaluating human-based rankings and converting images of flies and wasps into biometrical data). 


\subsection{Using neural network classifiers to estimate the degree of morphological similarity between mimics and models}

\subsubsection{Introduction}

Multilayer feedforward neural networks can be considered as a class of empirical non-linear models that can be used for regression or classification. An artificial neural network is an information processing paradigm that is inspired by the way biological nervous systems, such as the brain, process information. The key element of this paradigm is the novel structure of the information processing system. It is composed of a large number of highly interconnected processing elements (neurons) working in unison to solve specific problems. To date, unsupervised, self-organizing neural networks have been used in several studies in order to categorize different classes of organisms (e.g. Murray et al. 1998; Feraud \& Clerot 2002; Culverhouse et al. 2003; Lavin \& Vora 2005; Burks et al. 2005).

Holmgren \& Enquist (1999) were the first to use an artificial neural network in the context of mimicry. They investigated the evolution of mimicry by using a neural network as the receiver along with two populations of senders (potential mimics and models). Their results indicated that mimicry evolved simply because the mimics evolve faster towards the models than the models move away. However, they did not use their neural network to measure the mimetic similarity between specimens. Recently, neural networks have also been applied in a number of ways to understand aspects of predator behaviour such as the confusion effect (Tosh et al. 2006) and the evolution of warning signals in defended prey (Merilaita \& Tullberg 2005). 
In this part of the chapter I will address one of the challenges in the study of Batesian mimicry which is the lack of a quantitative and objective means of assessing the degree of similarity among mimics, particularly imperfect mimics, and their potential models. To deal with this problem, I estimated using a feedforward neural network classifier program (Fig 4.1), the degree of morphological similarity between selected species of hover flies (Diptera: Syrphidae) and their hymenopteran models.

\subsubsection{Methods}

A neural net work classifier is composed of many processing elements that sum the weighted inputs at the nodes of the hidden layer. At the hidden layer a non-linear activation function is applied to the weighted sums. The third layer takes the weighted sum of the output from the hidden layer plus, optionally, the weighted sum of the inputs (if skip-layer weights are being used). A softmax function (Bishop 1995; Sarle 1997) transforms the outputs into probabilities of inclusion in each class (Fig 4.2). The number of outputs always equals the number of classes.

The complexity of a neural network is controlled by the number of hidden layers, the number of nodes in each hidden layer as well as whether or not skip-layer weights are being used. Therefore, it is very important to optimize the system based on the number and the nature of the training data set. In our designed neural network the input variables could be entered as continuous, ordinal, and/or categorical. 


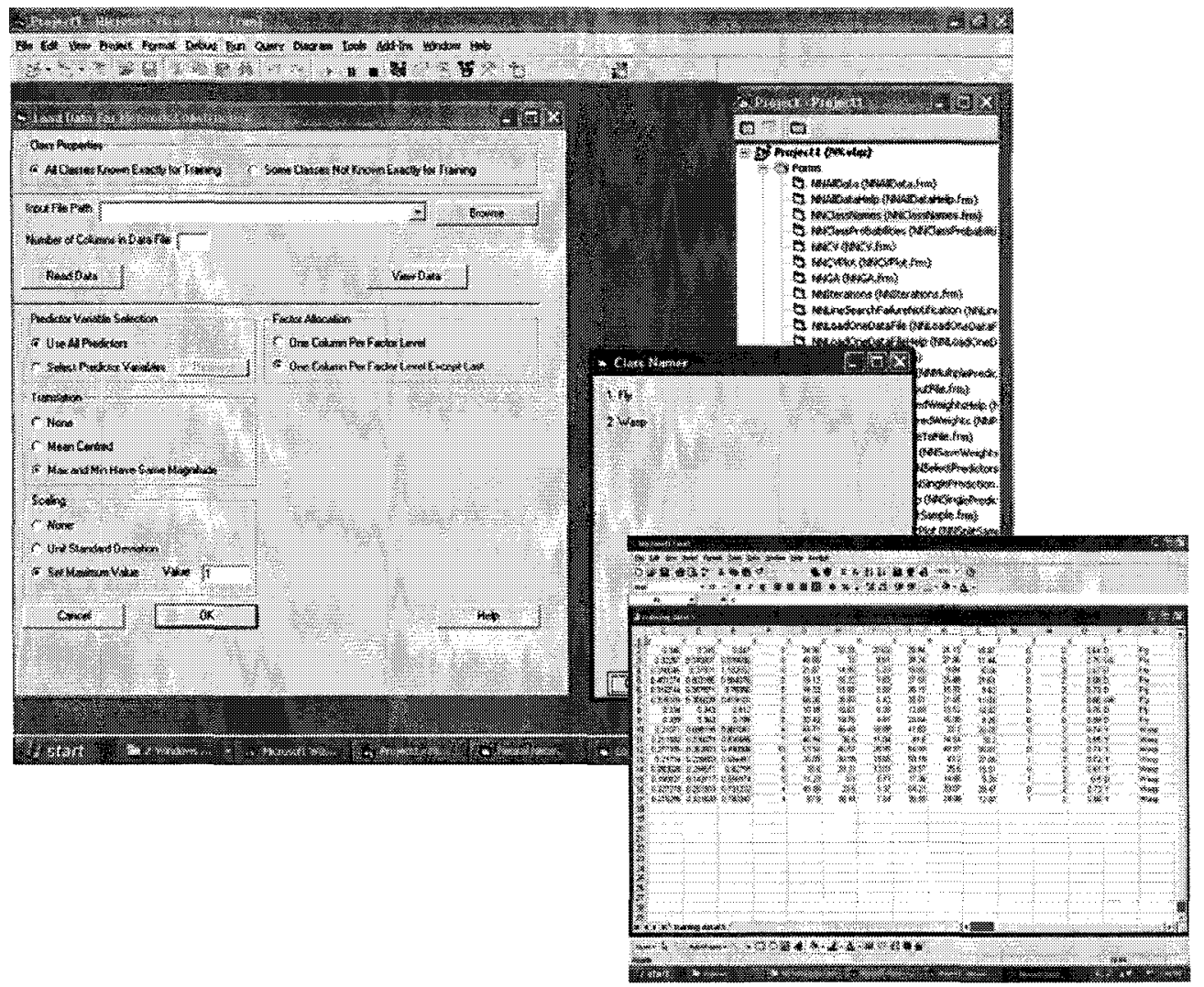

Figure 4.1: A typical view of the computer screen, showing the neural network classifier software, and data set. 
Input layer Hidden layer output layer Softmax

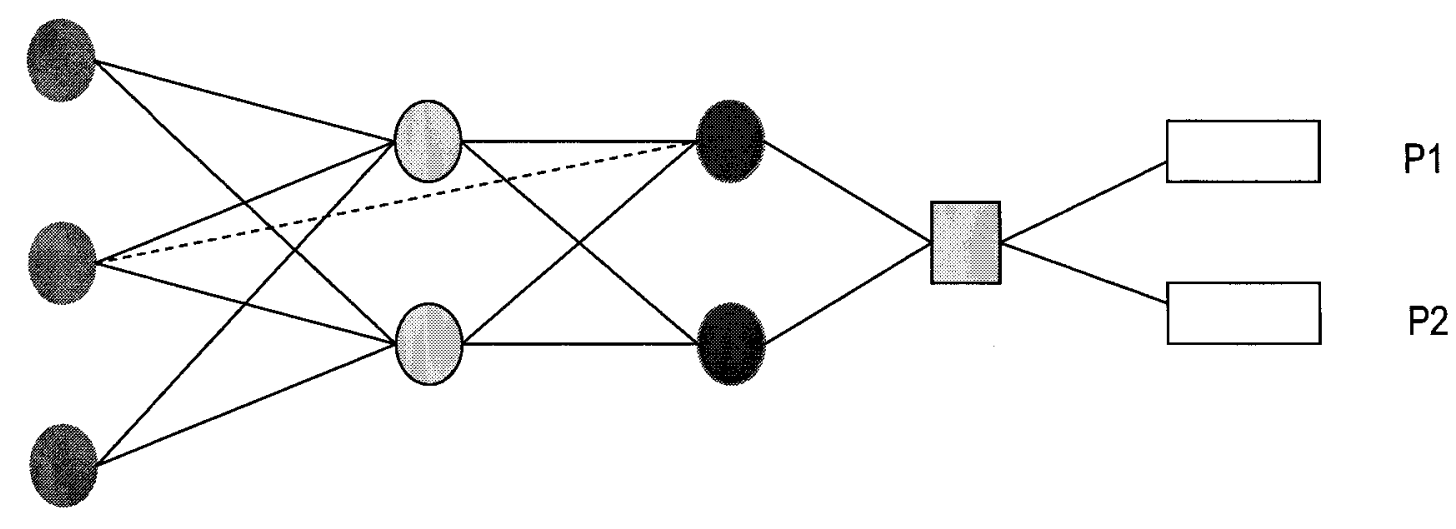

Figure 4.2: Graphical depiction of a single-layer feedforward neural network for classification with three Inputs, 2 hidden layer nodes and two output classes. Each line represents one weight and the dotted line represents the skip-layer weight. 
We trained the neural network to distinguish between nonmimetic flies and wasps, based on their morphological appearances. These measured morphological characteristics include continuous (length of antennae, head width, thorax width, abdominal width; all in relation to the body length, and abdominal RGB), categorical (wing transparency ( 0 : transparent,1: half transparent and half transluscent,2: translucent, 3: dark), base of the abdomen ( 0 : widely attached, 1 : attached through a petiolated segment), and colour of the patches (yellow, orange, etc.) and ordinal (number of patches and stripes) variables. We used image analysis software (Berosoft) and Adobe Photoshop PS to measure attributes of different images. By entering the morphological characteristics of test specimens not used in training the neural network, we were able to use this trained network to generate a measure of a specimen's similarity to both flies and wasps. The subsets testing allowed us to identify salient variables, such as colour and number of stripes, important in predicting the classes.

In this experiment we measured the effects of previous experience on the neural network performance. We prepared 10 different training data sets (different images of the same species) with a different number of observations $(1,2,3,4,5,6,7,8$ and 9 , each) of wasp (Vespula vulgaris) and nonmimetic flies (Sarcophaga spp.). After training the neural network with different training data sets and then presenting a test data set (none of the individuals presented in the test data set were used in the training sets) of 15 flies (Sarcophaga spp.), 15 wasps (Vespula vulgaris) and 15 hover flies (Syrphus ribesii) we examined the effect of experience on the neural network prediction. For each of the data 
sets the neural network was run 10 times. The average prediction (probability of being a wasp) over the 10 replicates was calculated and the mean of the averages was reported for each trial.

In our second experiment we added hover fly images (Syrphus ribesii) into our training data sets. As for the previous experiment we used 10 different training data sets each containing nonmimetic fly, wasp and hover fly images. Different numbers of observations $(1,2,3,4,5,6,7,8$ and 9 , each) of wasps (Vespula vulgaris), nonmimetic flies (Sarcophaga spp.) and hover flies (Syrphus ribesii) were used in each training regime. By presenting our test dataset which consisted of 15 nonmimetic flies (Sarcophaga spp.), 15 wasps (Vespula vulgaris) and 15 hover flies (Syrphus ribesii) (none of the individuals presented in the test data set were used in the training sets) we tested whether adding hover flies into the training set improves the neural network's classification of mimetic hover flies. For each of the data sets the neural network was run 10 times.

\subsubsection{Results and Discussion}

Our results indicated that the neural network gets better at distinguishing between wasps and nonmimetic flies by increasing the number of observations in the training set (Fig 4.3). 


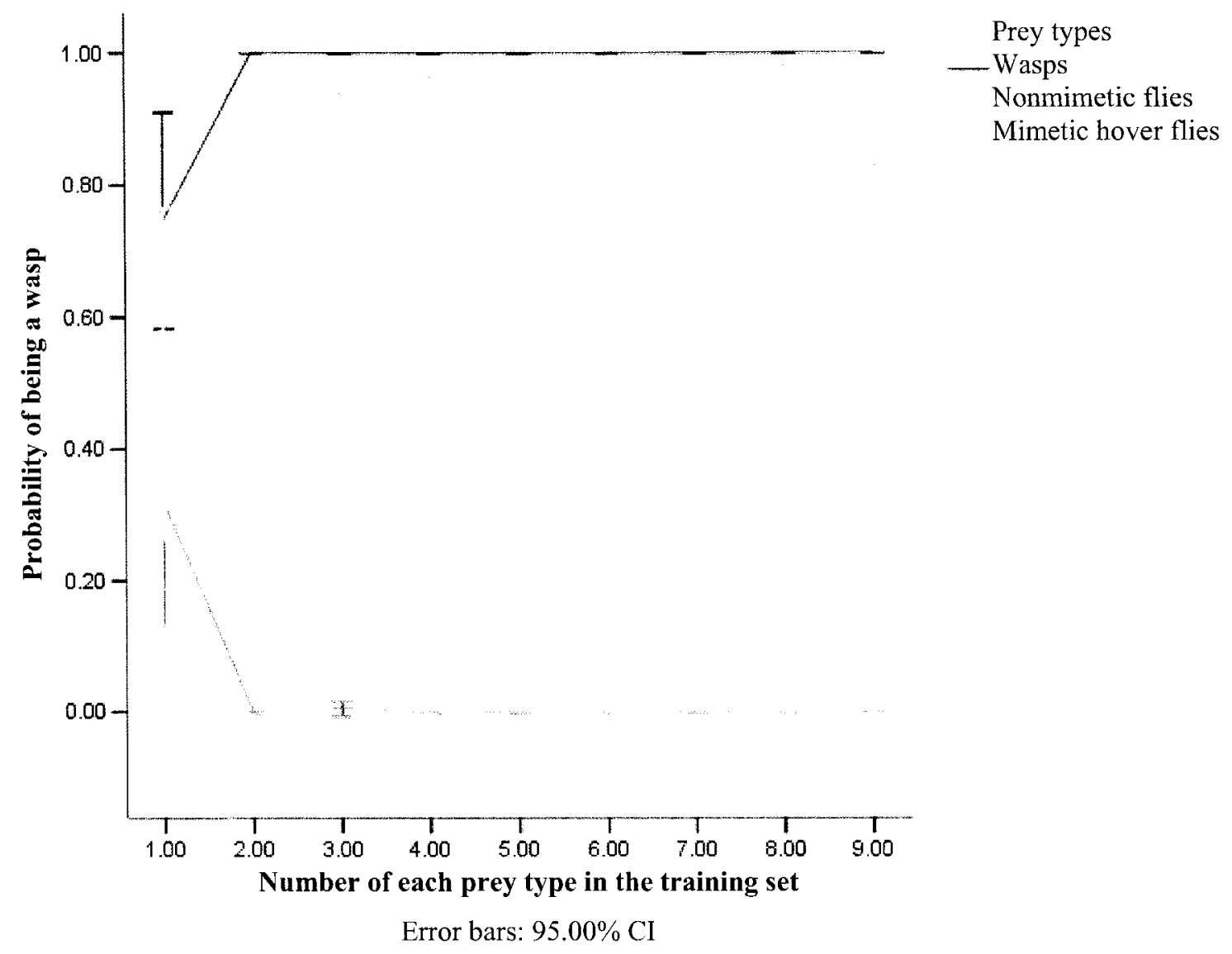

Figure 4.3: An illustration of the effect of the number of training observations on the neural network prediction. When the system was trained with two or more individuals of nonmimetic flies and wasps, each, both flies and wasps were classified $100 \%$ correctly. However, the neural network frequently misclassified hover flies as wasps. Error bars indicate the $95 \%$ confidence interval. 
When trained with only one wasp and one fly (trial 1), the neural network was not $100 \%$ accurate in classifying the test specimens (nonmimetic fly, wasp, hover fly). By training the neural network with two or more observations each of wasps and nonmimetic flies, we got $100 \%$ correct classification for wasps and nonmimetic flies in the test set. Mimetic hover flies were classified as wasps in most of the cases after the first trial. Therefore, the mimetic patterns of the hover flies caused the neural network to classify them as wasps.

The neural network, trained with nonmimetic flies and wasps, was able to distinguish between fly and wasp images, while hover flies were frequently misclassified by the system. However, by entering hover flies in the training regime, the ability of neural network to distinguish hover flies increased but wasps were classified as flies in some cases (Fig 4.4).

So far I have demonstrated that neural networks can be configured for specific applications such as pattern recognition or data classification, through a learning process. Learning in biological systems involves adjustments to the synaptic connections that exist between the neurons. Using my hover fly data set I showed that, like people, our tailormade neural network can learn by example. The performance of the system improves as we provide it with more previous experience. In the second experiment I demonstrated that the nature of the data set is also important in the accuracy of neural network's prediction. 
At the next stage in a novel approach we will use neural network system along with a genetic algorithm to determine the salient characteristics that birds use to rank hover flies based on their morphological similarity to their wasp models. 


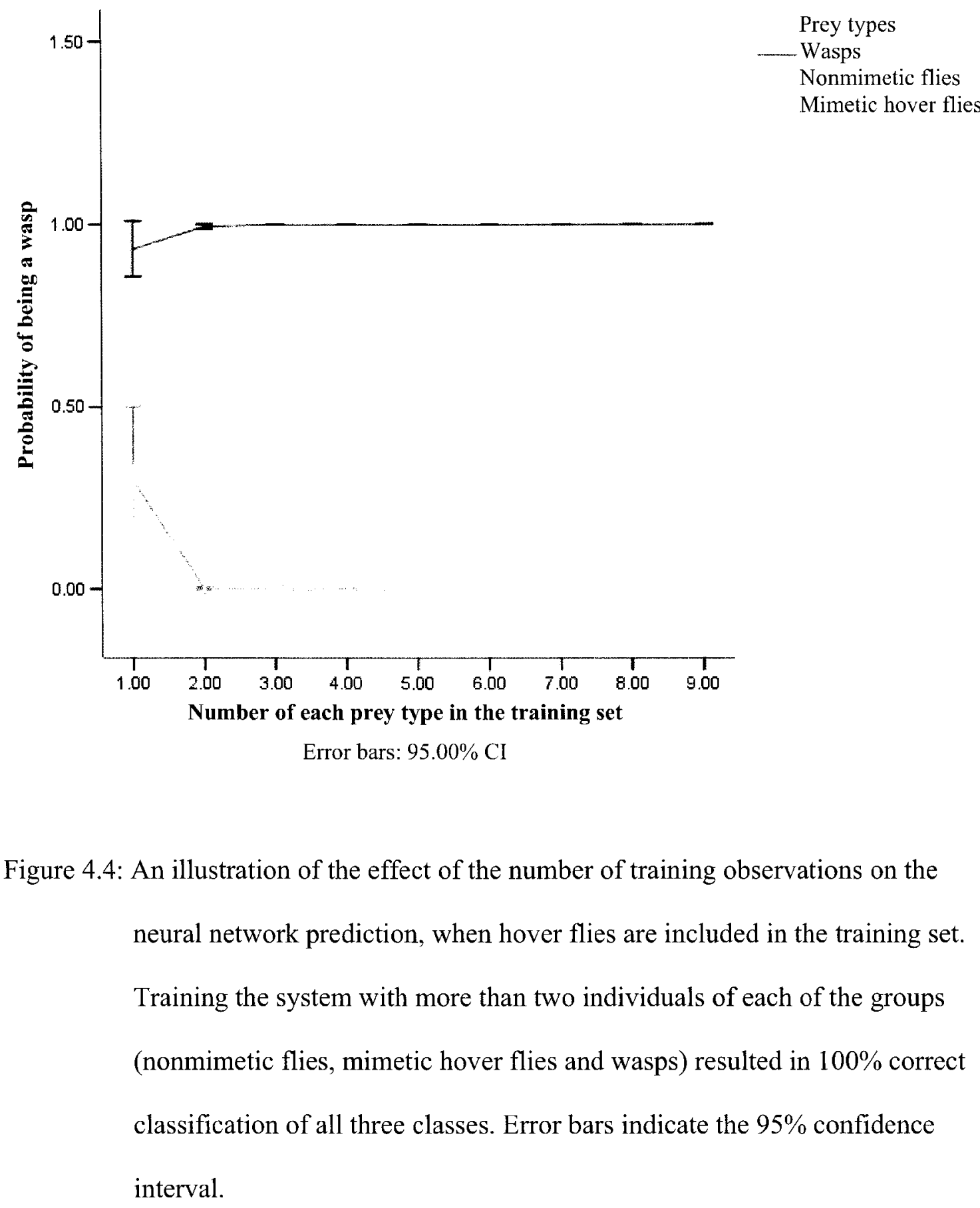




\subsection{A comparison of biological and empirical measures of the degree of mimicry by hover flies (Diptera: Syrphidae) to wasps (Vespula spp.)}

\subsubsection{Introduction}

Batesian mimicry (see Bates 1862), in which members of a palatable species (mimics) gain protection from predators by resembling an unpalatable or otherwise protected species (models), is a textbook example of the power of natural selection (see Edmunds 1974, Ruxton et al. 2004 for reviews). One continuing puzzle is the apparent stability of imperfect mimicry (Edmunds 2000, Johnstone 2002, Sherratt 2002, Gilbert 2005). Some mimics are really not good mimics at all. For example, many hover fly species (Diptera: Syrphidae) appear to be relatively imperfect ("low fidelity", Waldbauer \& Sternburg 1987) mimics of Hymenoptera.

To test whether potential predators such as birds rank the visual mimetic quality of hover flies in the way that humans do, Dittrich et al. (1993) conducted a series of experiments with pigeons (Columba livia). Their broad aim was to ascertain, using operant learning techniques, the degree to which pigeons perceived 11 species of seemingly wasp-like hover flies as wasps. They trained two groups of pigeons to discriminate between projected sets of wasp images and projected sets of nonmimetic fly images (the rewarding stimulus being either images of wasps or nonmimetic flies for different groups of pigeons). They expected mimetic hover fly images to be classified either as models or as non-mimics, but instead the peck-rate (the variable used by Dittrich 
et al. (1993) to create the pigeon classification) responses were intermediate. Subsequent work has confirmed that the results are similar when experiments are conducted using real insect specimens instead of slides as stimuli (Green et al. 1999).

Dittrich et al. (1993) noted that, while there was general agreement between human and pigeon ranking, it appeared that the pigeons treated some hover fly species as better mimics than they appear to be to the human eye. Consequently, our first objective was to formally compare human ordering in terms of hover flies' similarity to wasps or nonmimetic flies to the pigeons' ordering using a subset of the same images used by Dittrich et al. (1993).

Our second objective was to see how well an empirical classifier, in our case an optimised neural network, would perform if we provided it with digital data extracted from the same images, and to test whether the ordering of mimetic similarity matched the human ordering, pigeon ordering, or neither. If validated, neural networks applied like this could prove to be a useful tool, given the debate in the literature concerning mimetic similarity and the general acknowledgement that the degree of mimicry is "very difficult to quantify" (Turner 1984).

Finally, Dittrich et al. (1993) commented that "The question of why the visual systems of humans and pigeons reach such different conclusions remains open, but the answer is likely to lie in visual or learning constraints in the way in which birds classify 
their prey ...". Hence, our third objective was to attempt to determine a set of biometrical features that the pigeons may have used in making their assessment of the degree of mimetic similarity between the hover fly images and wasp or nonmimetic fly images. A genetic algorithm was developed to create an empirical model based on a neural network whose objective was to use information from the images to match the observed pigeon peck rates rather than maximizing the probability of a correct discrimination. To our knowledge this 'reverse engineering' approach is new in the context of understanding why predators make the discriminatory decisions that they do and it might in theory be applied to understand foraging decisions in a range of contexts.

\subsubsection{Methods}

\subsubsection{Data Collection}

Dittrich et al. (1993) labelled their experiments Wasp+ and Fly+ depending on which specimens produced the positive reward. The pigeon peck rates for both experiments were extracted from Figure 2 of Dittrich et al. (1993).

Manually extracted biometrical data from a set of 37 images (19 of wasps and 18 of nonmimetic flies) were used exclusively for obtaining an optimal neural network structure. Data extracted from a second set of 206 images (97 wasp images, 48 nonmimetic fly images and 61 hover fly images, see Appendix A) were used in optimising the neural network structure, evaluating the neural networks, and testing humans. Both sets of images were used by Dittrich et al. (1993). 
We did not have an enumeration of which images were used in each experiment, so, as an approximation, 10 different wasp/nonmimetic fly data sets (W-NF-1 to W-NF10) and corresponding wasp/nonmimetic fly/hover fly data sets (W-NF-H-1 to W-NF-H10) were created for both the neural network and reverse engineering analysis. For each combination, $i=1, \ldots, 10$, the biometrical information from the set of 37 images was always included in W-NF-i. From the set of 206 images, data from 21 randomly selected wasp images and 22 randomly selected nonmimetic fly images were added to the W-NF- $i$ set, so each set comprised 80 images. Data corresponding to 155 of the remaining 163 images were used for the corresponding W-NF-H- $i$ set. Eight hover fly images had to be discarded because they were of a colour not present on any wasp or nonmimetic fly and hence could not be input into the trained neural network (see Appendix B).

The extracted data from each image were: antennae length, head width, thorax width, abdomen width and wing length all expressed as a ratio to the total body length; number of visible colour stripes; number of visible colour patches; the mean and standard deviation of red $(\mathrm{R})$, green $(\mathrm{G})$ and blue $(\mathrm{B})$ colour on the abdomen as a whole; whether the abdomen broadly attached to the thorax (0) or was petiolate (1); a categorical description of wing transparency ( 0 . completely transparent and clear wings, 1 . half clear and half translucent, 2. translucent); abdominal curviness and the main colour of stripes and/or patches. The mean and standard deviation of abdominal RGB values were measured using Adobe Photoshop Version 6.0® (San Jose, CA). ImageJ version 1.29x (National Institutes of Health, USA) was used to measure all of the other continuous 
variables. Curviness of the end of the abdomen was calibrated using the coefficient of circularity as measured by Image J. Because dimensions were tabulated as ratios, actual size of the specimens was not used as a predictor variable.

\subsubsection{Quantitative Assessment of Mimetic Similarity by Humans}

For the human prediction, from the set of 206 images, 10 wasp images, 10 nonmimetic fly images and all of the hover fly images listed in Appendix B were printed as $10 \mathrm{~cm} \times 7 \mathrm{~cm}$ cards. The insect image was approximately the same size on all cards, so

that actual insect size was not a cue. A group of five randomly selected wasp images and another group of five randomly selected nonmimetic fly images were placed on a white background with space to place 13 cards between the two groups. From the remaining five wasp, five nonmimetic fly and all hover fly images, one wasp image, one nonmimetic fly image and one image from each of the 11 hover fly species were randomly selected. Twenty-five graduate and undergraduate students were enlisted to order these 13 images between the groups of 5 wasps and 5 nonmimetic flies at opposite ends, using visual similarity to these images as the criterion. Unlimited time was allowed for ordering and a new random set of cards was drawn for each volunteer.

\subsubsection{Neural Network Based Measures of Mimetic Similarity}

An empirical measure of mimetic similarity was developed using a feedforward neural network (see Fausett 1994, Bishop 1995, Sarle 1997, Hastie et al. 2001) that was trained using images of wasps and nonmimetic flies. The neural network used was nnet 
implemented in R Version 1.9.1 (R Development Core Team 2004); see Venables \& Ripley (2002) and Ripley (1996). See Appendix C for details.

The network structure was optimised for each W-NF- $i$ data set, so it was presented with only wasp and nonmimetic fly images. Predicted probabilities of being a wasp for each taxonomic group (wasps, nonmimetic flies and the 11 hover fly species) in each corresponding W-NF-H- $i$ data set were averaged to obtain an overall predicted probability for each group. These 13 mean predicted probabilities were averaged over the 10 data sets to obtain an overall predicted probability for each group.

\subsubsection{Numerical Modelling of the Pigeon Peck Rate}

Here our objective was to develop an empirical model that matched the observed pigeon response. This analysis combined nnet with an empirical conversion function that took as input a predicted probability and output a peck rate:

$$
\text { peck rate }=\theta_{1}+\left(\theta_{2}-\theta_{1}\right)\left(p^{\theta_{3}}+1-(1-p)^{\theta_{4}}\right) / 2, \theta_{3}, \theta_{4}>0
$$

where each $\theta_{k}$ is a parameter and $p$ is the probability assessment from the neural network that the image is that of a wasp (for Wasp+ data) or nonmimetic fly (for Fly+ data). This function was chosen because it is a monotonic function of $p$ that is capable of desired shapes (see Appendix D). 
A genetic algorithm was used to select (i) which of the 17 predictor variables were to be used, (ii) the neural network structure and (iii) the parameters in the conversion function. Given the predictor variables from (i) and the neural network structure from (ii), the W-NF- $i$ data (wasps and nonmimetic flies only) were used for optimising the neural network. The predicted probability of being a wasp (for Wasp+ data) or nonmimetic fly (for Fly+ data) corresponding to each image in the W-NF-H- $i$ data was obtained using the optimised network. These predicted probabilities were converted to predicted peck rates using the conversion function. The predicted peck rates were averaged for each taxonomic group (wasps, nonmimetic flies and 11 hover fly species) resulting in 13 mean predicted peck rates. The objective in this procedure was to find the combination of predictor variables, neural network structure and weights, and conversion function that maximised fitness defined by

$$
\text { fitness }=-S S E-\omega \text { number of weights }\}
$$

where $S S E$ is the sum of squared differences between mean predicted peck rate and observed pigeon peck rate from Dittrich et al. (1993) and $\omega$ is a cost coefficient for network complexity, i.e., find the best balance between fit and model simplicity (few predictor variables and simple network structure). The same procedure was used for each data set for the Wasp + data and for Fly + data; hence, for each value of $\omega(0.1$ or 1$)$ a total of 20 simulations were conducted. Details of the genetic algorithm-based model, designated REP ("reverse-engineered predator"), are given in Appendix D. 


\subsubsection{Results}

\subsubsection{Prediction of Wasp Probability By the Neural Network}

The overall mean predicted probability of being a wasp from complete-data testing for each taxonomic group is shown in Table 4.1. These are averages of taxonomic group averages for specimens in W-NF-H-i over the 10 data sets.

\subsubsection{Comparison of Orderings of the Morphological Similarity of Different Hover}

\section{Fly Species to Wasps}

Four types of ordering (I-IV) were obtained for the similarity of the hover fly species to wasps.

Ia Pigeon mean peck rate based on Wasp+ data from Dittrich et al. (1993).

Ib Same as Ia except using Fly+ data.

II Mean human ranking based on the data collected for this work.

III Neural network predicted probability of being a wasp using all 17 predictor variables. See Appendix C for details.

IVa Neural network-genetic algorithm combination (REP) predicted peck rate based on Wasp+ data using first a severe $(\omega=1)$ and then repeated using a modest ( $\omega=$ $0.1)$ penalty for complexity of the neural network. See Appendix D for details.

$\mathrm{IVb}$ Same as IVa except using Fly+ data. 
Table 4.1. Mean predicted wasp probability for each taxonomic group from nnet. Species names: S. ve: Sphecomyia vespiformis; T. ve: Temnostoma vespiforme; C. ca: Chrysotoxum cautum; X. pe:

Xanthogramma pedissequum; C. bi: Chrysotoxum bicinctum; E. gr: Epistrophe grossulariae; V. zo: Volucella zonaria; S. ri: Syrphus ribesii; S. py: Scaeva pyrastri; I. gl: Ischyrosyrphus glaucius; H. pe: Helophilus pendulus.

\begin{tabular}{llllllllllllll}
\hline $\begin{array}{l}\text { Taxonomic } \\
\text { group }\end{array}$ & Wasp & S. ve & T. ve & C. ca & X.pe & C. bi & E. gr & V.zo & S. ri & S. py & I. gl & H. pe & Fly \\
\hline $\begin{array}{l}\text { Mean } \\
\text { similarity to } \\
\text { wasp }\end{array}$ & 0.890 & 0.766 & 0.757 & 0.616 & 0.670 & 0.548 & 0.508 & 0.482 & 0.478 & 0.383 & 0.320 & 0.207 & 0.125 \\
\hline
\end{tabular}


For each of the 25 human tests, the ranking for each species was recorded. An overall ranking based on mean rank was obtained. A rank correlation hypothesis test (see Kanji 1993, p115) was conducted to test the null hypothesis of no consistency among the individual human rankings. The null hypothesis was rejected (test statistic $F_{12,312}=39.4$, $\mathrm{P}<0.001$ ), indicating that the judges arrived at highly consistent rankings of overall resemblance. Relationships between the various orderings and location of corresponding graphs are given in Table 4.2 .

In summary, the REP predicted the actual pigeon response considerably better than any other method. Humans ranked mimetic similarity in much the same way as pigeons did, and there was general agreement between the human ordering and the neural network ordering. However, the neural network using all predictor variables optimized to correctly classify wasp and nonmimetic fly images was overall a poor to fair predictor of the pigeon response data. 
Table 4.2. $\mathrm{R}^{2}$ and P-values for relationship between various orderings.

\begin{tabular}{llccc}
\hline First ordering & Second ordering & $\mathrm{R}^{2}$ & $\mathrm{p}$ & Figure \\
\hline & & & & \\
Human (II) & pigeon Wasp+ (Ia) & 0.73 & $<0.001$ & $4.5 \mathrm{a}$ \\
Human (II) & pigeon Fly+ (Ib) & 0.65 & $<0.001$ & E.1a \\
Human (II) & nnet (III) & 0.74 & $<0.001$ & $4.5 \mathrm{~b}$ \\
nnet (III) & pigeon Wasp+ (Ia) & 0.50 & 0.007 & $4.5 \mathrm{c}$ \\
nnet (III) & pigeon Fly+ (Ib) & 0.44 & 0.013 & E.1c \\
REP (IVa $\omega=1)$ & pigeon Wasp+ (Ia) & 0.89 & $<0.001$ & $4.5 \mathrm{~d}$ \\
REP (IVb $\omega=1)$ & pigeon Fly+ (Ib) & 0.84 & $<0.001$ & E.1d-1 \\
REP (IVa $\omega=0.1)$ & pigeon Wasp+ (Ia) & 0.89 & $<0.001$ & E.1d-2 \\
REP (IVb $\omega=0.1)$ & pigeon Fly+ (Ib) & 0.89 & $<0.001$ & E.1d-3 \\
\hline
\end{tabular}

$\mathrm{R}^{2}$ values are the square of the Pearson product-moment correlation $\mathrm{p}$ is the Pearson product-moment $\mathrm{p}$-value

Prefix E for figure number implies that the graph is shown in Appendix E 
Figure 4.5a-d: A comparison of the different measures of similarity of hover flies to wasps. Species names: S. ri: Syrphus ribesii; T. ve: Temnostoma vespiforme; C. ca: Chrysotoxum cautum; H. pe: Helophilus pendulus; E. gr: Epistrophe grossulariae; X. pe: Xanthogramma pedissequum; C. bi: Chrysotoxum bicinctum; S. ve: Sphecomyia vespiformis; V. zo: Volucella zonaria; S. py: Scaeva pyrastri; I. gl: Ischyrosyrphus glaucius. Wasps and nonmimetic flies were a mixture of species (see Appendix B). Graphs compare: (a) human ordering (ranging from 13, most wasp-like, to 1, most nonmimetic fly-like) and pigeon ordering (based on Wasp + data), (b) human ordering and neural network ordering, (c) neural network ordering and pigeon ordering based on Wasp+ data, (d) mean predicted peck rate from the REP with cost coefficient $\omega=1$ and observed peck rate based on Wasp + data (dashed line represents perfect matching of predicted and observed values). Additional graphs are provided in the Appendix E. 
a.

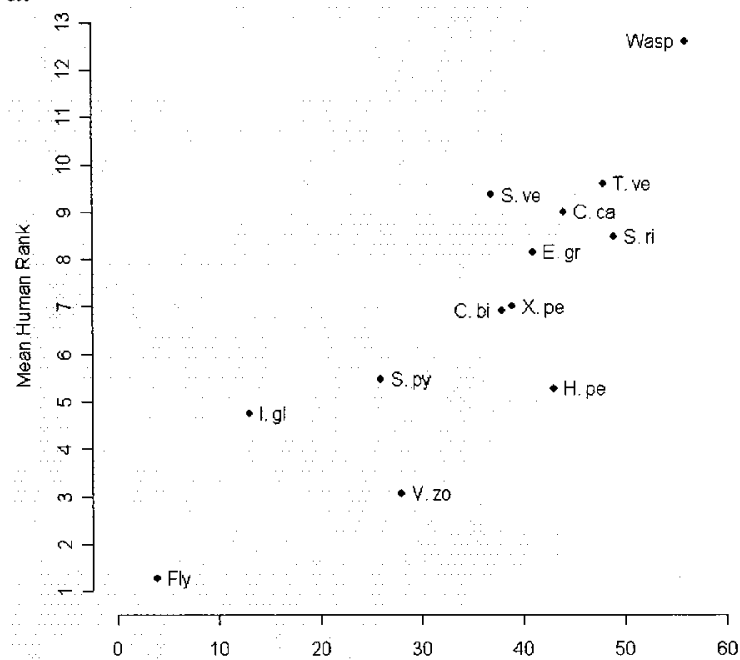

b.

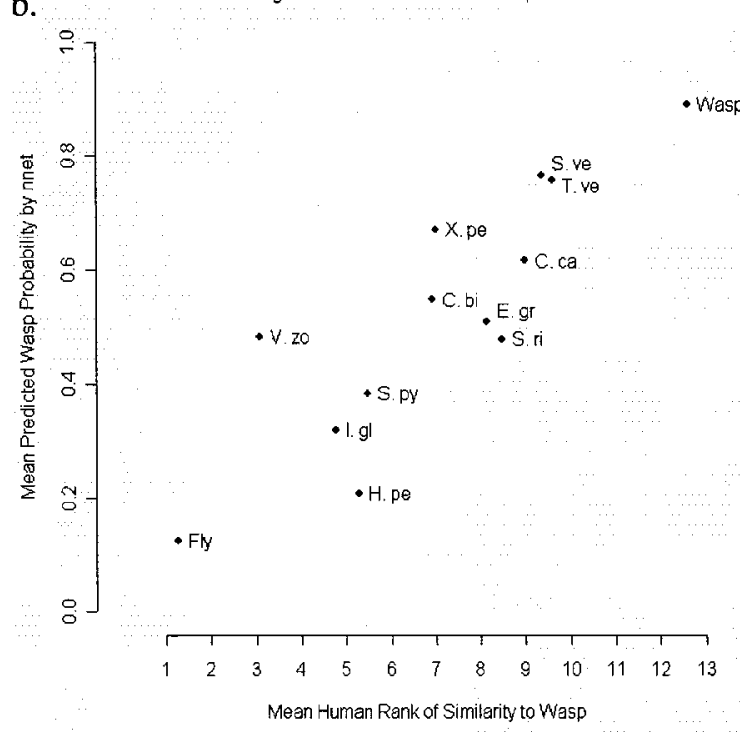

c.

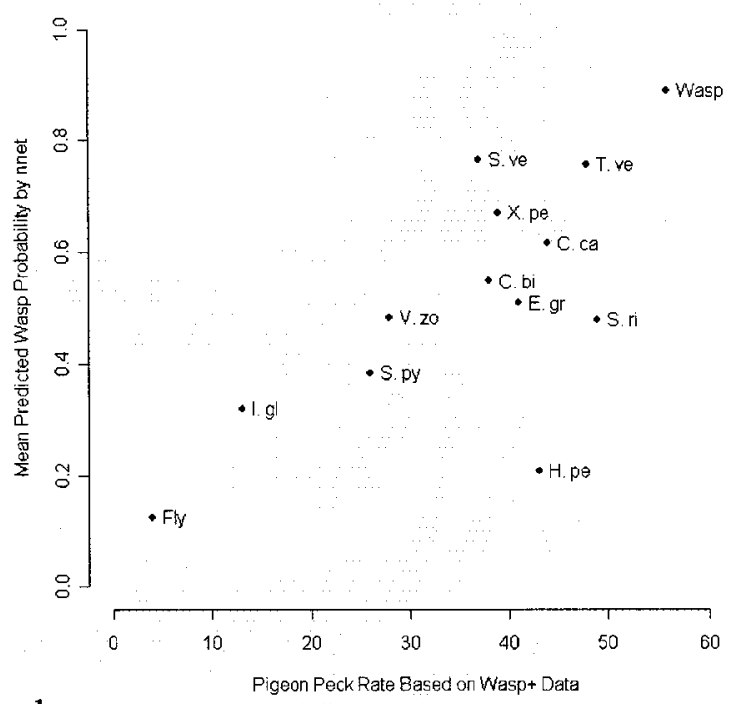

d.

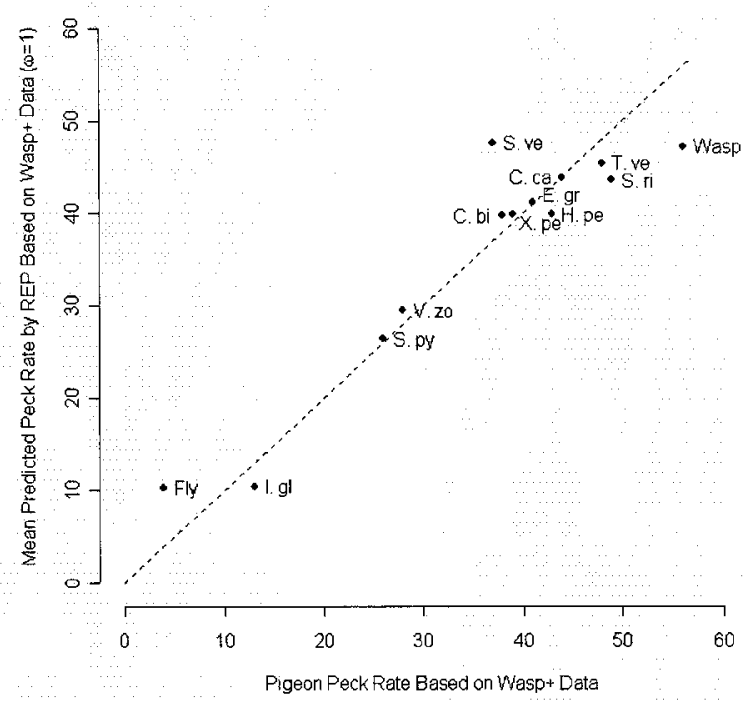




\subsubsection{Salient Predictor Variables in Discriminating Between Wasps and Flies}

To estimate the biometrical features that the neural network employed to discriminate between wasps and nonmimetic flies, separate optimised networks based subsets of predictor variables were obtained (see Appendix C). Similarly, to elucidate the biometrical features used by pigeons to discriminate between wasps and nonmimetic flies, we recorded how often predictor variables were retained by the REP.

(i) Subsets analysis for the neural networks

For the neural networks, subsets testing using all groups of one and two predictor variables was conducted for all ten W-NF- $i$ data sets. The most important predictor variable was clearly antennae length, but always in combination with another predictor variable. All predictor variables in combination with antennae length were able to achieve near-perfect prediction (median 100\% correct in the test set; see Appendix C) for at least one data set. The combination of wing transparency and path/stripe colour produced optimal prediction in a few instances for two data sets.

(ii) Retention of predictor variables by the REP

For both Wasp+ and Fly+ data and for both values of $\omega$ in Equation 2, the set of retained predictor variables used to produce the optimal fit was recorded. The total number of times retained for each predictor variable, out of a possible 20 based on each data set, is shown in Figure 4.6. 
For both the Wasp+ and Fly+ data, the frequency with which different variables were retained differed significantly from uniform (G-tests for homogeneity: Wasp $+\mathrm{G}=$ 82.73, $\mathrm{df}=16, \mathrm{P}<0.001 ; \mathrm{Fly}+\mathrm{G}=64.19, \mathrm{df}=16, \mathrm{P}<0.001)$. Furthermore, the relative use of the different predictor variables varied significantly with pigeon training regime $($ Wasp + or Fly+ $)\left(\chi^{2}\right.$-test for association: $\left.\mathrm{X}^{2}=57.89, \mathrm{df}=16, \mathrm{P}<0.001\right)$. The most important predictor variables overall in fitting the pigeon peck rate data were antennae length and standard deviation of abdominal $R$ values. The number of visible colour stripes and patches was important for models based on the Wasp+ data, while abdomenthorax attachment type and head width were important for models based on the Fly+ data. Conversely, wing transparency was not important at all. 


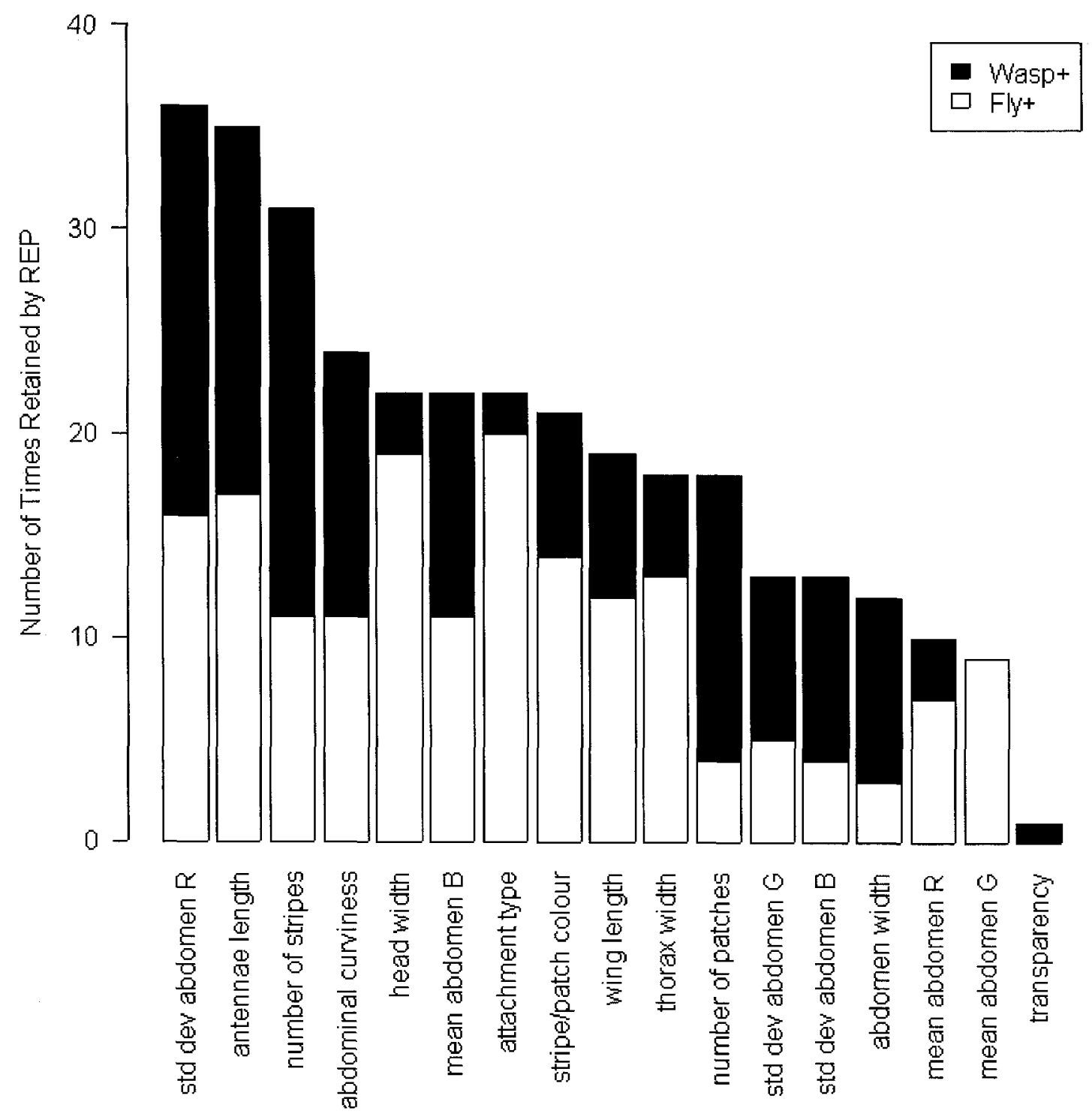

Figure 4.6: Occurrences of retained predictor variables based on each pigeon response set (filled bars based on Wasp+ data, open bars based on Fly+ data). Occurrences are based on the number of times a predictor variable was retained from the 10 simulations each with $\omega=1$ and $\omega=0.1$, based on Wasp + and Fly+ data $(10 \times 2 \times 2$ combinations $)$. 


\subsubsection{Discussion}

Neural networks have been applied in a number of ways to understand aspects of predator behaviour such as the confusion effect (Tosh et al. 2006), the evolution of warning signals in defended prey (Merilaita \& Tullberg 2005) and in co-evolutionary simulations of Batesian mimicry (Holmgren \& Enquist 2000). The approach has also been widely applied to aid taxonomic classification (e.g. see Culverhouse et al. 2003, Lavine \& Vora 2005, Burks et al. 2005). Here we have employed neural networks to evaluate the degree of mimicry in several hover fly species and to help identify the salient features used by pigeons when classifying the images with which they were presented. Such an approach is needed if we are to test several key theories relating to mimicry. For instance, it has been proposed that many imperfect mimetic species, including hover flies, are "jack-ofall-trades" mimics that have evolved to resemble several different model species simultaneously (Edmunds 2000), but without a suitable measure of mimetic similarity, this theory is difficult to test directly. The features that make neural networks, or related tools such as the REP, suitable for assessing mimetic similarity include their objectivity, their ability to nonlinearly combine a range of continuous and categorical predictor variables and the fact that they could, in theory, rapidly assess mimetic similarity in a wide range of species - some explicit examples of this are given below.

When trained with only wasps and nonmimetic flies (using W-NF-i) the neural network ascribed intermediate predicted probabilities of being a wasp for the hover fly species in W-NF-H- $i$ just as the pigeons had done. Clearly the images of hover flies 
provide combinations of traits some of which are similar to wasps, and others retain their fly-like qualities, making them difficult to evaluate. By contrast, a neural network trained using nonmimetic flies, mimetic hover flies and wasps is far more successful in correctly identifying hoverflies as flies when it encounters them out of sample (see part A.). We interpret the sensitivity of the neural network to the training regime as a positive feature. Much early work on mimicry has confirmed that the previous experiences of predators strongly influences their subsequentdietary preferences (e.g. Mostler 1935; Brower et al. 1960) and the vast majority of quantitative models of Batesian mimicry have made similar assumptions (see Ruxton et al. 2004 for review).

It is well known that mimicry of Hymenoptera can occasionally confuse even taxonomically-aware humans (Atkins 1948; Jackson \& Drummond 1974; Golding et al. 2005). Our human ordering of mimetic similarity in hover flies (see Figure 4.5a) supports the observation by Dittrich et al. (1993) that, compared to Syrphus ribesii and Episyrphus balteatus, "most observers consider much rarer species such a Temnostoma, Sphecomyia or Chrysotoxum cautum as much more wasp-like". The collected data also support the statement by Dittrich et al. (1993) that "most people agree that there is a rank order of mimetic quality, from Temnostoma to Syrphus to Scaeva". The relative distance between rankings of nonmimetic flies and wasps (Fig 4.5a) indicates that both humans and pigeons were able to perceive the differences that distinguish each of these extremes. There are some differences though: humans consistently ranked $V$. zonaria as the poorest mimic while pigeons ranked two other species as poorer mimics. In addition, the mean 
human rank for three of the poorer mimics, I. glaucius, S. pyrastri and H. pendulus, was nearly identical, while the pigeons made a clear distinction with $H$. pendulus treated as a better mimic. This distinction supports the notion that the pigeons focus on different features than humans.

Table 4.1 confirms that the neural network optimized for correct classification can be used to generate a measure of mimetic similarity because it generally matches both the human and pigeon derived measures. However, the neural network optimized to utilise criteria that allows one match the pigeon response data (REP) not surprisingly matched the pigeon response even more closely. This REP model can now be readily used to estimate the mimetic similarity of any species of hover fly to wasps. For example, we extracted biometrical data for nine specimens of the hover fly Episyrphus balteatus not included so far in any aspect of our analysis but utilized by Dittrich et al. (1993) in their Fly+ training regime. This species was singled out by Dittrich et al. (1993) (page 198) for appearing a poor mimic to human eyes, yet being assessed by pigeons as the most wasp-like. Fitting our model, we would expect that pigeons trained in the Fly+ regime to have a peck rate of 25 (the best mimic compared to all others tested by Dittrich et al. (1993), and pigeons trained in the Wasp + regime to have a peck rate of $45\left(3^{\text {rd }}\right.$ best mimic from those tested by Dittrich et al. (1993)). We have also examined the "internal predictability" of the REP model by fitting our model to all of the peck rate data except for a single species. When C. cautum (considered a good mimic) was omitted the mean predicted peck rate for this excluded species was 43 compared to an actual peck rate of 
44 for Wasp+ data. Similarly when $S$. pyrastri (considered a relatively poor mimic) was omitted, the mean predicted peck rate for this species was 38 compared to an actual peck rate of 26 for Wasp+ (see Figure 4.7).

Any identification of salient features used in discrimination is limited by the biometrical data that were extracted. However, in order to minimize the potential bias in the neural network prediction, we measured a wide range of visible biometrical attributes, not just the ones we viewed as taxonomically important. Our subsets testing indicated that antennae length was the key feature used by the neural network, but this does not necessarily mean that when training with all 17 predictor variables antennae length ultimately dominated the decision making. Nevertheless, it is notable that some hover flies possess elongated antennae to mimic the long antennae of yellow-jacket wasps (e.g. Sphecomyia vittata and Ceriana signifera); other hover fly species, such as Spilomyia longicornis and Temnostoma spp., wave their front tibia, which are darkened unlike other legs, to mimic the presence and movement of the antennae of their potential wasp models (Waldbauer 1970). Antennae length is thought to be amongst the most important cues used predators to discriminate wasps from palatable flies (Gilbert 2005), and it was reassuring that our neural network has independently identified this trait as a key diagnostic characteristic.

It is difficult to directly compare the features used by a neural network to maximise correct classification, with those used to match the pigeon data. However, one can readily 
compare the biometrical features that appear to have been important to pigeon's decision making following the Wasp + and Fly+ training regimes. In fact we have already provided evidence that the suite of variables that tend to be emphasised by pigeons are somewhat different in the two circumstances (Fig 4.6).

Different learning and discriminating strategies based on the nature of the stimuli could explain some of the differences in the features used by pigeons trained in the Wasp + regime versus the Fly+ regime. The antennae length and mean abdominal $\mathrm{R}$ value were used extensively by the pigeons for both experiments. However, it appears that the number of visible colour patches and stripes were also important features used by the pigeons trained in the Wasp+ regime, whereas abdomen-thorax attachment type and head width were important for the pigeons trained in the Fly+ regime. Shettleworth (2005) noted that when there are multiple cues available for the same response they compete for an animal's attention. It is possible that pigeons trained in the Wasp+ regime used the presence and abundance of colourful patches and stripes as important cues, while pigeons trained in the Fly+ regime (where the reward was given for pecking on images that often lack visible colourful patches or stripes) used a combination of other characteristics (such as head width) to discriminate between nonmimetic fly and wasp images.

Although our analysis was based on an approximation of the actual experiment and recognizing the constraints imposed by the neural network-conversion function model, given the goodness of fit achieved using only knowledge of biometrical features within 
the REP, we can safely conclude that the pigeons did respond to hover fly images based on their morphological appearances. The pigeon ranking was similar to that of humans but, dependent upon the reward system employed, it appears that they learned to use different features to distinguish profitable prey types. The neural network (with or without subsequent calibration to pigeon peck-rate data) was able to achieve an objective ranking of the degree of mimicry of the hover flies, and therefore could be used in further studies of mimicry where the degree of similarity between two or more species needs to be objectively measured. 


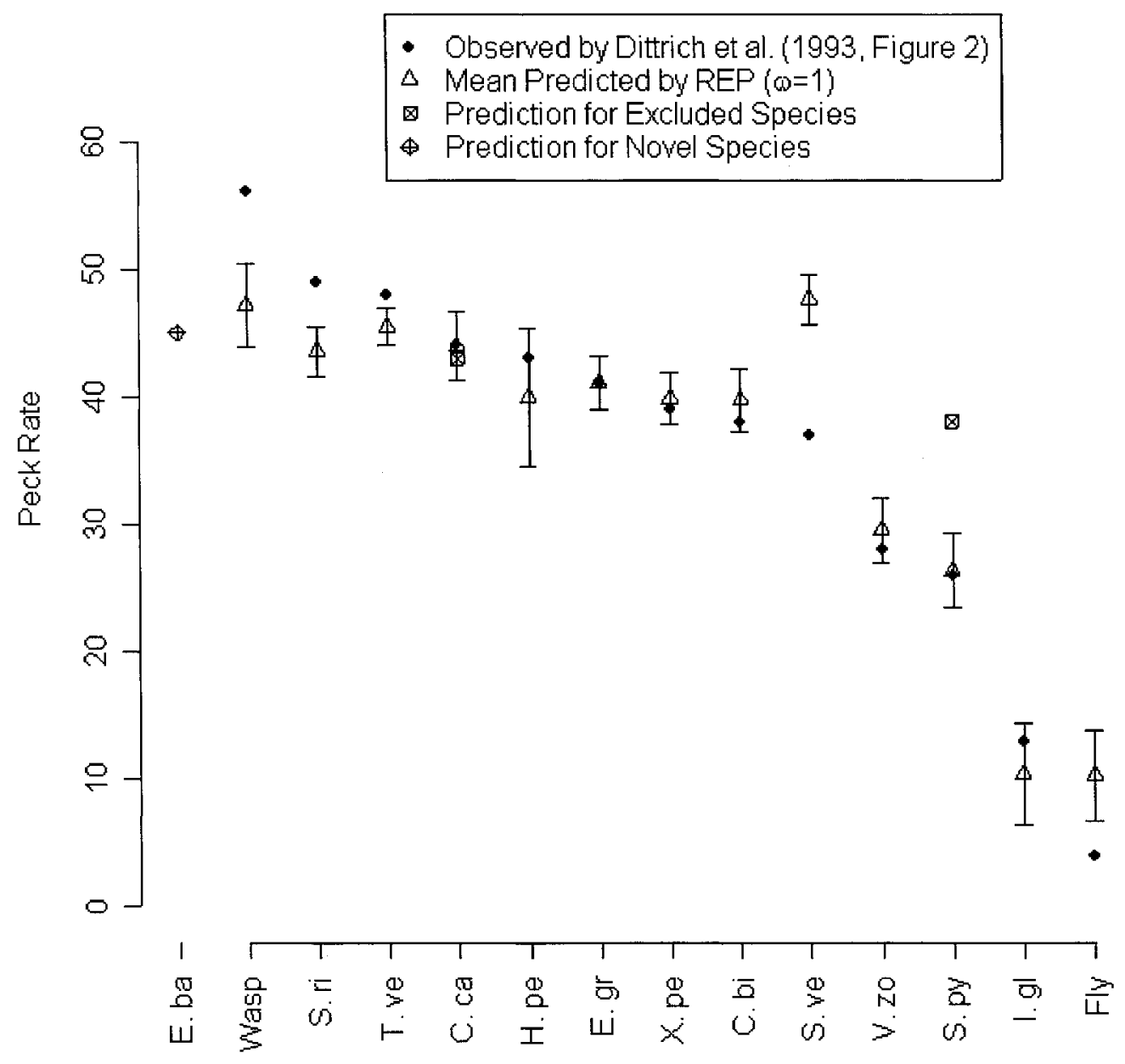

Figure 4.7: Mean predicted peck rate for each taxonomic group using REP based on

Wasp+ data with $\omega=1$ with predictions for novel and excluded species added.

Error bars represent \pm one standard deviation for predicted values from the ten data sets. The novel species was Episyrphus balteatus. 


\section{CHAPTER 5}

\section{Acoustic signaling following attack: do hover flies (Diptera: Syrphidae) sound like the Hymenoptera they morphologically resemble?}

\subsection{Preface}

In the three previous chapters I focused on morphological mimicry. Although

morphology is very important in predator deception, behavioural similarities might

further help undefended batesian mimics to render themselves as a defended model, and therefore provide them with a better protection. It has been noted that wasp mimic hover flies buzz similarly to their actual wasp models when attacked or grabbed by a predator. However, it has never been tested experimentally. In this chapter I address another aspect of mimic-model similarity so called "behavioural mimicry". In an original approach, I artificially attack a range of species of hymenopteran models, mimetic hover flies and nonmimetic flies and record the acoustic response by every species. By analyzing the recorded sound waves I estimated the similarities of species in terms of the sounds they emitted after attack. If hover flies are under selection to not only look like their models but also sound like them, then hover flies that resemble wasps should sound more like wasps and hover flies that resemble bees should sound more like bees. This work is in preparation for submitting for publication. 


\subsection{Introduction}

'... one function of the sound may be as an acoustic warning to attacking predators. The meaning conveyed is not simply a querulous 'let me go' but a rather more menacing 'let me go or else'! but the 'or else' may be a bluff'. W. M. Masters (1980, page 267)

Batesian mimicry (Bates, 1862) occurs when members of a palatable species (the "mimic") gain a degree of protection from predators by resembling an unpalatable or otherwise defended species (the "model"). Numerous examples have been described in the literature (see Edmunds, 1974; Ruxton et al., 2004 for reviews) including the resemblance of certain species of fish to poisonous eels (McCosker, 1977), and lizards to noxious beetles (Huey and Pianka, 1977).

One of the best known examples of Batesian mimicry occurs in hover flies (Diptera: Syrphidae). It has long been known that some species of hover fly resemble wasps, while other species resemble bumble bees and honeybees in appearance (e.g. Mostler 1935; Dittrich et al.1993; Gilbert 2005). Yet it has also long been realized that the mimicry in this group is not just limited to morphological similarity. For instance, some hover flies wave their front tibia in front of their heads to resemble the long antennae of hymenoptera (e.g. Spilomyia sayi and S. longicornis), some species wag their wings to resemble the wing movement of a wasp (e.g. Spilomyia spp.) and some species (e.g. Spilomyia longicornis, Chrysotoxum cautum and Temnostoma spp.) will even pretend to sting when grabbed (see Waldbauer 1970, 1988). Moreover, it has been shown that the drone fly, Eristalis tenax (Diptera: Syrphidae), flies in the same manner as 
honeybees, the defended models they morphologically resemble (Golding and Edmunds 2000; Golding et al. 2001).

One of the interesting, yet poorly researched, behaviours exhibited by mimetic hover flies such as wasp mimics, bumble bee mimics and honeybee mimics is that they tend to make a buzzing sound when attacked by a bird or a potential predator (Mostler 1935; Waldbauer 1988; Ruxton et al. 2005). It has been proposed that buzzing behaviour in bumble bees helps them to survive bird attacks (Mostler, 1935), but whether the sound acts as a startle or as a signal of unprofitablility is unclear. Recently, Kirchner and Röschard (1999) have shown that bumble bees produce a high intensity sound following a disturbance (or high levels of $\mathrm{CO}_{2}$ in their nest), which, the authors argue, is an interspecific warning signal. As with many natural signals, they are open to exploitation. For example, Waldbauer (1988) described wasp-like hover flies, stating that "...if the fly is grasped in the fingers, or presumably by the beak of a bird, it makes a loud sound that is almost identical to the squawk of a disturbed wasp" (Page 124).

Given the convincing morphological and behavioural similarity between hymenopterans and their hover fly mimics, it is conceivable that hover flies also mimic the sound characteristics of hymenopterans when attacked. However to our knowledge, this possibility has never been formally tested. In this study we set out to quantitatively compare among species the "buzzing" sounds produced by wasps, bumble bees, and honeybees, their hover fly mimics, and nonmimetic flies when they were artificially harassed. Our primary question was whether the hover flies that morphologically mimic 
wasps make sounds when attacked, which more closely resemble the sounds of wasps than those made by other hover flies which resemble another hymenopteran model (see Waldbauer 1988 quote above). Conversely, we wished to test whether hover flies that resembled bumble bees, and hover flies that resembled honeybees, sounded more like the defended model they morphologically resembled when attacked, than any other related species. If we observe no consistent pattern in the sound characteristics made by the various species then this would indicate that hover flies are not under selection to resemble their models in these sound characteristics, while a close similarity between mimetic hover flies and their related morphological hymenopteran models would indicate the reverse. Even outside the context of mimicry, almost no work has been done to document the sounds made by a variety of Diptera and Hymenoptera species when attacked, but we hope to show that this sort of experiment gives valuable insights into the "last ditch" defensive suites evolved by these different groups.

\subsection{Methods}

\subsubsection{Species Investigated}

The vast majority of specimens were collected between June $28^{\text {th }}$ and September $15^{\text {th }}, 2005$ at the Queens University Biological Station $\left(44^{\circ} 34^{\prime} \mathrm{N}, 79^{\circ} 15^{\prime} \mathrm{W}\right.$ ) (the only exceptions were bumble bees, Bombus impatiens, which were reared in the lab and the wasp species, Vespula germanica, which were collected from a residential area in Ottawa, Canada). Specimens were collected using hand nets and upon capture were placed in wooden and mesh cages measuring $30 \times 30 \times 50 \mathrm{~cm}$. Insects were transported 
back to the lab and acoustic recordings were made the same day as capture. Insects were typically tested within 2 hours of capture but never more than 4 hours after capture.

A total of 189 individuals from 14 different insect species were measured, analyzed and compared. Our Hymenoptera specimens included 48 wasps (20 Dolichovespula arenaria (Fabricius), $21 \mathrm{~V}$. germanica (Fabricius), $7 \mathrm{~V}$. vulgaris L.), 23 honeybees, Apis mellifera, and 21 bumble bees (12 Bombus impatiens (Cresson) and 9 Bombus sp.). The Diptera studied comprised 2 different genera of nonmimetic flies (23 Sarcophaga spp. and 7 individuals of Chrysops relictus). The mimetic hover flies we used in this study comprised 12 bumble bee mimics, Eristalis flavipes (Walker), 20 honey bee mimics, Eristalis arbustorum L., 10 honeybee mimics, E. transversa (Wiedemann) and a variety of wasp mimics (11 Spilomyia longicornis (Leow)7 S sayi (Goot) and 7 Helophilus fasciatus) (see Appendix A for voucher information).

\subsubsection{Acoustic Recordings}

Prior to recording, insects were dorsally tethered at the mesosternum to a $2.5 \mathrm{~cm}$ length of stainless steel wire (Elgiloy, double spring hard, AM Systems Inc., catalog \# 712700) using a small drop of hair-removal wax. The stainless steel wire was held in a chuck-type probe handle and attached to a micromanipulator. The insect could then be reliably positioned in front of the microphone. The micromanipulator was situated on a $5.5 \mathrm{~cm}$ thick block of foam to facilitate recordings. 
All sound recordings were made in a walk-in type anechoic chamber (Eckel Industries, Model C-14A MR) measuring $2.4 \mathrm{~m} \mathrm{X} \mathrm{2.4m} \mathrm{X} \mathrm{2.4m.} \mathrm{The} \mathrm{chamber}$ temperature was at $27.0 \pm 2.0^{\circ} \mathrm{C}$. We used a Sony stereo electret microphone (Model ECM-M5957) positioned $8 \mathrm{~cm}$ above the insect at an angle of approximately 45 degrees to capture the sound waves produced by insects. This microphone has a flat response from $100 \mathrm{~Hz}$ to $18 \mathrm{kHz}$. Sounds were stored on either a Sony DAT recorder (Model PCM-M1) or a Marantz Professional digital recorder (Model PMD671) digitizing at a rate of $48 \mathrm{kHz}$. Sound signals recorded by the Marantz digital recorder were stored directly on compact flash cards in PCM-WAV format. Signals recorded on the Sony DAT were re-digitized by playing them into the Marantz recorder so that they could be similarly stored in PCM-WAV format. These signals were digitized at $48 \mathrm{kHz}$.

Our primary aim was to record the wing beat sounds and/or 'buzzing sounds' of specimens following a simulated attack. Tethered specimens were harassed by gently squeezing their abdomens using a pair of soft forceps, as if clasped by a bird. All of the attacks were directed towards underneath the abdominal segments of the tethered specimens to avoid touching the wings. We realize that probing the insect's abdomen could affect the sound they produce; however, all of the specimens in this study were attacked in a similar manner, to minimize the experimental bias. Many of the specimens made a distinctive high pitch sound response after simulated attacks, which we refer to as "buzzing behaviour". This response invariably involved the specimens holding their wings almost parallel to the longitudinal axis of the body and beating them rapidly. Not all species exhibited this distinctive buzzing behaviour, but the response (buzz or no 
buzz) tended to be highly consistent when testing individuals of the same species. After recordings were complete, insects were measured in length (from head to the tip of the abdomen) using Vernier calipers to ensure they were in within the same size range of 11$14 \mathrm{~mm}$.

\subsubsection{Sound Signal Analysis}

The recorded sound waves produced by an individual immediately after an attack were characterized by measuring the dominant frequency $(\mathrm{Hz})$, first harmonic frequency $[\mathrm{F} 1$ frequency $](\mathrm{Hz})$, two quality factors $\left[\mathrm{Q}_{6 \mathrm{~L}}\right.$ and $\left.\mathrm{Q}_{6 \mathrm{R}}\right](\mathrm{Hz})$, power at the dominant frequency [dominant peak power] $(\mathrm{dB})$ and the dominant power at the first harmonic peak [F1 power] (dB) (Fig 5.1a). We used Sound Forge software (v8, SONY) to extract the quantitative measurements of the recorded sounds. We applied a Hanning window function to the selected time domain waveforms before calculating the power spectrum (Fig 5.1b). The selected sections of the oscillogram were variable in length and were chosen (between 426 to 1128 milliseconds) where there was a minimum of background noise so as to increase the signal to noise ratio.

We used Minitab (v14) to perform a discriminant function analysis on the sounds produced by specimens, assuming equal covariance matrices. This analysis generates a set of discriminant functions based on linear combinations of continuous predictor variables that provide the best ways to discriminate among the known species, and thereby renders a measure of the overall similarity among them (based on a Mahalanobis distance). 
Multivariate analysis of variance (MANOVA) was used to test for population differences in the six sound characteristics among species. For significant MANOVA, a further Post Hoc test (Tukey HSD) was performed to test for population differences between individual species in terms of the sounds they produced after attack. 
a.

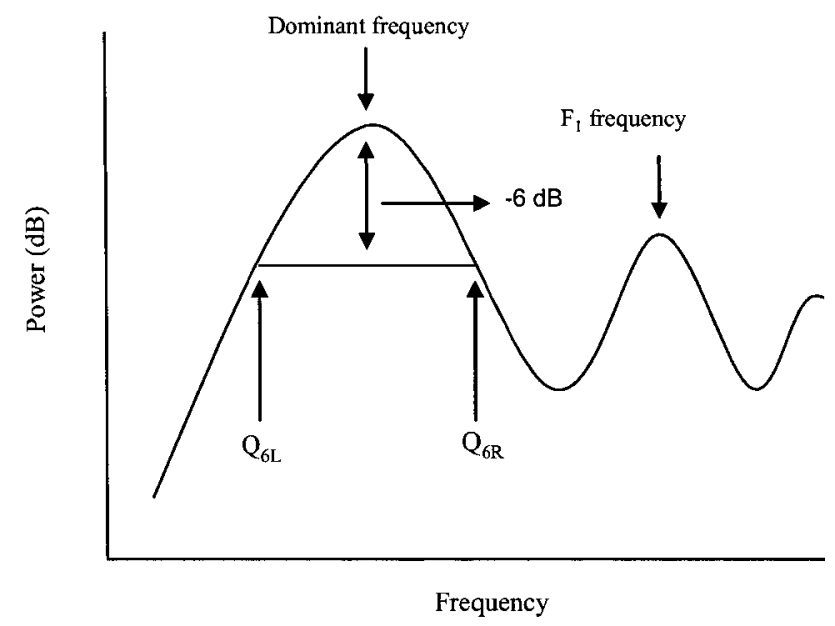

b.

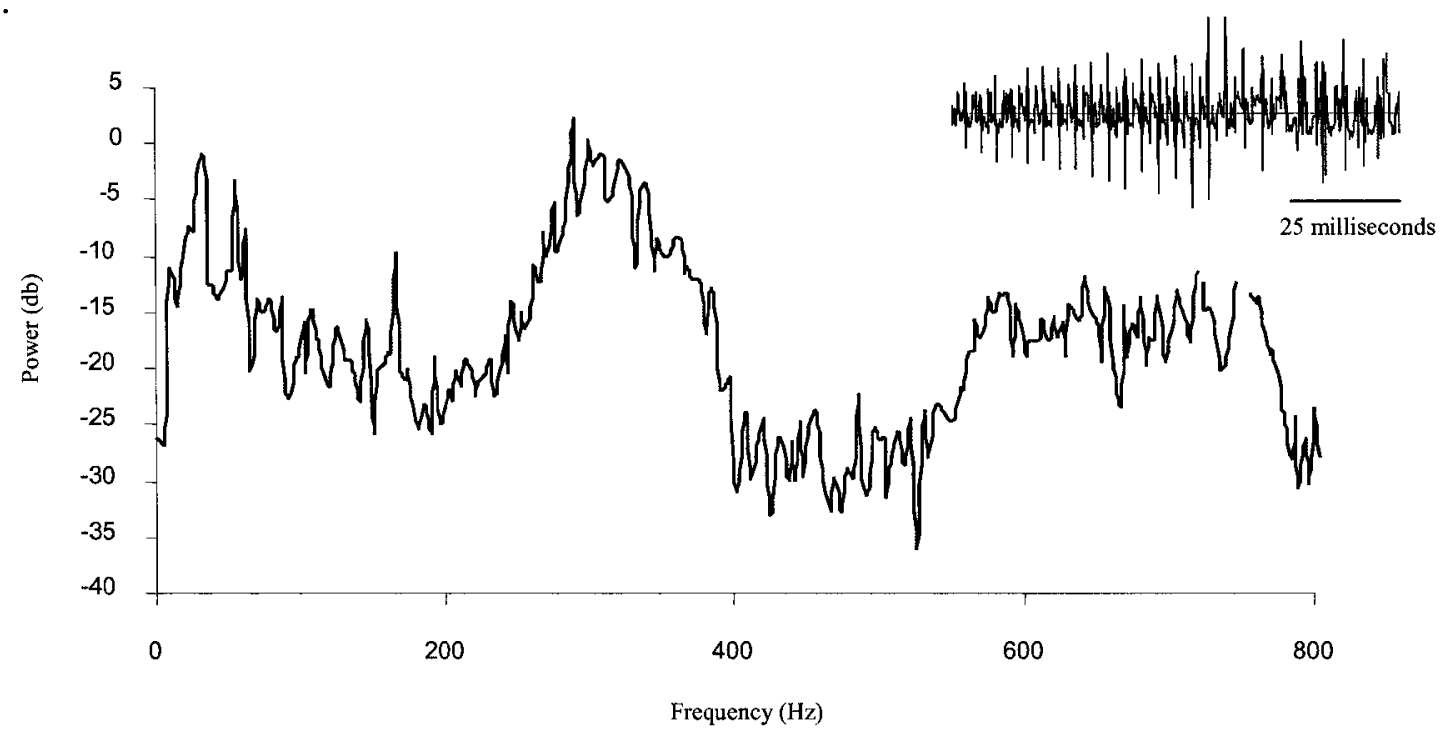

Figure 5.1: a) A schematic representation of a power spectrum showing the acoustic parameters measured for our analysis; $\mathrm{Q}_{6 \mathrm{~L}}$ and $\mathrm{Q}_{6 \mathrm{R}}$ indicate the quality factors measured $(\mathrm{Hz}) . \mathrm{F}_{1}$ frequency indicates the frequency at the first harmonic $(\mathrm{Hz})$. b) Frequency spectrum of the buzzing sound produced by a typical honeybee mimic hover fly, Eristalis arbustorum, immediately after a simulated attack, showing the dominant pick frequency and the harmonic. The inset represents the oscillogram. 


\subsection{Results}

\subsubsection{Buzzing Behaviour}

None of the individuals of the three social wasp species $V$.vulgaris, $D$. arenaria and $V$. germanica buzzed (wings held parallel to the body with associated marked change in sound produced) when they were artificially attacked, and all of them tried to sting as soon as they were grasped with forceps. However, all individuals of the wasp-like (Spilomyia longicornis, Spilomyia sayi and Helophilus fasciatus), bumble bee-like (E. flavipes) and honeybee-like (E. tenax and E. transversa) hover flies buzzed with high intensity when they were attacked and grasped (Table 5.1). This buzzing behaviour was also observed in bumble bee and honeybee species, although the buzzing sound produced by honeybees was not as intense as bumble bees and hover flies (Table 5.1). None of the two nonmimetic fly species, Sarcophaga spp. and C. relictus, responded by buzzing when they were artificially attacked. Overall, while buzzing behaviour tended to be characterized by a high dominant frequency (Table 5.1), our discriminant function analysis showed that the first discriminant function could readily partition buzzing species from non-buzzing species (Fig 5.2). 
Table 5.1: The mean sound characteristics emitted by each species following attack. Standard errors of the means are shown in parentheses. Those species, other than honeybees, with lower dominant frequencies (dominant frequency $<200$

Hz) did not exhibit buzzing behaviour after simulated attack

\begin{tabular}{|c|c|c|c|c|c|c|c|c|c|}
\hline Groups & Species & $\begin{array}{c}\text { Number of } \\
\text { observations }\end{array}$ & $\begin{array}{c}\% \\
\text { individuals } \\
\text { buzzed }\end{array}$ & $\begin{array}{c}\text { Dominant } \\
\text { frequency } \\
(\mathrm{Hz})\end{array}$ & $\mathrm{Q}_{6 \mathrm{~L}}(\mathrm{~Hz})$ & $\mathrm{Q}_{6 \mathrm{R}}(\mathrm{Hz})$ & $\begin{array}{c}\text { F1 frequency } \\
(\mathrm{Hz})\end{array}$ & $\begin{array}{l}\text { Dominant } \\
\text { peak power } \\
\text { (dB) }\end{array}$ & $\begin{array}{l}\text { F1 power } \\
\text { (dB) }\end{array}$ \\
\hline Bumble bee mimic & E. flavipes & 12 & 91.7 & $233.92(27.78)$ & $206.83(27.5)$ & $258.33(29.5)$ & $471.41(54.4)$ & $51.11(4.87)$ & $51.02(5.47)$ \\
\hline \multirow[t]{2}{*}{ Honeybee mimic } & E. arbustorum & 20 & 100 & $299.35(12.1)$ & $273.75(13.4)$ & $318.2(20.1)$ & $603.25(24.6)$ & $62.65(1.3)$ & $61.43(7.2)$ \\
\hline & E. transversa & 10 & 100 & $310.2(12.8)$ & $277.4(13.1)$ & $326.10(13.1)$ & $600.60(26.7)$ & $58.00(2.9)$ & $65.9(3.3)$ \\
\hline \multirow[t]{3}{*}{ Wasp mimic } & Spilomvia longicornis & 11 & 90 & $278.63(34.0)$ & $261.73(30.4)$ & $308.18(34.2)$ & $571.63(64.2)$ & $54.01(5.9)$ & $65.53(6.7)$ \\
\hline & S. sayi & 7 & 100 & $291.28(15.7)$ & $270.71(17.9)$ & $312.57(16.9)$ & $580.42(35.5)$ & $52.74(2.3)$ & $69.52(2.8)$ \\
\hline & Helophilus fasciatus & 7 & 100 & $271.71(31.5)$ & $247.85(33.2)$ & $297.28(31.3)$ & $541.57(64.0)$ & $53.68(5.1)$ & $64.68(2.1)$ \\
\hline \multirow[t]{2}{*}{ Bumble bee } & B. impatiens & 12 & 100 & $314.16(16.2)$ & $290.83(16.8)$ & $342.16(16.0)$ & $611.91(32.2)$ & $68.99(1.7)$ & $79.99(1.1)$ \\
\hline & Bombus sp. & 9 & 100 & $204.55(16.9)$ & $179.11(17.4)$ & $233.55(20.7)$ & $427.55(41.3)$ & $53.02(3.6)$ & $60.44(5.7)$ \\
\hline Honeybee & Apis mellifera & 23 & 78.26 & $87.91(16.2)$ & $58.43(15.5)$ & $112.52(17.4)$ & $137.48(30.6)$ & $51.46(4.5)$ & $41.64(6.6)$ \\
\hline \multirow[t]{3}{*}{ Wasp } & Vespula vulgaris & 7 & 0 & $155.57(3.3)$ & $131.14(4.0)$ & $187.85(3.7)$ & $317.14(7.3)$ & $56.72(1.7)$ & $61.08(1.3)$ \\
\hline & Dolichovespula arenaria & 20 & 0 & $166.2(3.4)$ & $141.95(3.5)$ & $191.20(3.4)$ & $331.05(7.5)$ & $55.06(1.2)$ & $59.70(1.4)$ \\
\hline & V. germanica & 21 & 0 & $151.04(2.5)$ & $129.42(2.9)$ & $173.23(2.5)$ & $304.14(5.2)$ & $51.7(0.8)$ & $56.28(0.9)$ \\
\hline \multirow[t]{2}{*}{ Non-mimetic fly } & Chrysops relictus & 7 & 0 & $148.71(4.5)$ & $122.42(6.7)$ & $177.42(4.8)$ & $300.57(10.4)$ & $36.40(3.1)$ & $23.00(16.1)$ \\
\hline & Sarcophaga spp. & 23 & 0 & $173.08(8.7)$ & $149.04(9.1)$ & $198.04(8.4)$ & $342.87(20.4)$ & $39.16(1.9)$ & $41.67(2.7)$ \\
\hline
\end{tabular}




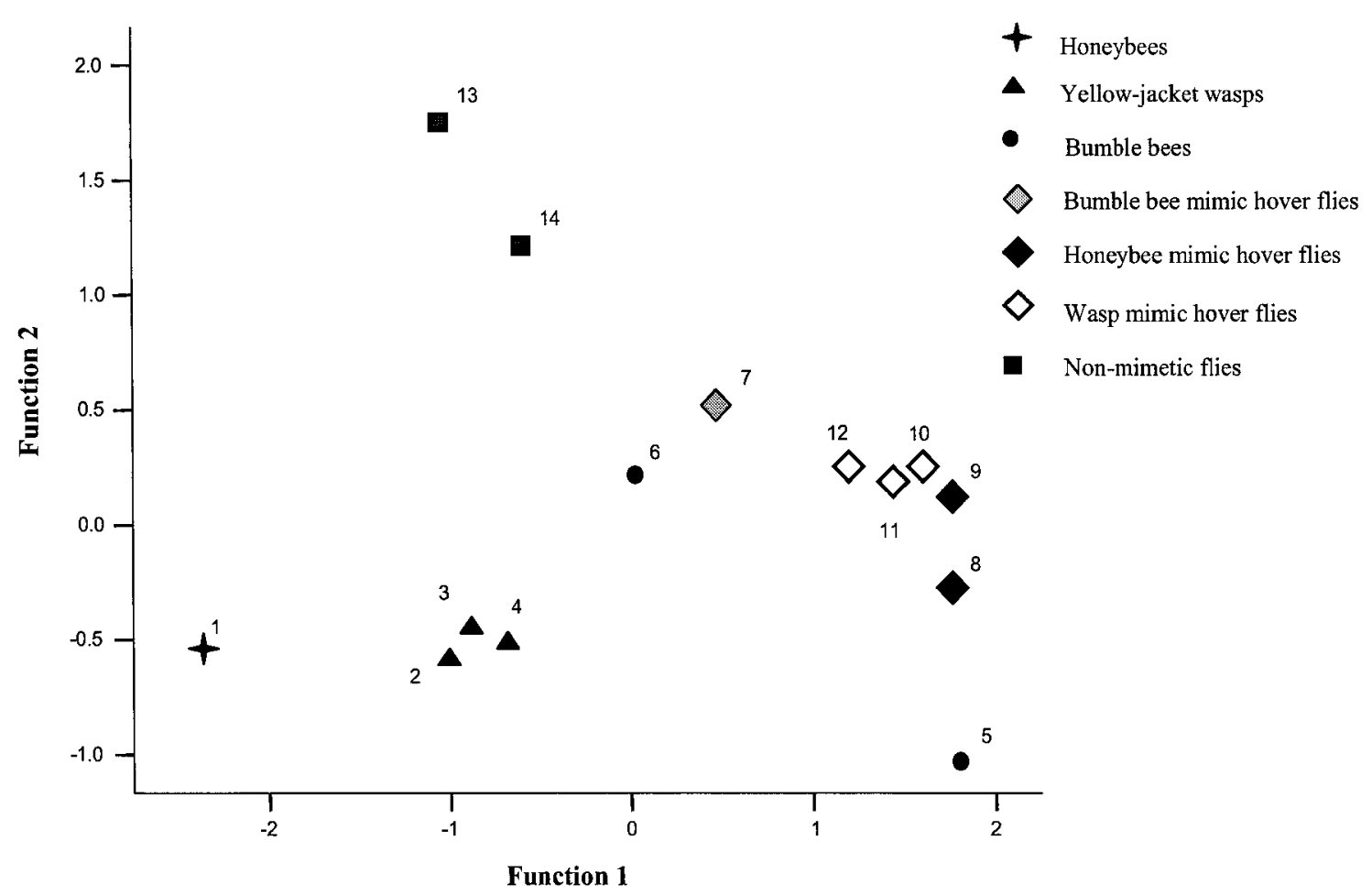

Figure 5.2: Discriminant function analysis of sounds produced after attack, showing the centroids of the measured species; 1) Apis mellifera, 2) $V$. vulgaris, 3) $V$. germanica, 4) D. arenaria, 5) B. impatiens, 6) Bombus sp., 7) E. flavipes, 8) E. transversa, 9) E. arbustorum, 10) S. sayi, 11) S. longicornis ,12) $H$. fasciatus, 13) C. relictus, 14) Sarcophaga spp. 


\subsubsection{Do Wasp Mimics Sound Like Wasps on Attack?}

Given that wasp mimics show distinctive buzzing behaviour on simulated attack and wasps do not, our expectation after performing the experiment was that wasp mimics do not sound like wasps, and this was confirmed through the following formal analysis. Overall, the results of the multivariate analysis of variance (MANOVA) on three wasp species (D. arenaria, $V$. germanica and $V$. vulgaris) and three wasp mimic species $S$. longicornis, $S$. sayi and $H$. fasciatus) showed that there was a significant variation among species in the sounds they made following attack (Wilks' lambda $=0.235, \mathrm{~F}_{30,250}=.63, \mathrm{P}<$ 0.001). Moreover, Tukey tests revealed that each and every wasp species differed significantly from each and every wasp mimic species in Dominant frequency $(\mathrm{P}<$ 0.002), $\mathrm{F}_{1}$ frequency $(\mathrm{P}<0.002), \mathrm{Q}_{6 \mathrm{~L}}(\mathrm{P}<0.004)$ and $\mathrm{Q}_{6 \mathrm{R}}(\mathrm{P}<0.003)$. In all cases involving a significant predictor variable, the three wasp species formed a statistically homogeneous subset and the three wasp mimics formed another homogeneous subset. Results from our discrininant function analysis strongly support this finding in that each wasp mimic shows a similar Mahalanobis distance profile to other wasp mimic species tested, and that the distances from wasps are relatively high (Fig 5.3). 


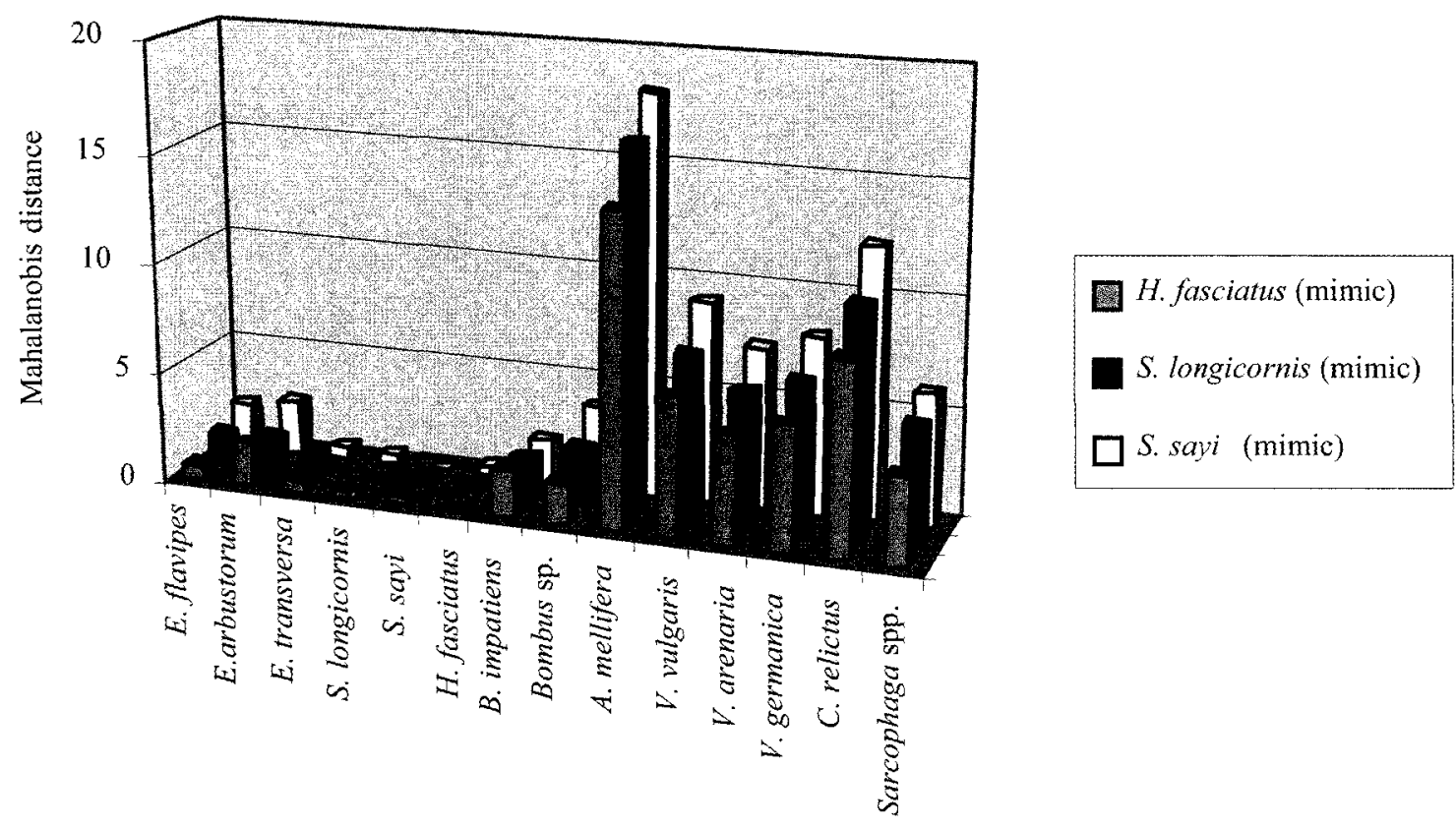

Figure 5.3: An illustration of the disriminant function analysis results comparing three wasp-mimic species (S. longicomis, S. sayi and H. fasciatus) and other insect species tested in this study. Bars indicate the observed Mahalanobis distance to the other species (low values indicating high similarity). 


\subsubsection{Do Honeybee Mimics Sound Like Honeybees on Attack?}

Overall, the results of the multivariate analysis of variance (MANOVA) of the sounds made by honeybee (A. mellifera) and the two honeybee mimic species (E. transversa and E. arbustorum) showed that there was significant among species variability in the sounds these species made following attack (Wilks' lambda $=0.178, \mathrm{~F}_{12,90}=10.3, \mathrm{P}<0.001$ ). Tukey tests confirmed that the sounds produced by the honeybee differed significantly from both honeybee mimic species in Dominant frequency $(\mathrm{P}<0.001), \mathrm{F}_{1}$ frequency $(\mathrm{P}<$ $0.001), \mathrm{Q}_{6 \mathrm{~L}}(\mathrm{P}<0.001)$ and $\mathrm{Q}_{6 \mathrm{R}}(\mathrm{P}<0.001)$. For each significant predictor variable, the honeybee formed a statistically distinct subset and the honeybee mimics formed another homogeneous subset. Once again the discriminant function analysis supports this finding, with the two honeybee mimics showing almost identical similarity profiles, that differ in sound from Apis mellifera (Fig 5.4). 


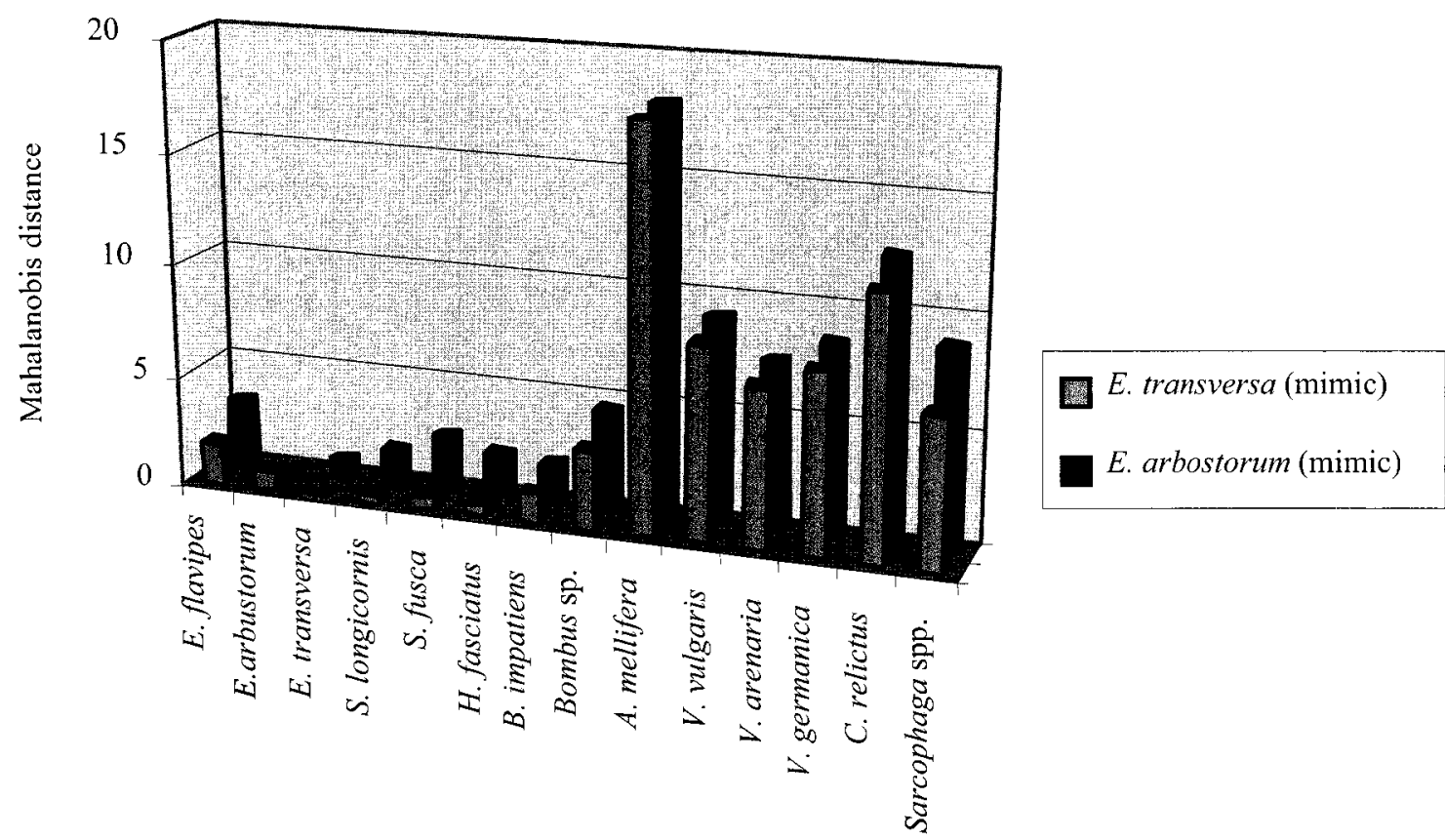

Figure 5.4: Disriminant function analysis results comparing two honeybee mimic species (E. arbustorum and E. transversa) with other insect species tested in this study. Bars indicate the observed Mahalanobis distance to the other species (low values indicating high similarity). 


\subsubsection{Do Bumble Bee Mimics Sound Like Bumble Bees on Attack?}

Here we find that the bumble bee mimic (E. flavipes) is overall more similar to one of the bumble bee species (Bombus sp.) than the two bumble bee species (Bombus sp. and Bombus impatiens) are to one another. Thus, the results of the multivariate analysis of variance show that the three species differ significantly overall based on the six predictor variables (Wilks' lambda $=0.256, \mathrm{~F}_{12,90}=4.074, \mathrm{P}<0.001$ ). For all of the individual predictor variables E.flavipes and Bombus sp. form a homogeneous subset, while $B$. impatiens forms the second subset (Dominant frequency: $\mathrm{P}<0.03 ; \mathrm{F}_{1}$ frequency: $\mathrm{P}<0.03$, $\mathrm{Q}_{6 \mathrm{~L}}: \mathrm{P}<0.04 ; \mathrm{Q}_{6 \mathrm{R}}: \mathrm{P}<0.03$; dominant peak power: $\mathrm{P}<0.03 ; \mathrm{F}_{1}$ power: $\mathrm{P}<0.02$ ). Our discriminant analysis supports this conclusion, in that E. flavipes and Bombus sp. show similar Mahalanobis distance profiles, which differ somewhat from B. impatiens (Fig $5.5)$. 


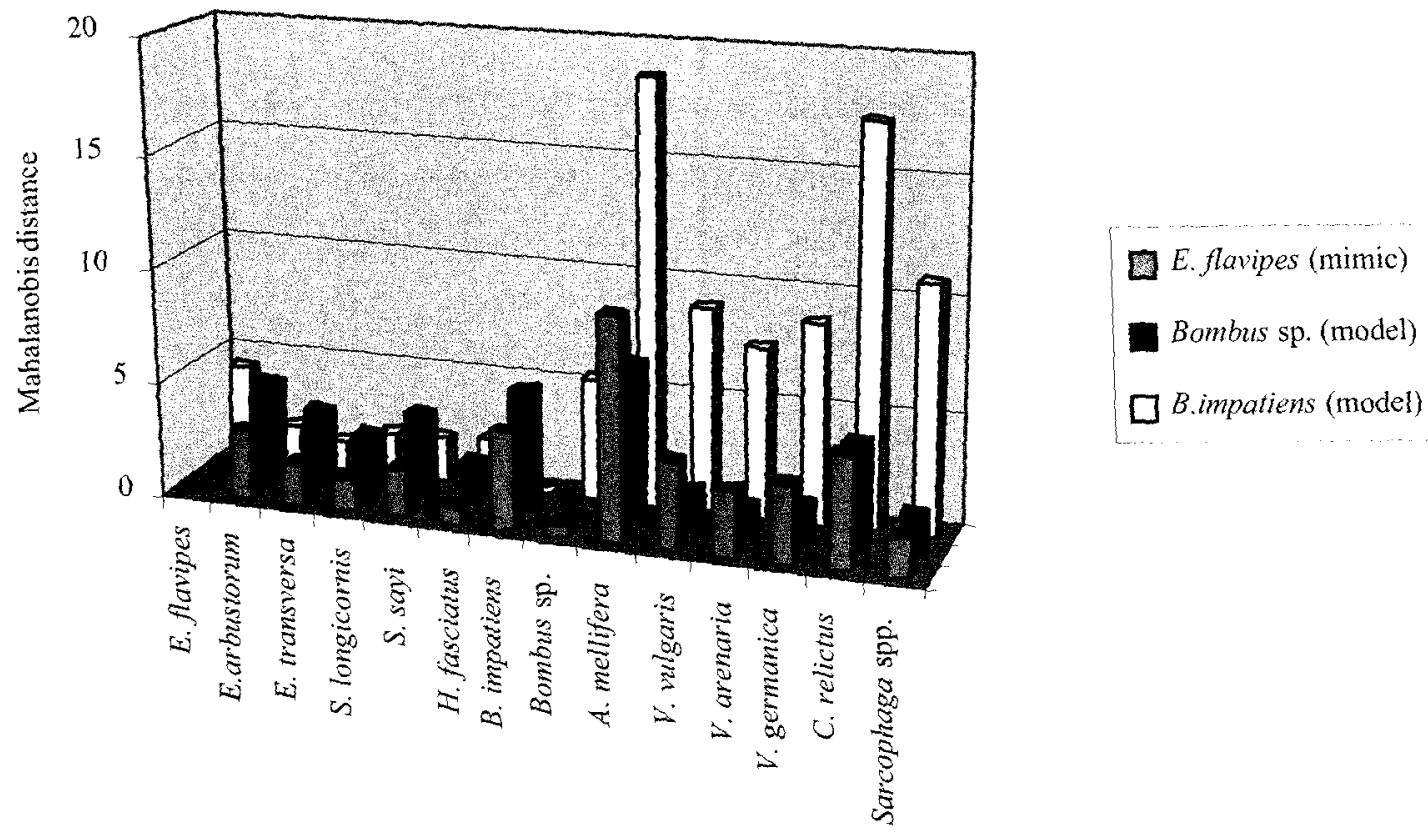

Figure 5.5: Discriminant function analysis results comparing bumble bee and bumble bee mimic species with other insect species tested in this study. Bars indicate the observed Mahalanobis distance of the models, B. impatiens and B. flavipes, and the mimic, E. flavipes, to the other species (low values indicating high similarity). 


\subsubsection{Do Mimetic Hover Flies Sound Like One Another, Independent of the Model}

\section{They Resemble?}

Multivariate analysis of the sounds made by all six species of mimetic hover fly on attack show that the species do not differ significantly in overall sounds produced (Wilks' lambda $\left.=0.653, \mathrm{~F}_{30,226}=0.847, \mathrm{P}=0.699\right)$ and none of the six sound components differ significantly between species $(\mathrm{P}>0.05)$. Our discriminant analysis also supports this conclusion, in that wasp mimics sound similar to bee mimics based on Mahalanobis distance (see figures 5.3, 5.4 and 5.5), both of which differ from the models they are supposed to resemble as well as the nonmimetic flies. Thus, hover fly mimics sound more like other species in the same group when attacked, independent of the model they morphologically resemble. 


\subsection{Discussion}

"Acoustic mimicry now seems to be where visual mimicry was before the Browers attacked it: lots of speculation and observations of strange phenomena but no really experiments addressing the question"' (A. C. Dunning, in G. Pasteur 1982, page 170).

In the present study, we examined the idea that mimetic hover flies sound more similar to their hymenopteran models when attacked or grabbed by a presumed predator than related hover flies which resemble a different model. Although we find similarity in the buzzing sounds produced by bumble bees and their hover fly mimic, E. flavipes, we did not detect a consistent pattern among other mimetic hover flies and their models. Indeed, we were able to statistically distinguish the sounds made by wasp mimics from the sounds made by wasps, and the sounds of honeybee mimics from honeybees, but could not distinguish among the sounds made by the variety of hover flies which resemble three different hymenopteran models.

All of the mimetic hover flies, bumble bees and honeybees investigated in our experiments showed buzzing behaviour, by vibrating their wings almost parallel to the longitudinal axis of their body when attacked. However, we also note that honeybees were very susceptible to handling as they sting very readily. Most of the individuals lost their stinger during the handling, and as a result were not in a perfect condition when recording. This could be the reason for the low mean frequencies of buzzing sound observed in honeybee individuals tested in this study (Table 5.1). 
Our results also indicated that the bumble bee mimic $E$. flavipes resembles the bumble bee Bombus sp. even more closely than the bumble bee B. impatiens. One possible reason could be the smaller size of $B$. impatiens (mean $11.08 \mathrm{~mm}$, s.e. $0.18 \mathrm{~mm}$ ) compared to the larger-sized Bombus sp. (mean $12.5 \mathrm{~mm}$ s.e. $0.31 \mathrm{~mm}$ ). Moreover, all the $B$. impatiens individuals were reared in the lab when all $B$. flavipes species were caught in the wild. This could be a biasing factor for our results as different environmental conditions could affect the behavioural characteristics of an individual (see Mappes \& Endler 2004).

A mechanism for buzzing in insects has recently been described for bumble bees and carpenter bees (King et al. 1996) and involves decoupling of the wings from the flight mechanism via deformation of the thorax. We know of no anatomical reason why wasps could not exhibit such behaviour, and indeed some wasp species appear to do so (Coelho 1998), but the wasps and nonmimetic flies we investigated simply did not show this distinctive and quantifiable buzzing behaviour.

Contrary to the suggestion made by Waldbauer (1988) we found no evidence that our wasp mimic hover flies sounded like wasps when grabbed (indeed if anything they sounded more like the buzzing of bees, as Figure 5.2 highlights), but of course we cannot rule out the possibility of acoustic mimicry in other, as yet untested, species pairs. Indeed, it came as something of a surprise to us that none of the social wasp species examined showed buzzing behaviour. Rather than buzz, all of the yellow-jacket wasp 
species we investigated attempted to sting and fly away without exception, while the nonmimetic flies we tested simply attempted to fly away. It is possible that since wasps are able to sting multiple times they do not invest in buzzing and instead use their stinger as the primary line of defense. One might wonder why bumble bees, which can sting multiple times, nevertheless tend to buzz. However, Bombus species are reluctant stingers and mechanical resistance of the body seem to be the main defense for bumble bees, especially to young birds (Mostler 1935). Nonmimetic flies may use evasive flight as the major defense response and there is no need to evolve sounds post attack. A basic and tentative rule, which can be readily tested, is that if a species can readily defend itself using stingers or flight, then further signals post-capture do not evolve. In support, cicada killing wasps (Sphecius speciosus) have stings that are not painful to vertebrates, and it has been argued that, as a consequence, the buzz (often from underground burrows) provides the primary deterrent of predators (Coelho 1998).

There are now numerous studies showing that sound could be used as a defense mechanism by some insects and animals (e.g. Rothschild \& Haskell, 1966; Dunning \& Krüger 1995; Hristov \& Conner, 2005; Rowe \& Owings 1978; Rowe et al. 1986). 'Startle displays', which are defined as a sudden conspicuous change in appearance and behaviour of an animal (see Stevens 2005), can be used by some insects to deter predation by potential predators. For instance, Vallin et al. (2005) showed that the peacock butterfly, Inachi io, uses sequences of wing movements exposing major eyespots followed by a hissing sound as an active type of defense against birds. The buzzing sound 
produced by hover flies and bumble bees might serve as a startle display to create an opportunity to escape when birds release them immediately after the buzz (see Mostler 1935). Mostler (1935) himself states that "in one test the origin of the letting go of the insect [a bumble bee] (which was almost dead already) was fear of the suddenly resumed buzzing".

In addition to startling function, in some cases the buzz may serve as a warning signal. For instance, Kirchner \& Röschard (1999) have suggested that the high intensity sound produced by bumble bees could function as a warning signal to the nest predator, Mus domesticus. Acoustic signals could sometimes combine with the visual component of an organism to produce multimodal warning signals (Rowe \& Guilford 1999). The possession of the abdominal bright stripes and patches in addition to the sudden buzzing behaviour upon an attack by a predator make it conceivable that bumble bees also use multimodal warning signals to protect themselves.

To our knowledge this is the first study to experimentally investigate the buzzing sounds produced by mimetic hover flies and their presumed models (bees and wasps) in a mimicry context. The outcome of our experiments showed that all of the hover flies, regardless of the model group they mimic, as well as bumble bees, buzzed when they were artificially attacked. In contrast to mimetic hover flies, nonmimetic flies did not express the buzzing behaviour upon an attack. Yellow-jacket wasps also did not perform this behaviour and used their stinger as their primary line of defense. The pattern that 
emerges from our tested specimens is that the buzzing behaviour occurs only when it benefits the carrier. Readily defended insects (yellow-jacket wasps) or insects that are protected by other means (flight speed, e.g. nonmimetic flies) do not need to buzz. However, species that are not readily protected (e.g. hover flies) benefit from buzzing behaviour presumably by creating the opportunity to escape either through startle, and/or through generalized mimicry of a hymenopteran. Further study is needed to test these conjectures. 


\section{CHAPTER 6}

\section{General Discussion and Conclusion}

Mimicry is perhaps one of the most fascinating examples of Darwinian natural selection theory. For at least the past 135 years scientists have been trying to find answers explaining the existence of this phenomenon in nature, yet many fundamental hypotheses remain to be tested: Why do mimetic animals more often resemble their presumed models imperfectly? Who are the receivers for these mimetic signals? Do humans, birds and insect predators/competitors receive the mimetic signals similarly? Is an imperfect mimic to our eyes a good mimic to a predator's eyes? All these unanswered questions encouraged me to start investigating some of the aspects of this interesting phenomenon. The mimetic diversity, the mimetic spectrum and the abundance of hover flies made them a suitable study model to address some of the untested areas in the field of mimicry, using both theoretical and experimental approaches.

In the first chapter I investigated the effect of invertebrate predation on the evolution of mimicry. Most of the studies on the evolution of mimicry and warning signals in insects have considered birds as the main predators of hover flies, however, predation by other taxonomic groups, such as insects, may far exceed avian predation at some localities. Very few studies have investigated the possibility that insect predators might facilitate selection for warning colours and mimicry in other insects. We experimentally evaluated whether prey size and/or wasp-like colours and patterns were important in deterring attacks by dragonflies, using pairwise and single presentations of 
both natural and artificial prey in the field. Dragonflies were more likely to attack smaller natural prey and smaller artificial prey. However, dragonflies showed no differences between attacks on prey with wasp-like colours and patterns and those on the same-sized prey that were nonmimetic. Moreover, dragonflies avoided attacking both mock-painted and black-painted wasps entirely. Overall, we found no evidence to support the hypothesis that wasp-like warning signals protect small insect prey from attack by dragonflies, although size seems to be an important cue in dragonfly prey choice.

In the second chapter of this thesis I tested the original idea of 'competitive mimicry'. Since in the first study I did not find any advantage for mimetic patterns of hover flies in escaping predation by dragonflies as invertebrate predators, I thought it possible that competition for food resources might potentially facilitate selection for these conspicuous signals. For example, when warningly coloured social wasps visit flowers then they frequently behave aggressively towards heterospecifics, and they also attack and feed on other flying insects. Under these conditions, a resemblance to a wasp may provide a mimetic hover fly with improved access to floral resources by reducing the frequency with which it is disturbed by other flower visitors. I experimentally evaluated whether wasp-like colours and patterns were important in preventing other flower visitors from sharing the same flower resource, using pairwise presentations of both natural and artificial prey in the field. Flower visitors were more likely to visit unoccupied flowers compared to the flowers pinned with either natural or artificial specimens, in two plant species with different inflorescences. However, flower visitors did not show reduced 
visits to flowers pinned with specimens bearing wasp-like colours and patterns compared to the flowers occupied by same-sized specimens that were nonmimetic. Overall, I found no evidence in this study to support the contention that wasp-like warning signals of hover flies prevent other flower visitors from sharing flower resources, although insects showed a greater tendency to avoid visiting flowers pinned with a wasp compared to flowers pinned with a nonmimetic fly.

Not all mimetic hover flies mimic their models closely and sometimes the similarity is imperfect. In my third chapter I introduced a neural network as a tool to objectively measure the degree of similarity to the model. Furthermore, I compared the neural network ranking of hover fly photos to human rankings and pigeon rankings. Dittrich et al. (1993) obtained a classification of mimetic hover fly images by pigeons, based on the degree of similarity they had either to yellow-jacket wasps or to nonmimetic flies. Using the exact same data set we showed that the human ordering corresponded to the broad ordering postulated in the original analysis, and matched the pigeon ordering more closely than the neural network's ordering. In an original approach, using genetic algorithm along with the neural network, we successfully created a model that closely predicted the observed peck rate of pigeons (Dittrich et al. used birds peck rate on every image as a criterion to create the pigeons ordering of hover flies) and, in doing so, identified a reduced set of image characteristics that pigeons may have employed when classifying the images. 
Even though the morphological similarities are important in avoiding predation, there is no doubt that behavioural similarities could also play a role in convincing the receivers. In the last chapter of this thesis I quantitatively compared the sounds produced by a range of wasps, bumble bees, honeybees, their hover fly mimics, and nonmimetic flies when they were artificially attacked, using a pair of soft forceps. Although I found some similarity in the buzzing sounds produced by bumble bees and their hover fly mimic, E. flavipes, I failed to detect a consistent pattern among other mimetic hover flies and their related models. Thus, the sounds made by wasps on attack were statistically distinguishable from their mimics on attack, as were the sounds made by honeybees and their mimics. Moreover, the tested wasp mimic, honeybee mimic and bumble bee mimic hover flies buzzed similarly to one another, independent of the model they resemble. While hover flies, bumblebees and honeybees all emitted a distinctive and quantifiable "buzz" when probed, neither recorded social wasps nor nonmimetic flies exhibited this response, most likely because they have evolved alternative ways of defending themselves from predators. Although we did not investigate the function of this behaviour in this study it is possible that this buzzing behaviour also serve as a warning signal and/or defensive startle behaviour. However, further experiments are needed to investigate this hypothesis.

My goal in this thesis was to test the factors that potentially could influence the evolution and maintenance of mimicry in hover flies. I have tested three different hypotheses, two of which were original ideas, using novel approaches. I also for the 
first time introduced a neural network as a tool to assess the degree of similarity between mimics and models. More importantly using a built in genetic algorithm in a novel approach I identified the salient variables that predators might use to distinguish between mimics and models.

I hope that this body of work opens new areas to fellow researchers to investigate. Profitable lines of future enquiry include a study of the phylogeny of hover flies, with respect to mimicry. Based on the most recent available phylogeny inferred from both molecular and morphological characteristics by Stahl et al. (2003) one might study different mimetic forms of hover flies (wasp mimics, honeybee mimics, bumblebee mimics and imperfect mimics) and their distribution in the family of Syrphidae. Mapping different mimetic forms onto the phylogenetic tree will also allow one to evaluate how frequently sister species tend to diverge in the species of model they resemble and how many times different mimetic characteristics evolved during the evolutionary process of this family. Understanding the evolutionary choice of noxious model has never been attempted, but might provide important insights as to how and why mimicry evolves in this group.

While a lot of the mimetic hover flies are in fact imperfect mimics the question Why they do not evolve to resemble their hymenopteran models perfectly?- still remained to be answered. As a potential explanation I would like to study the possible trade-offs between mimicry and sexual selection in this group of Diptera. Turner (1978) 
has examined sex-limited mimicry in Lepidoptera, including discussing the role of sexual selection but almost nothing has been done on with Diptera. A certain degree of similarity to a model might be enough for a mimic to obtain some degree of protection against predators while also optimizing its mating chances.

I have enjoyed working on this subject for the past four years and wish to have chance to continue my research in the field of evolution which is a deep pool of fascinating and unanswered questions. 


\section{LITERATURE CITED}

Allen, J. A. \& Cooper, J. M. 1985. Crypsis and masquerade. Journal of Biological Education, 19, 268-270.

Atkins, E. L. 1948 Mimicry between the drone fly, Eristalis tenax and the honeybee, Apis mellifera. Its significance in ancient mythology and present day thought. Annals of the Entomological Society of America, 41, 387-392.

Azmeh, S., Owen, J., Sorensen, K., Grewcock, D. \& Gilbert, F. 1998. Mimicry profiles are affected by human- induced habitat changes. Proceeding Royal Society of London, 265, 2285 - 2290.

Baird, J. M. 1991. Behavioural ecology of foraging in Pachydiplax longipennis (Odonata: Libellulidae). Journal of Insect Behavior, 10, 655-678.

Bates, H. W. 1862. Contributions to an insect fauna of the Amazon valley. Lepidoptera: Heliconidae. Transactions of Linnean Society of London, 23, 495-566.

Beatty, G. H. 1951. Odonate bionomics: I. Notes on the food of dragonflies. 1. Odonata vs. ants and bees. Bulletin of Brooklyn Entomological Society, XLVI, 29- 37.

Berenbaum, M. R. \& Miliczky, E. 1984. Mantid and milkweed bugs: efficacy of aposematic coloration against invertebrate predators. American Midland Naturalist, 111, 64-68.

Biesmeijer, J. C., Richter, J. A. P., Smeets, M. A. J. P. \& Sommeijer, M. J. 1999. Niche differentiation in nectar-collecting stingless bees: the influence of morphology, floral choice and interference competition. Ecological Entomology, 24, 380-388. 
Bishop, C. M. 1995 Neural Networks for Pattern Recognition, Oxford: Oxford University Press.

Borror, D. J., Triplehorn C. A. \& Johnson N. F. 1992. An introductory to the study of insects. Toronto, ON: Saunders College Publishing.

Bowdish, T. I. \& Bultman, T. L. 1993. Visual cues used by mantids in learning adversion to aposematically colored prey. American Midland Naturalist, 129, 215-222.

Branquart, E. \& Hemptinne J. L. 2000. Selectivity in the exploitation of floral resources by hoverflies (Diptera: Syrphinae). Ecography, 23, 732-742.

Briscoe, A. D. \& Chittka, L. 2001. The evolution of color vision in insects. Annual Review of Entomology, 46, 471-510.

Burks, T. F., Shearer, S. A., Heath, J. R. \& Donohue, K. D. 2005 Evaluation of neural-network classifiers for weed species discrimination. Biosystems Engineering, 91, 293-304.

Church, S. C., Bennett, A. T. D., Cuthill, I. C. \& Partridge, J. C. 2004. Avian ultraviolet vision and its implications for insect protective coloration. In Insect and Bird Interactions (ed. H. van Emden \& M. Rothschild), pp. 165-184. Andover: Intercept.

Coelho, J. R. 1998. An acoustical and physiological analysis of buzzing in cicada killer wasps (Sphecius speciosus). Journal of comparative Physiology A, 183, 745-751.

Cohen, J. 1988. Statistical Power Analysis for the Behavioral Sciences. 2nd edn. New York: L. Eribaum. 
Colegrave, N. \& Ruxton, G. D. 2003. Confidence intervals are a more useful complement to nonsignificant tests than are power calculations. Behavioral Ecology, 14, 446-450.

Colegrave, N. \& Ruxton, G. D. 2005. What hipótesis tests are not: a reply to Johnson. Behavioral Ecology, 16, 325-325.

Corbet, P. S. 1999. Dragonflies: Behaviour and Ecology of Odonata. Ithaca, NY: Cornell University Press.

Cott, H. B. 1940. Adaptive coloration in Animals. Meuthen.

Culverhouse, P. F., Williams, R., Reguera, B., Herry, V. \& Gonzalez-Gil, S. 2003. Do experts make mistakes? A comparison of human and machine identification of dinoflagellates. Marine Ecology Progress Series, 247, 17-25.

Cuthill I. G. \& A.T. D. Bennett. 1993. Mimicry and the eye of beholder. Proceeding of the Royal Society of London B, 253, 203- 204.

Dejean, A. 1988. Memory effect on predatory behaviour of Odontomachus troglodytes (Formicidae - Ponerinae). Behaviour, 107, 131- 137.

Dittrich W., Gilbert, F., Green, P., McGregor, P. \& Grewcock, D. 1993. Imperfect mimicry: a pigeon's perspective. Proceeding of the Royal Society of London, 251, 195- 200.

Dukas, R. 2001. Effect of perceived danger on flower choice by bees. Ecology Letters, 4, 327-333.

Dukas, R. \& Morse, D. H. 2003. Crab spiders affect flower visitation by bees. OIKOS, 101, 157-163. 
Dunning, D.C. \& Krüger, M. 1995. Aposematic sounds in African moths. Biotropica, 27, 227-231.

Edmund, M. 1974. Defence in animals: a survey of anti-predator defences. Harlow, Essex: Longman.

Edmunds, M. 2000. Why arethere good and poor mimics? Biological Journal of the Linnean Society, 70, 459- 466.

Endler, J. A. 1984. progressive background matching in moths, and quantitative measure of crypsis. Biological Journal of Linnean Society, 22, 187-231.

Fausett, L. V. 1994. Fundamentals of neural networks: architectures, algorithms, and applications, Englewood Cliffs, New Jersey: Prentice-Hall.

Feraud, R. \& Clerot, F. 2002. A methodology to explain neural network classification. Neural Networks, 15, 237-246.

Fisher, R. A. 1930. The Genetical Theory of Natural of Natural Selection. Oxford University Press. 318 pp.

Gamberale, G. \& Tullberg, B. S. 1996. Evidence for a peak-shift in predator generalization among aposematic prey. Proceedings of the Royal Society of London B, 263, 1329-1334.

Gamboa, G. J., Grudzien, T. A., Esplie, K. E. \& Bura E. A. 1996. Kin recognition pheromones in social wasps: combining chemical and behavioural evidence. Animal Behaviour, 51, 625-629. 
Gilbert, F. 1981. Foraging ecology of hoverflies (Diptera, Syrphidae): morphology of the mouthparts in relation to feeding on nectar and pollen in some common urban species. Ecological Entomology, 6, 245-262

Gilbert, F. 2005. The evolution of imperfect mimicry. In: Insect Evolutionary Ecology (Ed. by M.D.E. Fellowes G.J. Holloway \& J. Rolff), pp. 231-288. CABI, Wallingford.

Gilbert, F. \& Owen, J. 1990. Size, shape, competition and community structure in hoverflies (Diptera: Syrphidae). Journal of Animal Ecology, 59, 21-39.

Golding, Y. C. \& Edmunds, M. 2000. Behavioural mimicry of honeybees (Apis mellifera) by droneflies (Diptera: Syrphidae : Eristalis spp.). Proceedings of the Royal Society of London B, 267, 903-909.

Golding, Y. C., Ennos, A. R. \& Edmunds, M. 2001. Similarity in flight behaviour between the honeybee Apis mellifera (Hymenoptera : Apidae) and its presumed mimic, the dronefly Eristalis tenax (Diptera:Syrphidae). Journal of Experimental Biology, 204, 139-145.

Golding, Y., Ennos, R., Sullivan, M. \& Edmunds, M. 2005. Hoverfly mimicry deceives humans. Journal of Zoology, 266, 395-399.

Goulson, D., Stout, J. C., Langley, J. \& Hughes, W. O. H. 2000. Identity and function of scent marks deposited by foraging bumblebees. Journal of Chemical Ecology, 26, 2897-2911. 
Green, P. T., Gentle, L., Peake, T. M., Scudamore, R. E., McGregor, P. K., Gilbert, F. \& Dittrich, W. H. 1999. Conditioning pigeons to discriminate naturally lit insect specimens. Behavioural Processes, 46, 97- 102.

Guilford, T. 1990. The evolution of aposematism,. In: Insect Defenses: Adaptive Mechanisms and Strategies of Prey and Predators (Ed. by D. L. Evans \& J. O. Schmidt), pp. 23-61. Albany: State University of New York Press.

Hastie, T., Tibshirani, R. \& Friedman, J. 2001. The Elements of Statistical Learning: Data Mining, Inference and Prediction. New York: Springer.

Hoenig, J. M. \& Heisey, D. M. 2001. The abuse of power: the pervasive fallacy of power calculations for data analysis. American Statistician, 55, 19- 24.

Holen, Ø. H. \& Johnstone, R. A. 2004. The evolution of mimicry under constraints. American Naturalist, 164, 598-613.

Holmgren, N. M. A. \& Enquist, M. 1999. Dynamics of mimicry evolution. Biological Journal of the Linnean Society 66, 145-158.

Howarth, B., Edmunds, M. \& Gilbert, F. 2004. Does the abundance of hover fly (Syrphidae) mimics depend on the numbers of their hymenopteran models? Evolution, 58, 367-375.

Hristov, N. I. \& Conner, W. E. 2005. Sound strategy: acoustic aposematism in the battiger moth arms race. Naturwissenschaften, 92, 164-169.

Huey, R. B. \& Pianka, E. R. 1977. Natural selection for juvenile lizards mimicking noxious beetles. Science, 195, 201-203. 
Jackson, J. F. \& Drummond, B. A. 1974. Batesian ant mimicry complex from the Mountain Pine Ridge of British Honduras, with an example of transformational mimicry. American Midland Naturalist, 91, 248-251.

Johnson, D. H. 2005. What hypothesis tests are not: a reply to Colegrave \& Ruxton. Behavioral Ecology, 16, 323-324.

Johnstone, R. A. 2002. The evolution of inaccurate mimics. Nature, 418, 524-526.

Kanji, G. K. 1993. 100 Statistical Tests, London: Sage Publications.

Kauppinen, J. \& Mappes, J. 2003. Why are wasps so intimidating: field experiments on hunting dragonflies (Odonata: Aeshna grandis). Animal Behaviour, 66, 505-511.

King, M. J., Buchmann, S. L. \& Spangler, H. 1996. Activity of asynchronous flight muscle from two bee families during sonication (buzzing). The journal of Experimental Biology, 199, 2317-2321.

Kirchner, W. H. \& Röschard, J. 1999. Hissing in bumble bees: an interspecific defence signal. Insectes Sociaux, 46, 239-243.

Lavine, B. K. \& Vora, M. N. 2005. Identification of Africanized honeybees. Journal of Chromatography A, 1096, 69-75.

Mallet, J. \& Joron, M. 1999. Evolution of diversity in warning color and mimicry; polymorphisms, shifting balance, and speciation. Annual Review of Ecology and Systematics, 30, 201-233.

Masters, W. M. 1980. Insect disturbance Stridulation: Characterization of airborne and vibrational component of the sound. Journal of Comparative Physiology A, 135, $259-268$ 
Merilaita, S. \& Tullberg, B. S. 2005. Constrained camouflage facilitates the evolution of conspicuous warning coloration. Evolution, 59, 38-45.

Mostler, G. 1935. Beobachtungen zur frage der wespenmimikry. Z Morph Okol Tiere, 29, 381-454.

Müller, F. 1878. Ueber die vortheile der mimicry bei schmetterlingen. Zoologischer Anzeiger, 1, 54-55.

Murray, S. O., Mercado, E. \& Roitblat, H. L. 1998. The neural network classification of false killer whale (Pseudorca crassidens) vocalizations. Journal of the Acoustical Society of America, 104, 3626-3633.

Nagamitsu, T. \& Inoue, T. 1997. Aggressive foraging of social bees as a mechanism of floral resource partitioningn in an Asian tropical rainforest. Oecologia, 110, 432439.

Nickol, M. 1994. Volucella zonaria (Diptera: Syrphidae)in Rheinland-Pfalz: distribution, flower visiting, behaviour, colour and ecology and remarks on related species. Mitteilungenn der Pollichia, 81, 383-405.

O'Donnell, S. 1996. Dragonflies (Gynacantha nervosa Rambur) avoid wasps (Polybia aequatorialis Zavattari and Mischocyttarus sp.) as prey. Journal of Insect Behavior, 9, 159- 162.

Ottenheim, M. M., Wertheim, B., Holloway, G. L. \& Brakefield, P. M. 1999. Survival of color-polymorphic Eristalis arbustorum hoverflies in semi-field conditions. Functional Ecology, 13, 72-77. 
Parrish, M. D. \& Flower, H. G. 1983. Contrasting foraging related behaviours in two sympatric wasps (Vespula maculifrons and V. Germanica). Ecological Entomology, 8, 185-190.

Pasteur, G. 1982. A classificatory review of mimicry systems. Annual Review of Ecology and Systematics, 13, 169-199.

Pinheiro, C. E. G. 1996. palatability and escaping ability in neotropical butterflies: tests with kingbirds (Tyrannus melancholicus, Tyrannidae). Biological Journal of Linnean Society, 59, 351-365.

Poulton, E. B. 1890. The Colours of Animals: Their Meaning and Use especially Considered in the Case of Insects. London: Keegan Paul, Trench \& Trübner.

Pritchard, G. 1964. The prey of adult dragonflies in North Alberta. Canadian Entomologist, 96, 821-825.

R Development Core Team. 2004. R: A language and environment for statistical computing. R Foundation for Statistical Computing, Vienna, Austria. ISBN 3900051-00-3, URL http://www.R-project.org.

Rashed, A., Beatty, C. D., Forbes, M. R. \& Sherratt, T. N. 2005. Prey selection by dragonflies in relation to prey size and wasp-like colours and patterns. Animal Behaviour, 70, 1195-1202.

Reader, T., MacLeod, I., Elliot, P. T., Robinson, O. J. \& Manica, A. 2005. Inter-order interactions between flower-visiting insects: Foraging bees avoid flowers previously visited by hoverflies. Journal of Insect Behaviour, 18, 51-57. 
Richter, M. R. \& Tisch, V. L. 1999. Resource choice of social wasps: influence of presence, size, and species of resident wasps. Insectes Sociaux, 46, 131-136.

Richter, M. R. 2000. Social wasp (Hymenoptera: Vespidae) foraging behaviour. Annual Review of Entomology, 45, 121-150.

Ripley, B. D. 1996. Pattern Recognition and Neural Networks. Cambridge: Cambridge University Press.

Rotheray, G. \& Gilbert, F. 1999. Phylogeny of palaearctic Syrphidae (Diptera): evidence from larval stages. Zoological Journal of the Linnean Society, 127, 1112.

Rothschild, M. \& Haskell, P. T. 1966. Stridulation of the garden tiger moth, Arctia caja L., audible to the human ear. Proceedings of the Royal entomological Society of London, A. 41, 167- 170.

Rowe, M. P. \& Owings D. H. 1978. Meaning of sound of rattling by rattlesnakes to California ground squirrels. Behaviour, 66, 252-267.

Rowe, M. P., Coss, R. G. \& Owings, D.H. 1986. Rattlesnake rattles and Burrowing ow1 hisses: A case of acoustic Batesian mimicry. Ethology, 72, 53-71.

Rowe, C. \& Guilford T. 1999. Novelty effects in multimodal warning signal. Animal behaviour, 57, 341-346.

Ruxton, G. D., Sherratt T. N. \& Speed, M. P. 2004. Avoiding attack: the evolutionary ecology of crypsis, warning signals and mimicry. New York: Oxford University Press. 
Sarle, W. S., ed. 1997 Neural Network FAQ, part 1 of 7: Introduction, periodic posting to the Usenet newsgroup comp.ai.neural-nets, URL: ftp://ftp.sas.com/pub/neural/FAQ.html.

Schoener, T. W. 1974. Resource partitioning in ecological communities. Science, 185, $27-39$.

Shelly, T. E. \& Pearson, D. L. 1978. Size and color discrimination of the robber fly Efferia tricella (Diptera: Asilidae) as a predator on tiger beetle (Coleoptera: Cicindelidae). Environmental Entomology, 7, 790- 793.

Sherratt, T. N. 2002. The evolution of imperfect mimicry. Behavioural Ecology, 13, 821- 826.

Sherratt, T. N. 2003. State dependent risk-taking by predators in systems with defended prey. Oikos, 103, 93-100.

Sherratt, T. N. \& Beatty, C. D. 2003. The evolution of warning signals as reliable indicators of prey defense. American Naturalist, 162, 377-389.

Shettleworth, S. J. 2005. Taking the best for learning. Behavioural Processes, 69, 147149.

Sokal, R. R. \& Rohlf, F. J. 1995. Biometry. 3 rd Edition. New York: W. H. Freeman and Company.

Speed, M. P. \& Turner, J. G. P. 1999. Learning and memory in mimicry: II. Do we understand the mimicry spectrum? Biological Journal of Linnean Society, 67, 281-312. 
Stevens, M. 2005. The role of eyespots as anti-predator mechanisms, principally demonstrated in the Lepidoptera. Biological Reviews, 80, 573-588.

Southwood, T. R. E. 1978. Ecological Methods. 2nd edn. New York: Chapman and Hall.

Thayer, G. H. 1909. Concealing-colouration in the Animal Kingdom, Macmillan.

Thomas, L. \& Juanes, F. 1996. The importance of statistical power analysis: an example from Animal Behaviour. Animal Behaviour, 52, 856- 859.

Tosh, C. R., Jackson, A. L. \& Ruxton, G. D. 2006. The confusion effect in predatory neural networks. American Naturalist, 167, E52-E65.

Turner, J. R. G. 1978. Why male butterflies are non-mimeitc: natural selection, sexual selection, group selection, modification and sieving. Biological Journal of the Linnean Society, 10, 385-432.

Turner, J. R. G. 1984. The palatability spectrum and its consequences. In The Biology of Butterflies. Symposium of the Royal Entomological Society of London 11 (Ed. By R. I. Vane-Wright, and P. Ackery,), Princeton: Princeton University Press.

Vallin, A., Jakobsson, S., Lind, J. \& Wiklund, C. 2005. Prey survival by predator intimidation: An experimental study of peacock butterfly defence against blue tits. Proceedings of the Royal Society B, 272, 1203-1207.

Venables, W. N. \& Ripley, B. D. 2002. Modern Applied Statistics with $S, 4^{\text {th }}$ Edition. New York: Springer. 
Vockeroth, J. R. \& Thompson, F. C. 1987. Syrphidae, In: Manual of Nearctic Diptera v.2. (Ed. by J.F. McAlpine), pp. 713-746. Research Branch Agriculture Canada, Ottawa.

Waldbauer, G. P. 1970. Mimicry of hymenopteran antennae by Syrphidae. Psyche, 77, 45-49.

Waldbauer, G. P. 1988. Insects through the Seasons. Cambridge, MA: Harvard University Press.

Waldbauer, G. \& Sternburg, J. G. 1987. Experimental field demonstration that 2 aposematic butterfly color patterns do not confer protection against birds in northern Michigan. American Naturalist, 118, 145-152.

Wallace, A. R. 1867 Proceedings of the Royal Society of London: Ixxx-Ixxxi.

Whitley, D. 1994. A Genetic Algorithm Tutorial http://www.cs.colostate.edu/ genitor/Pubs.html.

Yang, E. C. \& Osorio, D. 1991. Spectral sensitivities of photoreceptors and lamina cells in the dragonfly, Hemicordulla-tau. Journal of Comparative Physiology A, 169, $663-669$. 


\section{APPENDICES}

Appendix A. Voucher Numbers For the Plant and Insect Specimens, Deposited at Agriculture and Agri-Food Canada.

\begin{tabular}{lcc}
\hline Species & Deposited at & Voucher \# \\
\hline Bombus impatiens & $\mathrm{CNC}^{\mathrm{I}}$ & 3053 \\
Bombus sp. & $\mathrm{CNC}$ & 3052 \\
Daucus carota & $\mathrm{DAO}^{2}$ & 818624 \\
Dolichovespula arenaria & $\mathrm{CNC}$ & 3061 \\
Eristalis arbustorum & $\mathrm{CNC}$ & 3058 \\
E. flavipes & $\mathrm{CNC}$ & 3054 \\
E. transversa & $\mathrm{CNC}$ & 3059 \\
Helophilus fasciatus & $\mathrm{CNC}$ & 3057 \\
Sarcophaga bullata & $\mathrm{CNC}$ & 3063 \\
Sarcophaga sp. & $\mathrm{CNC}$ & 3056 \\
Solidago canadensis & $\mathrm{DAO}$ & 318623 \\
Spilomyia sayi & $\mathrm{CNC}$ & 3060 \\
Spilomyia longicornis & $\mathrm{CNC}$ & 3055 \\
Vespula germanica & & 3062 \\
\hline
\end{tabular}

${ }^{1}$ Canadian National Collection of Insects and Arthropods

${ }^{2}$ Department of Agriculture Ottawa 
Appendix B. Species List for Images in the Set of 206 (see Dittrich et al. (1993))

\begin{tabular}{|c|c|c|c|}
\hline Image Type & Number & Code & Abbreviation \\
\hline wasp* & 97 & 1 & Wasp \\
\hline Syrphus ribesii & 7 & 2 & S. $r i$ \\
\hline Temnostoma vespiforme $e^{\dagger}$ & 10 & 3 & T. ve \\
\hline Chrysotoxum cautum & 10 & 4 & C. $c a$ \\
\hline Helophilus pendulus & 1 & 5 & H. pe \\
\hline Epistrophe grossulariae & 5 & 6 & E. $g r$ \\
\hline Xanthogramma pedissequum & 4 & 7 & X. pe \\
\hline Chrysotoxum bicinctum & 3 & 8 & C. $b i$ \\
\hline Sphecomyia vespiformis ${ }^{\dagger}$ & 6 & 9 & S. ve \\
\hline Volucella zonaria & 6 & 10 & V. zo \\
\hline Scaeva pyrastri & 5 & 11 & S.py \\
\hline Ischyrosyrphus glaucius ${ }^{\dagger, \ddagger}$ & 4 & 12 & I. $g l$ \\
\hline nonmimetic fly** & 48 & 13 & Fly \\
\hline
\end{tabular}

* wasps were a mixture of Vespula vulgaris and Vespula rufa

** nonmimetic flies were a mixture of Diptera species, e.g., Tabanus spp., Tachina spp., Sarcophaga spp., Scatophaga spp., among others

$\dagger \quad$ Three T. ve, four S. ve and one I. $g l$ were classed with 'cream' for stripe or patch colour. Since there were no wasps or nonmimetic flies with this colour to train the neural network these images were discarded for all neural network analyses to avoid predictions being made for images with a novel value for a categorical variable.

$\ddagger \quad$ The three remaining $I . g l$. images all had colour 'grey'. The only other specimen with this colour was a nonmimetic fly. That fly was forced to be in W-NF-i for all data sets so that predictions could be made for $I$. $g l$. with the trained neural network. This might potentially bias the analysis slightly because the neural network only 'sees' grey images as being nonmimetic flies.

The colours mentioned here are those taken from the images as seen by the pigeons not the actual specimen colour and reflect the influence of lighting when the photographs were taken.

For the human ordering experiment all of the images were used regardless of colour. 


\section{Appendix C. Description of the Neural Network}

The classifier used here was the fully-connected feedforward neural network nnet (Venables \& Ripley, 2002). It uses weight decay to prevent overfitting. Weight decay aims to keep the magnitude of the network weights small, and the severity of the penalty for large-magnitude weights is governed by the decay parameter. This method runs the optimisation to determine optimal weights to conversion so the final set of weights is used (as opposed to early stopping which is another method to prevent overfitting). The core classifier was later specifically integrated within a genetic algorithm to implement the REP.

The first step was to linearly translate and scale the continuous and ordinal predictor variables to lie in the interval $[-1,1]$.

To obtain Ordering III, 20 repetitions of the following procedure were done for each of the 10 constructed data sets. For each repetition, the 80 observations in the wasp/nonmimetic fly (W-NF-i) data were randomly partitioned into a training set $(2 / 3)$ and a test set (1/3). All 17 predictor variables were used in each case. A suite of neural network structures was tested $(0,1,3,6$ or 12 nodes, with and without skip-layer connections, and a range of decay parameters $(0.0001,0.0003,0.001,0.003,0.01,0.03$, $0.1,0.3))$

The best network structure, based on percent of correct predictions for the test set, from training on this suite was then used to train a neural network with the complete WNF- $i$ data set. Subsequently, each trained network was presented with the corresponding W-NF-H- $i$ data, and the predicted probability for specimens being a wasp was obtained 
for each of the 155 images. There is variability in the final network, and hence in its predictions, when training with complete $\mathrm{W}-\mathrm{NF}-i$ data because random values are used to initiate training. However, the variability in the predictions for each corresponding W$\mathrm{NF}-\mathrm{H}-i$ data set turned out to be small, hence any single set of predictions was deemed to be representative for each $i=1, \ldots, 10$. The 155 predictions were averaged for each taxonomic group then these averages were averaged over the 10 data sets. It is these average-of-averages that are reported in Table 4.1.

Subsets testing implied using all groups of one and all groups of two predictor variables to train the network. This implied that there were (17 choose 1$)$ plus (17 choose 2) which equals 153 different optimal network structures found. For subsets testing we used the same range of tuning parameters as listed above for split-sample testing. Once completed, a sorted list (in terms of median percent correct in the test set for every structure for every subset of predictor variables) is used to select, by observation, which predictor variables occur most frequently in the networks that achieved the best prediction.

Specifically the call to nnet was:

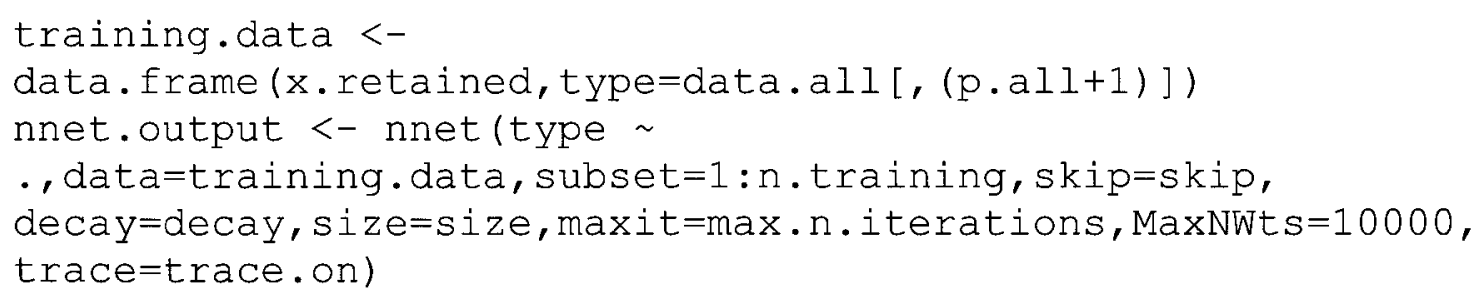

where $x . r e t a i n e d$ is the set of retained predictor variables, data.all is the combined W-NF- $i$ and W-NF-H- $i$ data, p.a $11+1$ indicates the last column is the classes, n.training is 80 , and max.n.iterations is 10000 and trace on is simply an 
indicator of whether output from nnet is sent to screen. This formulation produces warnings from nnet because it sees the hoverfly species as classes but they are not used for training.

The median percent correct prediction for split-sample testing and for the best subsets was always $100 \%$. This is misleading in the sense that if the network predicted at least a $50 \%$ probability that a test specimen was a wasp then this was counted as a correct prediction. Hence the averaged predicted probability in Table 4.1 for wasps is only 0.890 instead of being near 1.0 as one might assume given the $100 \%$ median predicted correct. 
Appendix D. Description of the Genetic Algorithm For Matching Pigeon Peck Rate Data

For the genetic algorithm (see Whitley (1994)) 400 chromosomes were used. A chromosome consisted of a string of 55 zeros and ones in which there were three information packets encoded: (i) an enumeration of the predictor variables to be used; (ii) the structure of the neural network; and (iii) the parameters in the conversion function:

$$
\text { peck rate }=\theta_{1}+\left(\theta_{2}-\theta_{1}\right)\left(p^{\theta_{3}}+1-(1-p)^{\theta_{4}}\right) / 2, \theta_{3}, \theta_{4}>0
$$

The general shapes permitted by this function are shown in Figure D.1.

$$
\text { C. } 1 \mathrm{a}: \theta_{3}=0.5 \quad \theta_{4}=5
$$

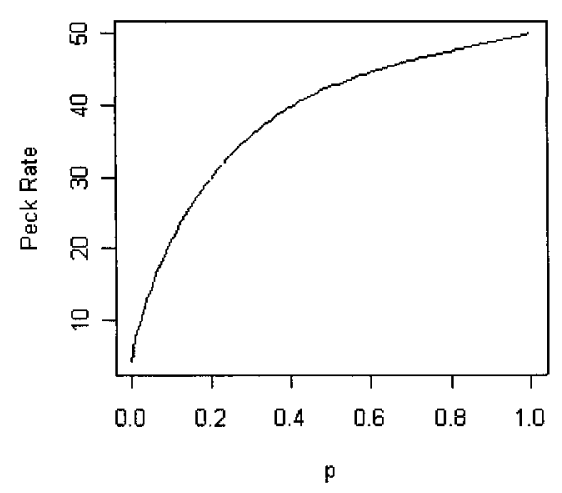

C. 1 C: $\theta_{3}=0.5 \quad \theta_{4}=0.5$

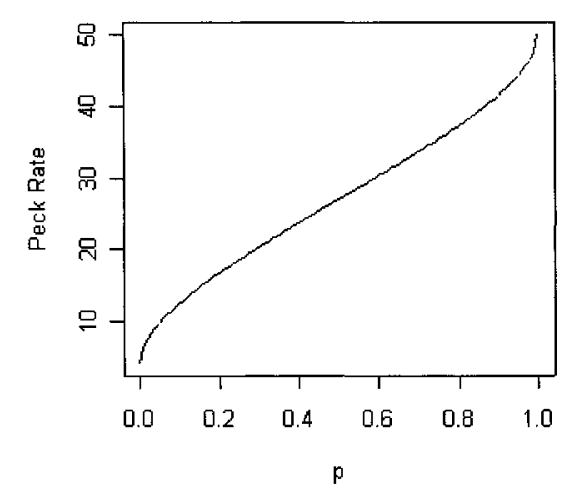

C. $1 \mathrm{~b}: \theta_{3}=5 \quad \theta_{4}=0.5$

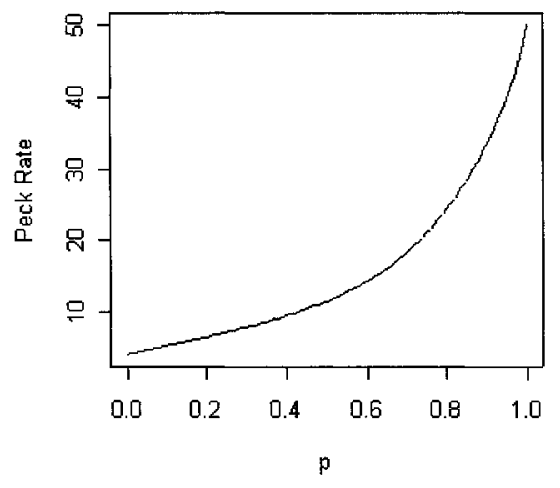

C. $1 d: \theta_{3}=5 \quad \theta_{4}=5$

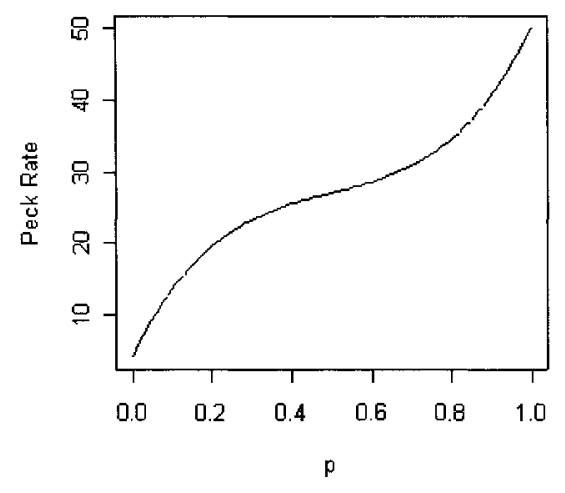

Figure D.1 General Shapes of Conversion Function Permitted 
The rationale was to allow concave or convex functions (C.1a and C.1b) and to allow rapid change in predicted peck rate at the extremes as probability of being the target species predicted by the neural network approached zero or one (C.1c and C.1d).

A separate simulation was run for each data set $i=1, \ldots, 10$ for each experiment. The initial set of 400 chromosomes was generated randomly.

For each generation, the algorithm is:

1. Extract the indices of the predictor variables to be used based on the first 17 entries in the chromosome, i.e., use predictor variable $j$ only if the entry is 1 at location $j$.

2. Extract the structure of the neural network. By structure we mean that the number of nodes is encoded to be between 0 and 15 in the hidden layer. The value 15 was chosen as it is 1111 in base 2 ; hence four entries are allocated in the chromosome. There is also an indicator for whether skip-layer weights are to be used. The network is always checked for viability, e.g., if there are no nodes in the hidden layer then skip-layer weights are forced to be present. There are eight possible values for the decay parameter (see Appendix $\mathrm{C}$ for the list) hence three entries are allocated on the chromosome.

3. Using the W-NF- $i$ data only, randomly select two thirds of the observations for training and one third as the test set.

4. Run the neural network training for a maximum of 10000 iterations. This is a huge number for this system so essentially convergence is achieved for every optimisation. 
5. Using the network weights corresponding from the optimal structure in (4), find the predicted probabilities of inclusion in the class 'wasp' for all 155 images in W-NF-H- $i$ if Wasp + data is being used, class 'fly' if Fly+ data is being used.

6. Decode the parameter values for the conversion function from the chromosome. For each of parameters $\theta_{1}$ and $\theta_{2}$, a string of eight 0 or 1 entries are allocated in the chromosome. This string represents a base- 2 value equivalent of integers 0 to 255 in base 10 . The base- 10 value is divided by 4 to give a range of possible values from 0 to 63.75 . For parameter 3 , the following formula was used for $k$ ranging from 0 to $2^{7}-1$ :

$$
\theta_{3}=20^{k\left(\frac{2^{7}-1}{2}-1\right)}
$$

This formula gives a distribution whose logarithms are symmetrically distributed about 0.0 . This implies that seven entries are required on the chromosome for a base- 2 representation of $k$. The range of values produced is

$$
\begin{array}{lllllllllllllll}
0.050 & 0.052 & 0.055 & 0.058 & 0.060 & 0.063 & 0.066 & 0.070 & 0.073 & 0.076 & 0.080 & 0.084 \\
0.088 & 0.092 & 0.097 & 0.101 & 0.106 & 0.112 & 0.117 & 0.123 & 0.128 & 0.135 & 0.141 & 0.148 \\
0.155 & 0.163 & 0.170 & 0.179 & 0.187 & 0.196 & 0.206 & 0.216 & 0.226 & 0.237 & 0.249 & 0.261 \\
0.273 & 0.286 & 0.300 & 0.315 & 0.330 & 0.346 & 0.363 & 0.380 & 0.399 & 0.418 & 0.438 & 0.459 \\
0.481 & 0.505 & 0.529 & 0.554 & 0.581 & 0.609 & 0.639 & 0.670 & 0.702 & 0.736 & 0.771 & 0.809 \\
0.848 & 0.889 & 0.932 & 0.977 & 1.024 & 1.073 & 1.125 & 1.180 & 1.237 & 1.296 & 1.359 & 1.425 \\
1.493 & 1.565 & 1.641 & 1.720 & 1.803 & 1.891 & 1.982 & 2.078 & 2.178 & 2.283 & 2.394 & 2.509 \\
2.630 & 2.757 & 2.891 & 3.030 & 3.177 & 3.330 & 3.491 & 3.660 & 3.836 & 4.022 & 4.216 & 4.420 \\
4.633 & 4.857 & 5.092 & 5.338 & 5.595 & 5.866 & 6.149 & 6.446 & 6.758 & 7.084 & 7.426 & 7.785
\end{array}
$$




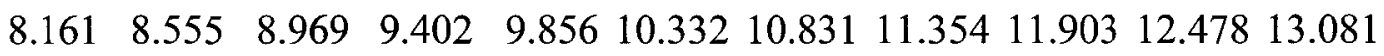
13.71314 .37515 .06915 .79716 .56117 .36118 .19919 .07820 .000

Parameter 4 was encoded identically.

7. Convert the probabilities from (5) using the conversion function with parameters from (6) to obtain the predicted peck rates for all 155 images in W-NF-H-i.

8. Find mean peck rates for each taxonomic group (wasp, fly and 11 hoverfly species).

9. Find the sum of squared differences, SSE, between the 13 mean observed and mean predicted peck rates.

10. Find the fitness for each chromosome based on (i) $S S E$, (ii) the cost coefficient $\omega$ and (iii) the number of weights in the network:

$$
\text { fitness }=-S S E-\omega\{\text { number of weights }\}
$$

The number of weights increases with the number of nodes in the network and the number of predictor variables. Parameter $\omega$ controls the severity of the penalty for added weights. Two values were used for $\omega$ namely 1.0 and 0.1 . We did not know beforehand the degree of severity of the penalty for our initial value 1.0. The optimal networks after the first suite of tests contained few if any hidden nodes, so we relaxed $\omega$ to be 0.1 for the second suite to allow for more complex networks.

To update the chromosomes an intermediate set of 400 chromosomes was created using the following mechanism 400 times:

1. Randomly find two unique integers, $i$, and $j$ in $[1,400]$. 
2. Retrieve the fitness of the chromosomes $i$ and $j$ in the current set.

3. Add the chromosome with the greater fitness to the intermediate set.

When the intermediate set has been created, use the following mechanism 200 times to create the new chromosome set:

1. Randomly find two unique integers $i$ and $j$ in $[1,400]$.

2. Do single-point crossover with chromosomes $i$ and $j$ in the intermediate set with crossover rate of 0.8 (meaning about $80 \%$ of the time crossover is done) to create two new chromosomes. For example, if the index 10 is randomly selected, then entries 1 to 10 from chromosome $i$ and entries 11 to 55 from chromosome $j$ form a new chromosome, and entries 1 to 10 from chromosome $j$ and entries 11 to 55 from chromosome $i$ form a second new chromosome.

3. If crossover is not done pass chromosomes $i$ and $j$ directly to the new set.

Finally, each entry in each chromosome is flipped (mutated), 0 to 1 or 1 to 0 , with probability of 0.005 . After mutation, all chromosomes are checked to ensure that the combination of zero nodes and no skip-layer weights is not present. If it is, skip-layer weights are enforced. This completes one generation.

All simulations were run for 200 generations. The overall structure (retained predictor variables, neural network and conversion function parameters) that corresponded to the greatest fitness was recorded. Note that the calculation of fitness is not repeatable because in step 4 the training of the neural network always starts with random values for the weights. 
To predict peck rates based on the nine specimens of the novel species Episyrphus balteatus, the 20 optimal overall structures (10 sets of retained predictor variables, neural network structure and conversion function parameters for simulation based on each of Wasp + and Fly + data) with $\omega=1$ were used, hence there were $10 \times 9=90$ predicted peck rates for simulations based on each of Wasp+ and Fly+ data. The reported predicted peck rates were the average over these 90 values for each.

When one species was excluded, the procedure for obtaining the optimal REP for each data set was identical to the original procedure outlined above except that there were now 12 taxonomic groups (wasps, nonmimetic flies and 10 hoverfly species) used to create the REP models. Structures based on Wasp+ data with $\omega=1$ were used, so for $C$. cautem there were $10 \times 10=100$ and for $S$. pyrastri there were $10 \times 5=50$ predicted peck rates that were averaged to get the reported values. 


\section{Appendix E.}

Several correlations were reported without the corresponding graphs. The graphs are presented here. Figures E.1a,c,d corresponds to Figures 4.1a,c,d; see Table 4.2.

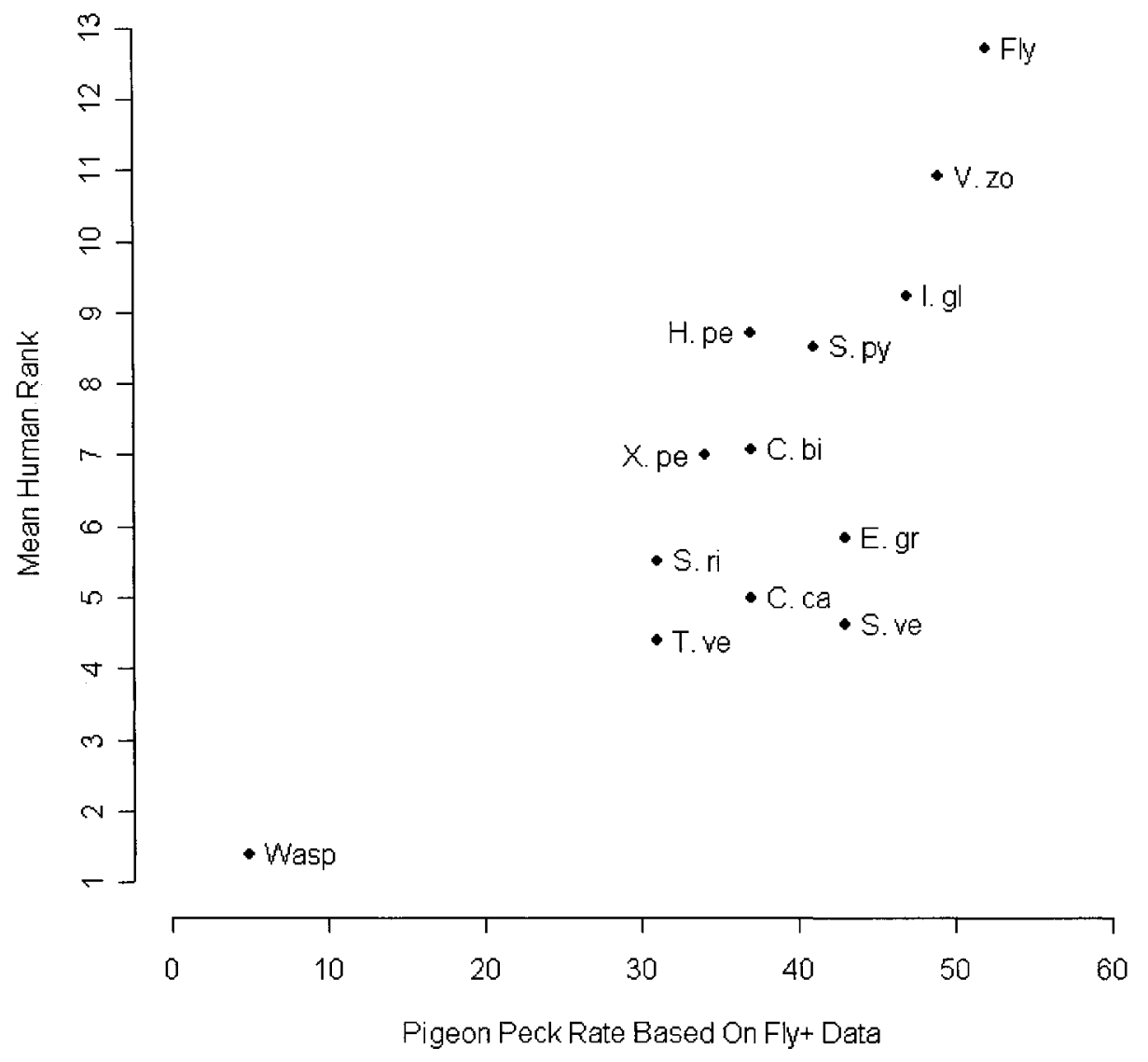

Figure E.1a. A comparison of human ordering (ranging from 13, most nonmimetic flylike, to 1, most wasp-like) and pigeon ordering (based on Fly+ data). 


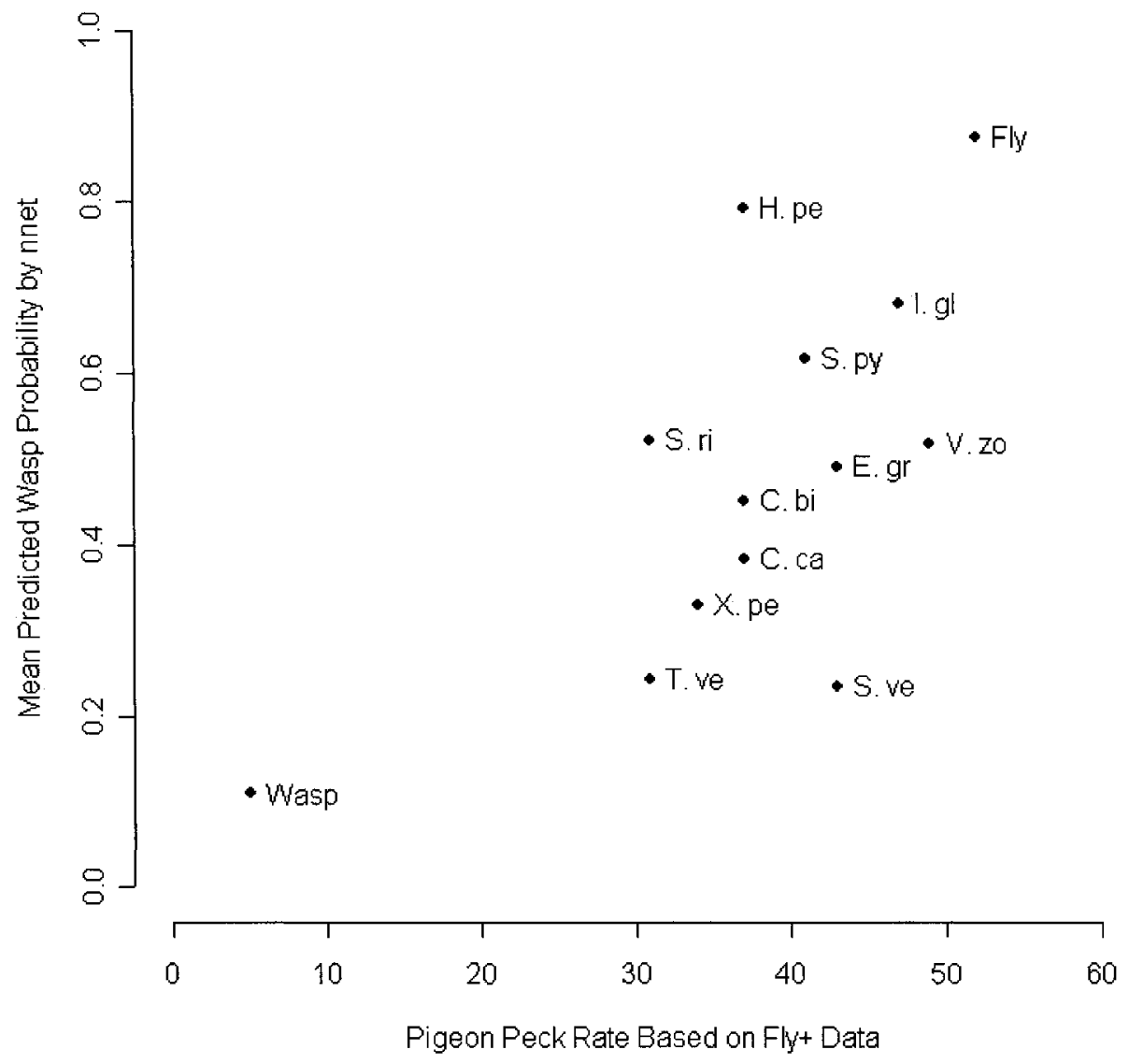

Figure E.1c A comparison of neural network (nnet) ordering and pigeon ordering based on Fly+ data. 


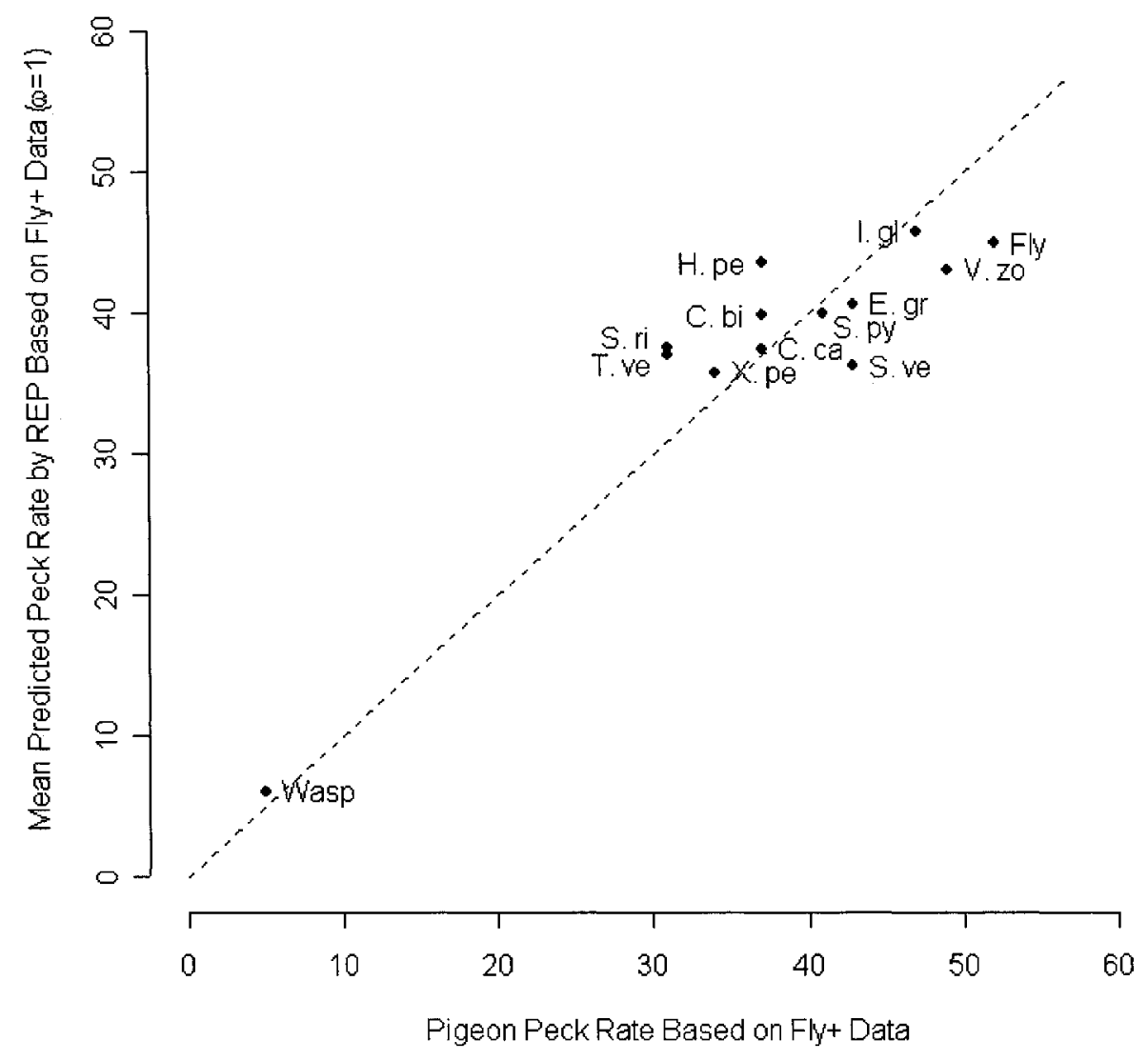

Figure E.1d-1. A comparison of mean predicted peck rate from the REP with cost coefficient $\omega=1$ and observed pigeon peck rate based on Fly + data (dashed line represents perfect matching of predicted and observed values). 


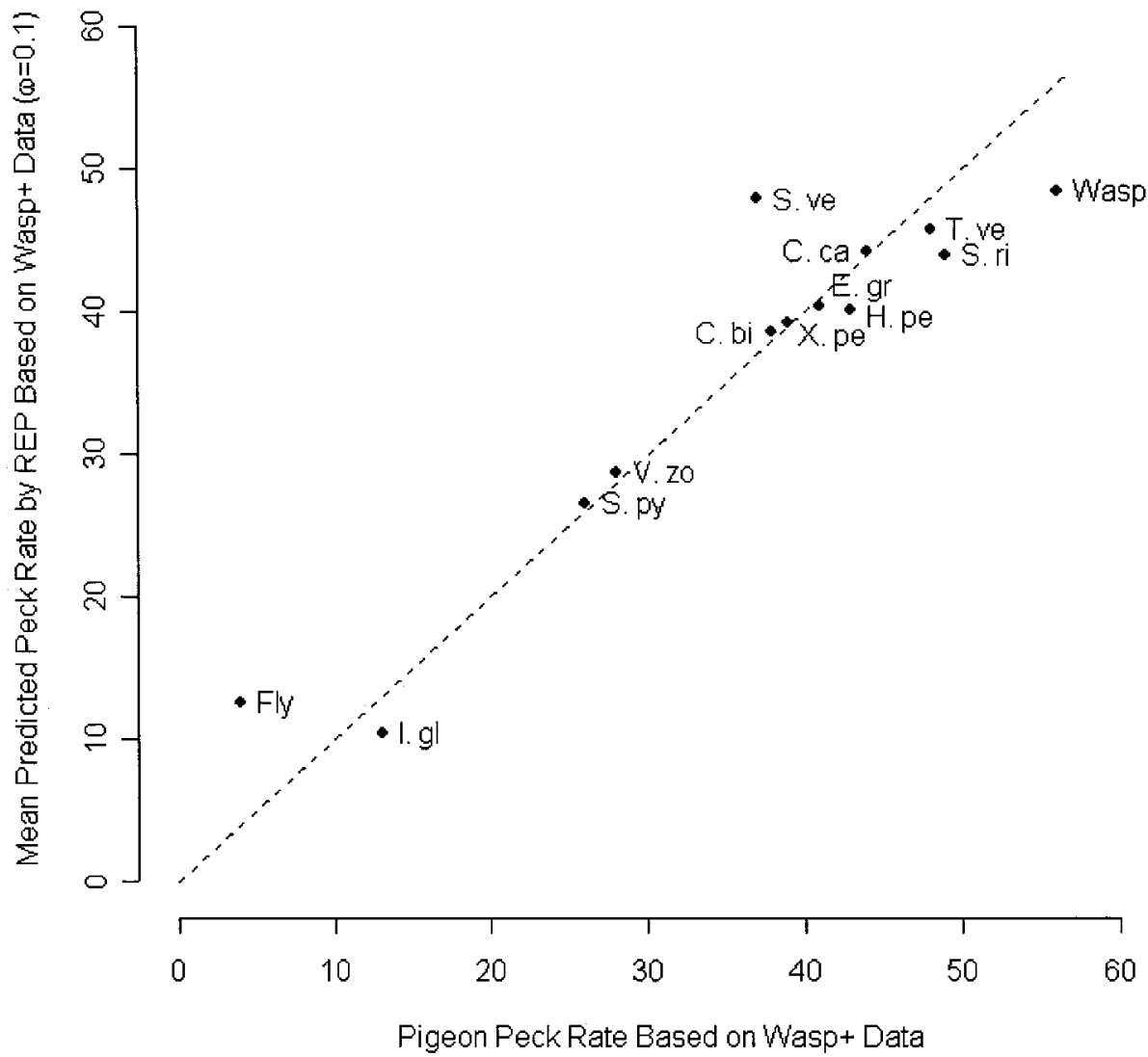

Figure E.1d-2. A comparison of mean predicted peck rate from the REP with cost coefficient $\omega=0.1$ and observed pigeon peck rate based on Wasp+ data (dashed line represents perfect matching of predicted and observed values). 


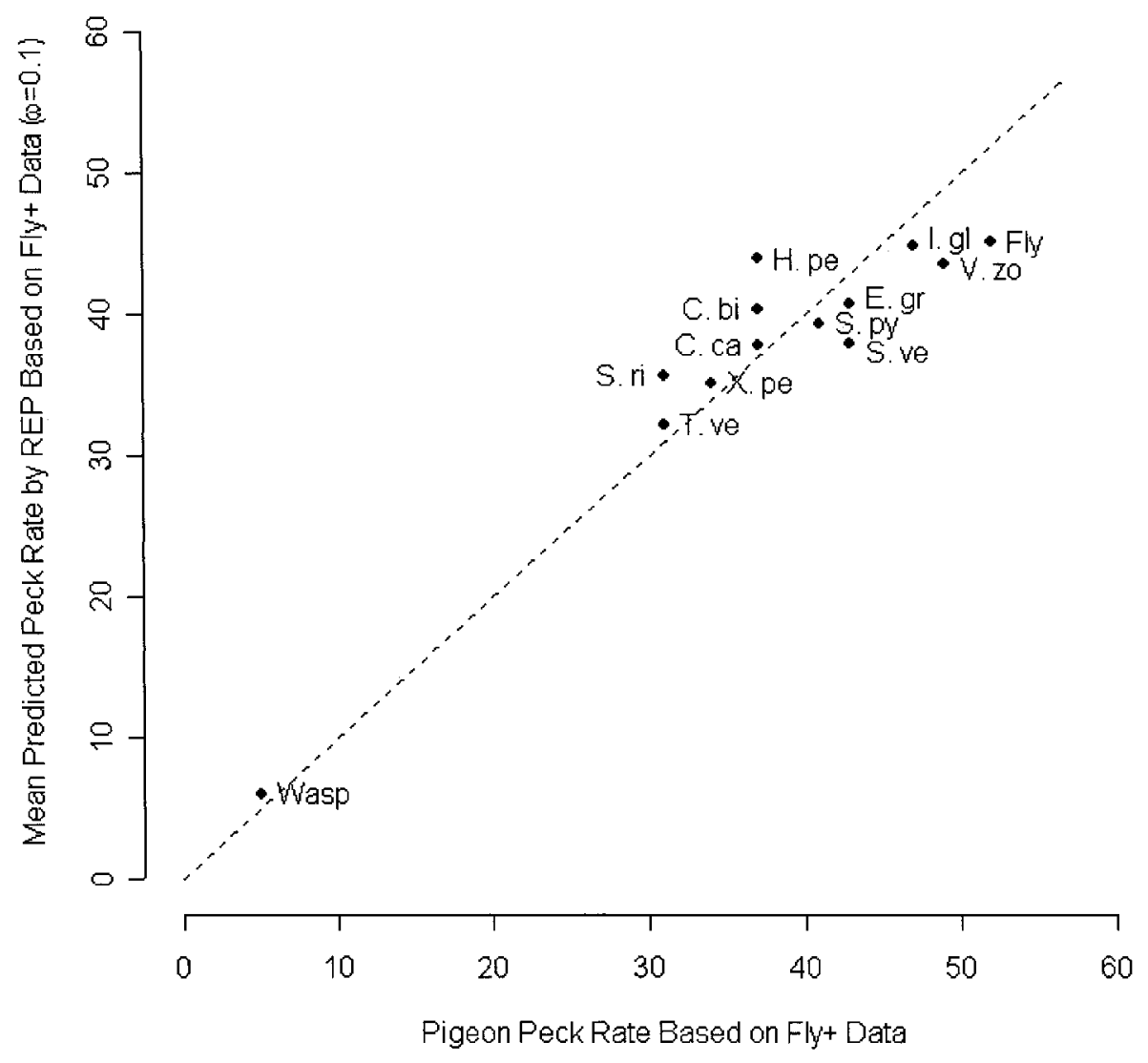

Figure E.1d-3. A comparison of mean predicted peck rate from the REP with cost coefficient $\omega=0.1$ and observed pigeon peck rate based on Fly + data (dashed line represents perfect matching of predicted and observed values). 